\title{
Analysis of Joist Masonry Moisture Content Monitoring
}

Kohta Ueno

Building Science Corporation

October 2015 


\begin{abstract}
NOTICE
This report was prepared as an account of work sponsored by an agency of the United States government. Neither the United States government nor any agency thereof, nor any of their employees, subcontractors, or affiliated partners makes any warranty, express or implied, or assumes any legal liability or responsibility for the accuracy, completeness, or usefulness of any information, apparatus, product, or process disclosed, or represents that its use would not infringe privately owned rights. Reference herein to any specific commercial product, process, or service by trade name, trademark, manufacturer, or otherwise does not necessarily constitute or imply its endorsement, recommendation, or favoring by the United States government or any agency thereof. The views and opinions of authors expressed herein do not necessarily state or reflect those of the United States government or any agency thereof.
\end{abstract}

Available electronically at http://www.osti.gov/bridge

Available for a processing fee to U.S. Department of Energy

and its contractors, in paper, from:

U.S. Department of Energy

Office of Scientific and Technical Information

P.O. Box 62

Oak Ridge, TN 37831-0062

phone: 865.576 .8401

fax: 865.576 .5728

email: mailto:reports@adonis.osti.gov

Available for sale to the public, in paper, from:

U.S. Department of Commerce

National Technical Information Service

5285 Port Royal Road

Springfield, VA 22161

phone: 800.553 .6847

fax: 703.605.6900

email: orders@ntis.fedworld.gov

online ordering: http://www.ntis.gov/ordering.htm 


\title{
Analysis of Joist Masonry Moisture Content Monitoring
}

\author{
Prepared for:
}

The National Renewable Energy Laboratory

On behalf of the U.S. Department of Energy's Building America Program

Office of Energy Efficiency and Renewable Energy

15013 Denver West Parkway

Golden, CO 80401

NREL Contract No. DE-AC36-08GO28308

Prepared by:

Kohta Ueno

Building Science Corporation

3 Lan Drive, Suite 102

Westford, MA 01886

NREL Technical Monitor: Stacey Rothgeb

Prepared under Subcontract No. KNDJ-0-40337-05

October 2015 
The work presented in this report does not represent performance of any product relative to regulated minimum efficiency requirements.

The laboratory and/or field sites used for this work are not certified rating test facilities. The conditions and methods under which products were characterized for this work differ from standard rating conditions, as described.

Because the methods and conditions differ, the reported results are not comparable to rated product performance and should only be used to estimate performance under the measured conditions. 


\section{Contents}

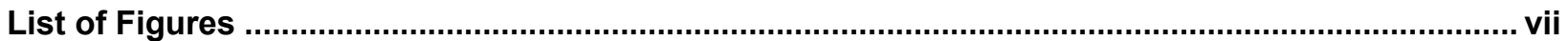

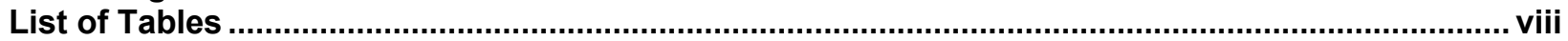

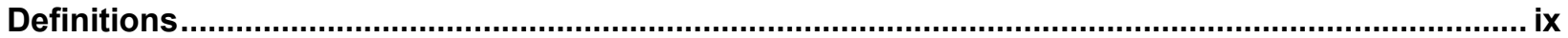

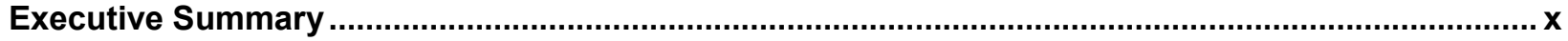

1 Introduction

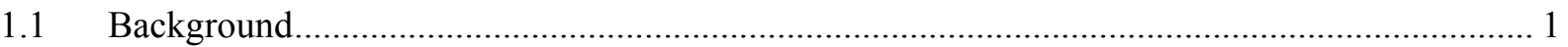

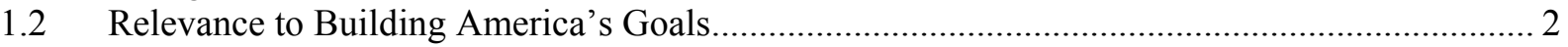

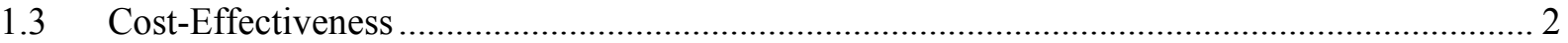

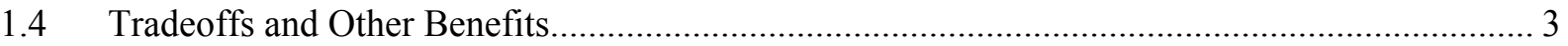

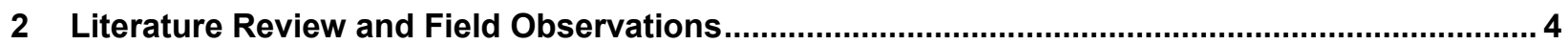

$2.1 \quad$ Dumont et al. (2005) Field Monitoring ............................................................................... 4

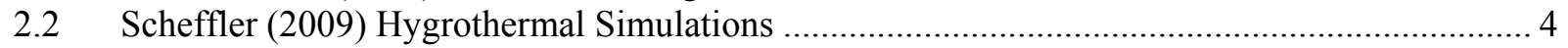

$2.3 \quad$ Morelli et al. (2010) Hygrothermal Simulations ................................................................ 4

2.4 Morelli and Svendsen (2012) Simulations and Literature Review .......................................... 5

2.5 Rudd (2014) Crawl Space Retrofit Field Measurements ....................................................... 5

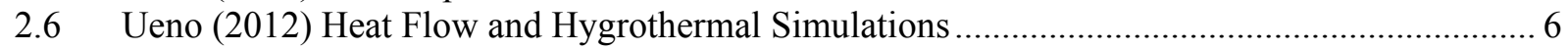

$2.7 \quad$ Field Observations of Embedded Wood Members ................................................................ 7

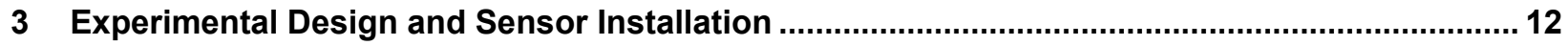

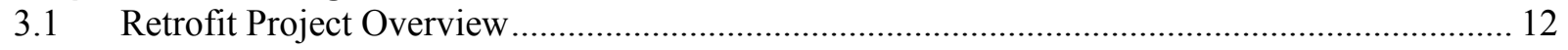

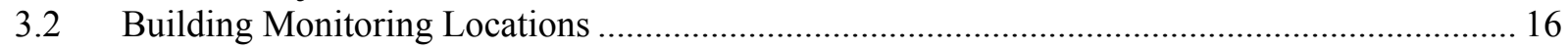

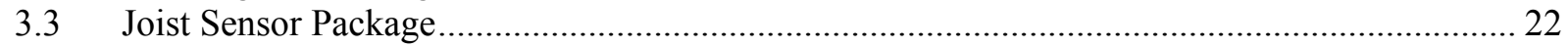

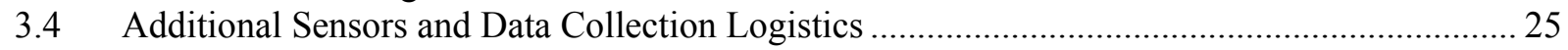

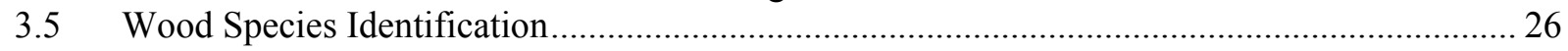

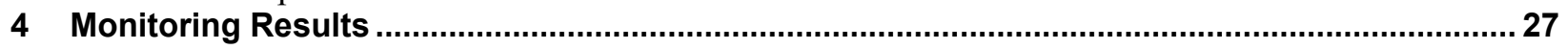

4.1 Data Overview and Boundary Conditions ............................................................................ 27

4.2 Moisture Contents and Wood Durability ....................................................................... 29

4.3 Joist Moisture Content Measurements: Minimally Heated Wing Basement............................. 29

$4.4 \quad$ Joist Moisture Content Measurements: Unheated Wing First Floor ......................................... 34

4.5 Joist Moisture Content Measurements: Heated Wing Basement.............................................. 36

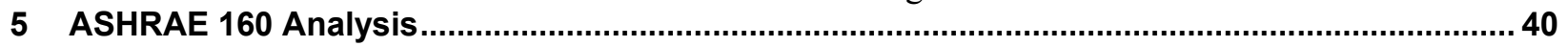

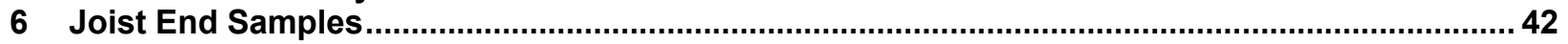

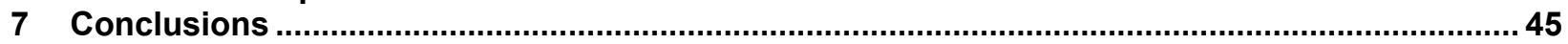

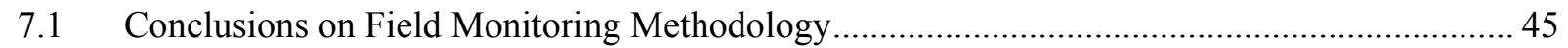

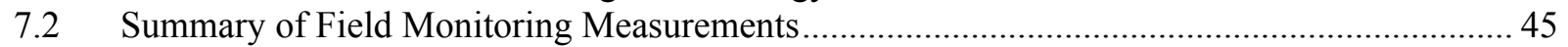

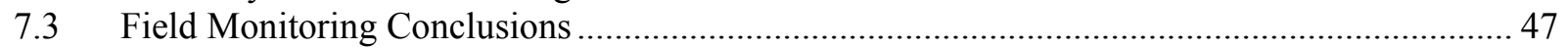

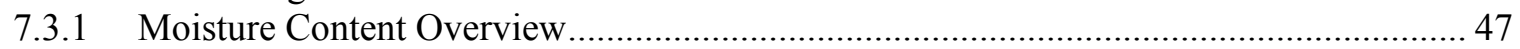

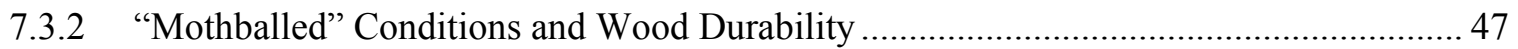

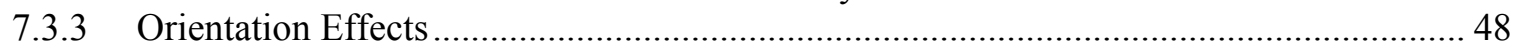

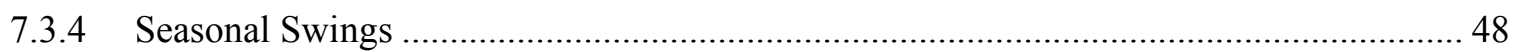

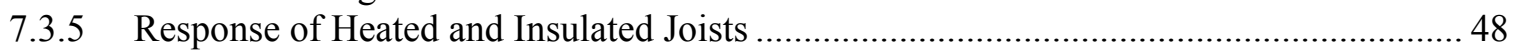

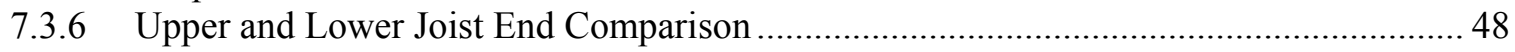

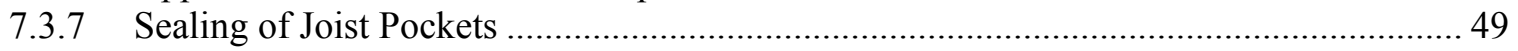

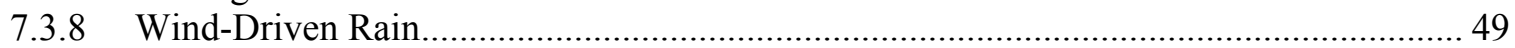

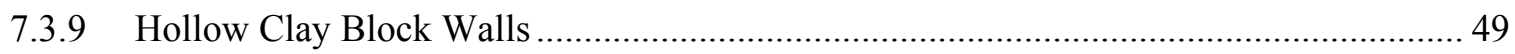

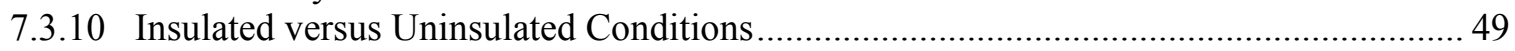

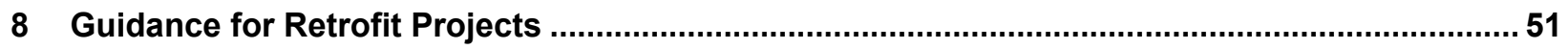

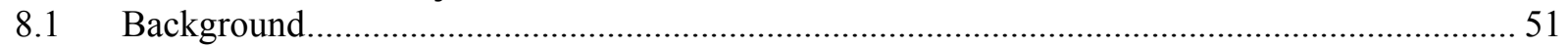

8.2 Risks to Joist Ends Near and Below Grade ....................................................................... 51

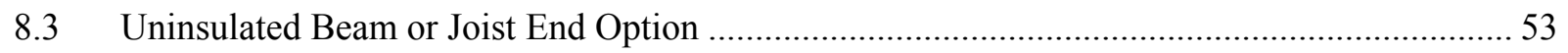

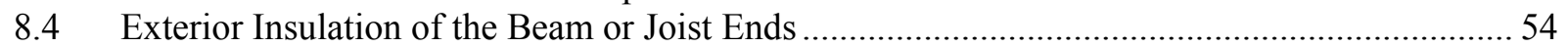




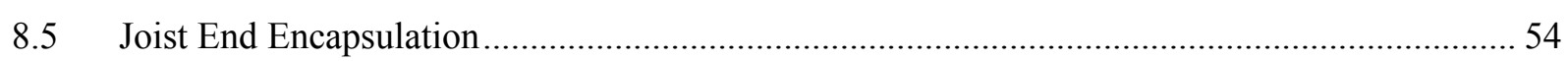

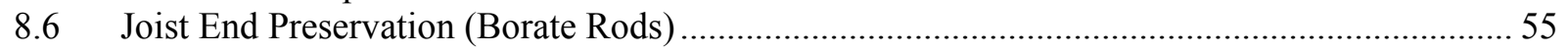

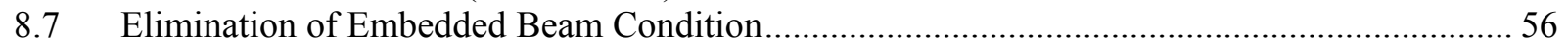

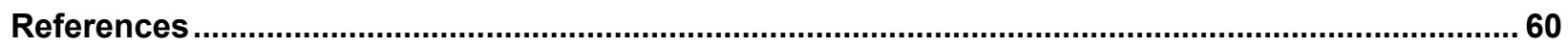

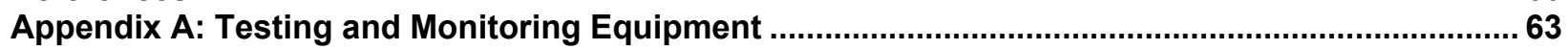

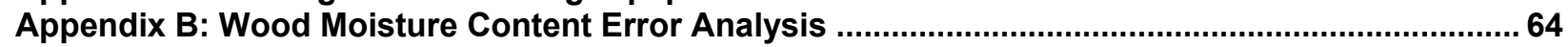




\section{List of Figures}

Figure 1. Mass masonry retrofit project overview (left); interior insulation at beam ends (right)...... 1

Figure 2. Overview of apartment complex (left); preretrofit joist ends in concrete masonry unit walls (right).

Figure 3. Postretrofit crawl space conditions (left); insulation board sealed at joist ends (right)..... 6

Figure 4. Embedded beam uninsulated case (left); insulated case (right) ........................................... 7

Figure 5. Typical large beam geometry (left); water damage at beam end (right).............................. 8

Figure 6. Large timber beam pocket (left); iron or steel bearing plate (right) ................................... 8

Figure 7. Beam pocket gap on sides; conditions vary by building .................................................... 9

Figure 8. Steel saddle hanger detail, with beam clear of masonry wall at grade ................................9

Figure 9. Wood clear of masonry (left); low MC despite wetting stains (right) ................................. 10

Figure 10. Embedded joist end from exterior showing dimensions and fire cut ............................ 10

Figure 11. Building exterior grade condition (left); beam interface to below-grade wall (right)....... 11

Figure 12. Damage to embedded beams at walls ........................................................................ 11

Figure 13. Retrofit building exterior view from west (left); view from north (right) ........................ 12

Figure 14. Overhead view of retrofit building from west (left); overhead view from north (right).... 12

Figure 15. Driving rain rosette for KLWM, rain in mm/year (left); overhead view (right).................. 13

Figure 16. Exterior wall conditions at solid brick (left); hollow clay block infill (right) .................... 13

Figure 17. Wall section at solid brick (left); at hollow clay block infill (right) conditions ................ 14

Figure 18. Multiple layers of insulation (left); framing installed inboard of insulation (right) .......... 14

Figure 19. Embedded joist foam blocks (left); close-up showing clamping jig (right) .................... 15

Figure 20. Unit-to-unit floor-to-ceiling assembly at exterior wall; joists perpendicular to wall........ 15

Figure 21. Location of monitored joist ends at basement level (basement ceiling) with driving rain;

residential units highlighted.................................................................................................. 17

Figure 22. Location of monitored joist ends at first floor (first-floor ceiling) with driving rain;

residential units highlighted.

Figure 23. Comparison of insulation strategies for joist ends BSMT-N-1/2/3, predrywall ................ 19

Figure 24. Infrared comparison of BSMT-N1/N2/N3 joist ends (interior unheated)........................... 19

Figure 25. BSMT-E2 joist, showing existing water staining ...................................................... 20

Figure 26. BSMT-W1 and BSMT-W2 joists showing water deposition at wall jog.............................20

Figure 27. FIRST-N joists showing brick and clay block wall construction ....................................21

Figure 28. Wood color comparison at BSMT-E1 joist (left); FIRST-E joist (right) .......................... 21

Figure 29. Two-component spray foam air seal at joists BSMT-W1 and BSMT-E1 ..........................21

Figure 30. Schematic of typical joist end sensor monitoring package .......................................... 22

Figure 31. 6-in. extended MC pins (left); determining drilling depth (right)....................................... 23

Figure 32. Pocket hole jig (left); installed MC pins (right) .................................................................. 24

Figure 33. Caulked pocket holes (left); air seal at joist pocket (right) .......................................... 24

Figure 34. Installation of pocket RH sensor (left); installed RH sensor (right)............................... 24

Figure 35. Conditions in joist pocket at north-facing building at addition ....................................... 25

Figure 36. Exterior (left) and interior hallway (right) temperature and RH sensors.........................26

Figure 37. Data acquisition system showing placement (left) and wiring connections (right) ........ 26

Figure 38. Interior and exterior temperatures (Lawrence/KLWM airport data for comparison) ........ 27

Figure 39. Interior and exterior RH measurements (KLWM data for comparison).......................... 28

Figure 40. Interior and exterior dew point temperatures (KLWM data for comparison)....................28

Figure 41. Basement unheated wing joist end measurements highlighted..................................... 29

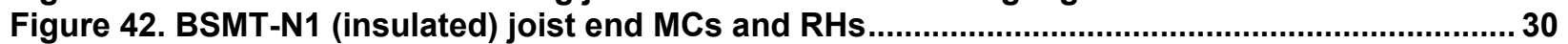

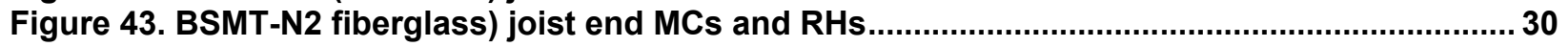

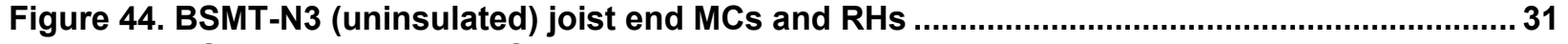

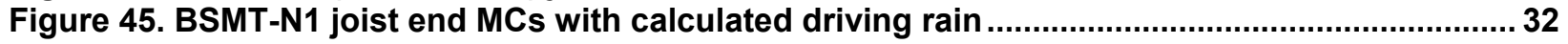

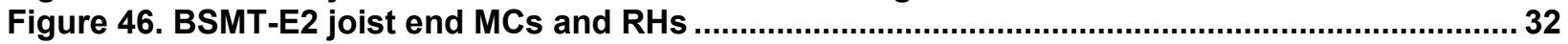

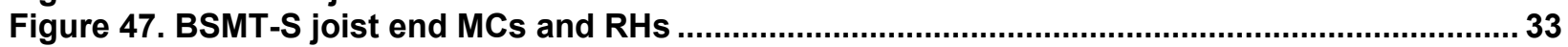

Figure 48. Basement North and South joist pocket winter temperature comparison ....................... 33

Figure 49. Basement North and South joist pocket summer temperature comparison ..................... 34

Figure 50. First-floor unheated wing joist end measurements highlighted ........................................ 34 
Figure 51. First-N joist end MCs and RH

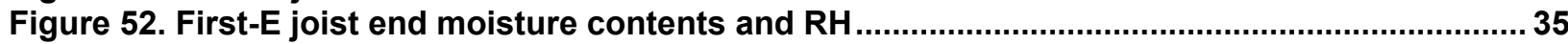

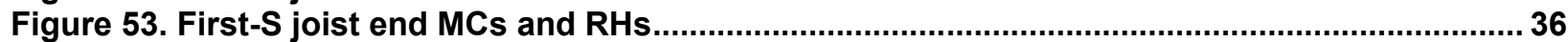

Figure 54. Basement heated wing joist end measurements highlighted ........................................... 37

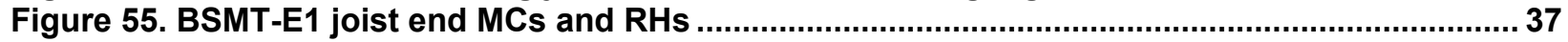

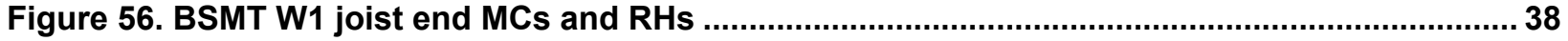

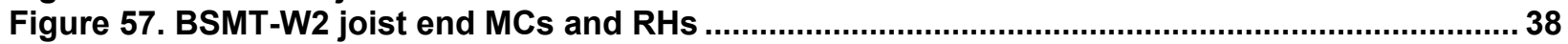

Figure 58. Basement West and East joist end winter/spring temperature comparison ................... 39

Figure 59. ASHRAE 160 failing hours for joist ends, with exterior temperature 30 -day average..... 40

Figure 60. Joist end stub in southeast corner (left), plan showing stub locations (right) ................. 42

Figure 61. Joist end stub embedded in wall (left); joist pocket showing mortar (right).................... 42

Figure 62. Joist end stub MCs: southeast corner/east-facing (wetter) ................................................ 43

Figure 63. Joist end stub MCs: southwest corner/west-facing (drier) .............................................. 43

Figure 64. Box/whisker plot for joist end MCs; minimally heated basement joists ......................... 46

Figure 65. Box/whisker plot for joist end MCs; unheated first-floor joists ......................................46

Figure 66. Box/whisker plot for joist end MCs; heated basement joists.........................................47

Figure 67. Evidence of water penetration at embedded beam end in masonry ................................51

Figure 68. Guidance on protection of embedded floor framing near grade ..................................52

Figure 69. Exterior excavation of masonry building with water shedding detail below grade ......... 52

Figure 70. Thermal simulation of uninsulated and insulated joists in masonry ...............................53

Figure 71. Conceptual sketch of exterior insulation at embedded floor members ........................... 54

Figure 72. Borate rods (left); diffusion of borate into wood at joist end (right) .............................. 55

Figure 73. Conceptual sketch of embedded joist geometry with interior insulation .........................56

Figure 74. Conceptual sketch of joist hanger retrofit option ........................................................57

Figure 75. Transfer of load from masonry using joist hanger (left) or structural angle (right) ........ 58

Figure 76. Conceptual sketch of steel angle retrofit option ...........................................................58

Figure 77. Conceptual sketch of interior bearing wall retrofit option ........................................... 59

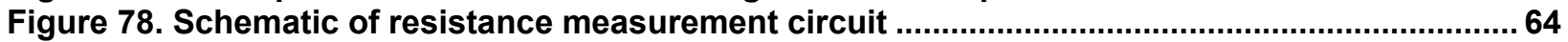

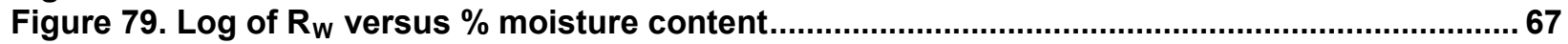

Unless otherwise noted, all figures were created by Building Science Corporation.

\section{List of Tables}

Table 1. Number of Hours Failing ASHRAE 160 and Percentage of Hours at Failure ..................... 41

Table 2. Testing and Monitoring Equipment Specifications..........................................................63

Table 3. Calculation of Wood Resistance Error $\left(\Delta r_{w}\right)$ at Various Wood MC Levels..........................65

Table 4. Calculation of Wood MC Error $\left(\Delta \mathrm{mc}_{\text {uncorrected }}\right)$ at Various Wood MC Levels......................... 66

Unless otherwise noted, all tables were created by Building Science Corporation. 


\section{Definitions}

$\begin{array}{ll}\text { ASHRAE } & \begin{array}{l}\text { American Society of Heating, Refrigerating and Air-Conditioning } \\ \text { Engineers, Inc. }\end{array} \\ \text { BSC } & \begin{array}{l}\text { Building Science Corporation } \\ \text { ccSPF }\end{array} \\ \text { FPL } & \text { Closed-Cell Spray Polyurethane Foam } \\ \text { ICC } & \text { USDA Forest Products Laboratory } \\ \text { IECC } & \text { International Code Council } \\ \text { KLWM } & \text { Lawrence, Massachusetts, Municipal Airport (weather station) } \\ \text { MC } & \text { Moisture content (wood \% by weight) } \\ \text { MVHfH } & \text { Merrimack Valley Habitat for Humanity } \\ \text { RH } & \text { Relative humidity } \\ \text { XPS } & \text { Extruded polystyrene }\end{array}$




\section{Executive Summary}

\section{Background}

Load-bearing mass masonry buildings comprise a significant fraction of the existing building stock in the United States. However, adding insulation to the interior side of walls of such buildings in cold climates may cause performance and durability problems in some cases. Some problems, such as interstitial condensation and brick freeze-thaw damage, are being addressed. Another durability risk that has received less investigation is the hygrothermal behavior of moisture-sensitive wood beams or joists that are embedded in the load-bearing masonry. Wood members that are embedded in a masonry structure are colder (and possibly wetter) after an interior insulation retrofit; the potential impact is not as well understood.

\section{Literature Review}

The U.S. Department of Energy's Building America research team Building Science Corporation (BSC) conducted a literature review of several practitioners who used in-situ monitoring and simulations to examine the moisture risks at embedded members in masonry walls. Monitoring of joist ends in Ontario, Canada (zone 6A), showed elevated moisture contents or MCs $(20 \%+)$ but drier conditions in the low-rainfall climate of Saskatchewan (zone 7). European simulations showed that MCs in joist ends are highly dependent on wind-driven rain deposition rates. The practitioners also simulated the effect of leaving a gap in the insulation above and below the floor to allow greater drying. The European literature reviewed historical methods to protect beam ends. The European researchers covered field studies that typically found that driving rain did not cause moisture problems at beam ends. Some researchers found that cracks in the façade could cause problems, but crack-free façades had acceptable performance. BSC performed simulations of joist end geometries, including three-dimensional heat flow and one-dimensional hygrothermal simulations. These hygrothermal simulations gave inconclusive results; the author recommended in-situ measurements of beam pocket temperatures, relative humidities (RHs), and wood MCs.

\section{Experimental Work}

This work involved the field monitoring of embedded wood joist ends in a solid brick building in zone 5A that was retrofitted with interior insulation. Eleven joists throughout the building (which have a variety of orientations, exposures, and masonry wall types) were monitored for wood MCs at the embedded joist ends and for temperatures and RHs within the joist pocket. Indoor and outdoor conditions were also recorded. Results were collected for 28 months (December 2012-April 2015). One limitation was that the renovation was still ongoing; limited wintertime construction heating and no permanent occupancy were factors. Much of the building experienced cold interior temperatures (e.g., construction heating) during the winters. These were not typical interior heating set points. Because the building was essentially unoccupied, no significant interior moisture was generated. These boundary conditions are not normal service conditions.

\section{Results and Conclusions}

Overall, the RHs and MCs measured in joist pockets were higher than recommended for longterm durability. Many of the joist pockets had sustained conditions of $100 \% \mathrm{RH}$, and many wood MCs were in the $25 \%-35 \%$ range for extended periods. Typical guidance includes: (1) MCs lower than $20 \%$ are safe, and (2) decay fungi become active at MCs higher than $28 \%$. ASHRAE 
160 analysis showed that high $\mathrm{RH}$ levels coincided with temperatures that were high enough to support mold growth for most of the monitoring period (60\%-70\% of the hours) in most joists. However, no damage was seen at the joist ends when the instrumentation was installed or when a joist end sample was removed. This suggests that dense, old-growth framing might be able to survive these MCs without damage.

Orientation has a significant effect on RH and MC levels: solar heating and drying kept all southfacing joist MCs well within the safe range. The east and west orientations had mixed results: some were in the safe range, but others exceeded the $20 \% \mathrm{MC}$ level. The north side joists consistently had the highest MCs.

Almost all the joists showed seasonal rises and falls; $\mathrm{MC}$ and $\mathrm{RH}$ conditions were higher during the summer and lower during the winter. This indicates the temperature gradient caused moisture to be driven inward during the summer. MC plots with driving rain showed no discernable correlations.

In the parts of the building that had significant wintertime heating, many joists showed a drop in MC that coincided with the addition of heat, even after insulation and air sealing were installed.

The joist ends showed a repeated pattern of MC measurements at their upper and lower ends. The lower joist end was consistently wetter than the upper joist end, which can be attributed to contact with the masonry pocket, gravity drainage of bulk water to the bottom of the pocket, greater drying at the top of the beam or deeper embedment at the bottom of the beam, and a larger air pocket at the top of the beam.

The north-facing insulated and uninsulated joist ends were compared; a significant or consistent $\mathrm{MC}$ or RH difference was not seen between these cases. All three joist pockets essentially remained at a constant $100 \% \mathrm{RH}$.

The retrofit neared completion in spring to summer 2015. This is the final Building America report for this project.

\section{Guidance for Retrofits}

Given the uncertainty demonstrated by the research, definitive guidance on the vulnerability of embedded wood members (i.e., a go/no-go situation) is difficult to formulate. Many of the joist ends operated consistently at high MCs, and the joist pockets demonstrated high RH (100\%); these factors suggest the embedded members are at risk of moisture problems. However, disassembly revealed no structural decay.

One risk factor is embedded beam ends that are near or below grade; they are vulnerable to splashback, capillary rise from the foundation, and exterior bulk water; details of methods that can ameliorate these issues are shown. Another method to protect beam ends is to apply exterior insulation in a horizontal band at that area if exterior aesthetic changes are permissible.

Another risk control method is to protect the joist ends with a preservative such as solid borate rods inserted into holes that are drilled into the joist end. These rods provide long-term protection from insect infestation and fungal decay; the preservative activates when the wood is wetted. 
In high-risk situations (e.g., when water damage and wood decay are already evident), or when a very conservative approach is warranted, some options are presented for eliminating the embedded wood member condition entirely. Details are provided for cutting off the embedded "tail" of the joist to eliminate capillary wicking and supporting the floor structure from another point. Support options include joist hangers attached to the masonry, a continuous angle iron attached to the masonry, and a wood-frame-bearing wall below the joists. 


\section{Introduction}

\subsection{Background}

Load-bearing mass masonry buildings comprise a significant fraction of the existing building stock in the East Coast and Midwest regions of the United States. However, adding insulation to the interior side of walls of such masonry buildings in cold (particularly cold and wet) climates may cause performance and durability problems. Some of these problems, which include interstitial condensation and brick freeze-thaw damage, have been (or are being) addressed (see Maurenbrecher et al. 1998; Gonçalves 2003; Straube and Schumacher 2002, 2004, 2007; Morelli et al. 2010; Straube et al. 2012; Ueno et al. 2013).

However, another durability risk that has been less investigated is the hygrothermal behavior of moisture-sensitive wood beams or joists that are embedded in the load-bearing masonry (Figure 1). With the retrofit of interior insulation, the embedded beam ends spend longer periods at colder temperatures than at their preretrofit condition. Therefore, reduced heat or energy flow reduces the drying potential of these wood members (Lstiburek 2008). The wood is also subjected to higher relative humidity (RH) conditions in the beam pocket and remains at a higher moisture content (MC); both factors increase the risk to the beam's durability. Also, vaporretarding insulation materials reduce inward drying.
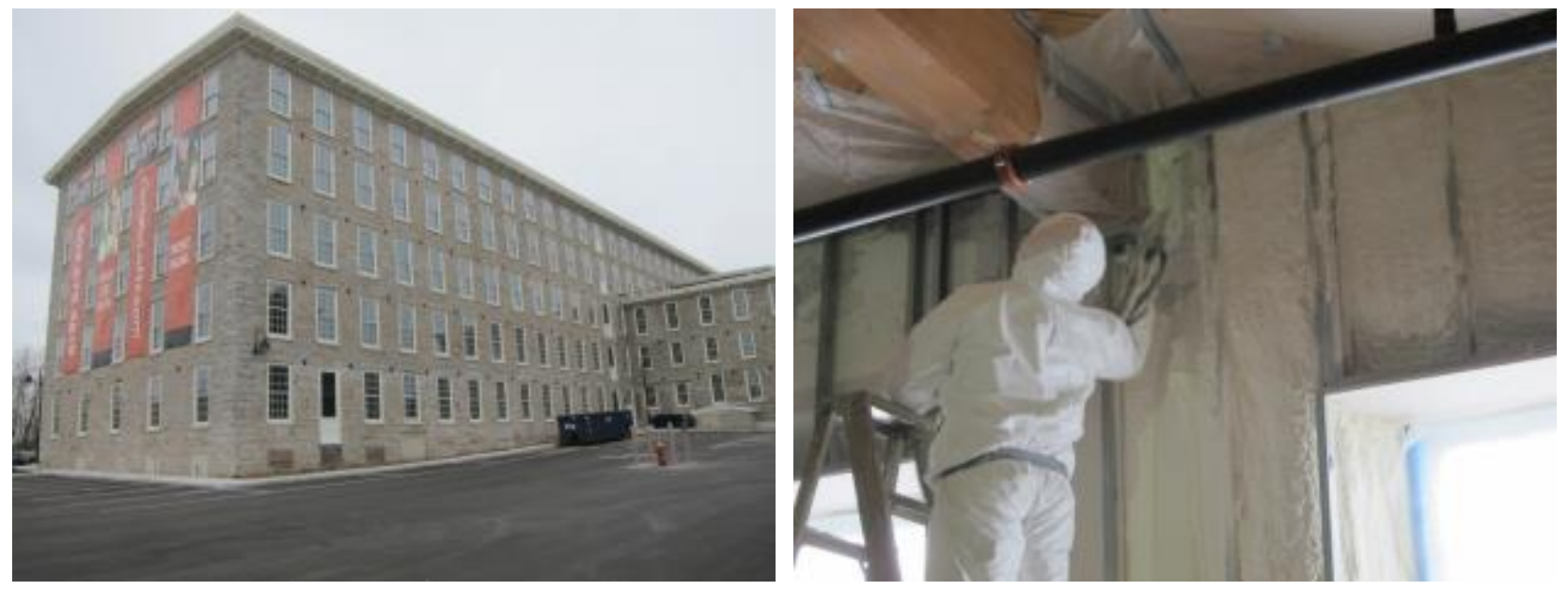

Figure 1. Mass masonry retrofit project overview (left); interior insulation at beam ends (right)

Solutions that have been proposed or used to protect embedded members include borate preservative injections into the wood, metal plates next to the member to provide passive heat flow, active heating at the beam ends, construction of a load-bearing structure inside the masonry, and cutting off the end of the beam.

Previous simulation work on embedded wood members in insulated masonry walls left many open questions, which could be addressed - at least in part - by in-situ measurement of embedded member MC. Therefore, the U.S. Department of Energy's Building America research team Building Science Corporation (BSC) conducted field testing in collaboration with Merrimack Valley Habitat for Humanity in Lawrence, Massachusetts, which is currently renovating a mass masonry multifamily building into 10 condominium units with interior insulation. 
The BSC team monitored 11 joists scattered throughout the building (which have a variety of orientations, exposures, and masonry wall types) for wood MC (low and high at the joist end) and temperature and RH within the joist pocket. Indoor and outdoor conditions were also recorded. Results were collected for 28 months (December 2012-April 2015). One limitation is that the renovation was still ongoing; limited wintertime construction heating and no permanent occupancy were factors.

As a general note, exterior insulation provides the ideal conditions for building durability for the masonry and embedded wood members. Exterior insulation addresses many thermal bridging problems (e.g., masonry tee walls) that occur with interior insulation. However, many buildings cannot be retrofitted with insulation on the exterior for reasons such as historic preservation, cost, zoning or space restrictions, and aesthetics.

\subsection{Relevance to Building America's Goals}

Given the Building America goals of reducing home energy use by $30 \%-50 \%$ (compared to 2009 energy codes for new homes and preretrofit energy use for existing homes), insulation and air sealing of mass masonry walls will need to be components of the work if mass masonry residential buildings are to be addressed. Potentially millions of housing units could benefit from a better understanding of the moisture risks that are associated with interior retrofits and the means of reducing these risks.

Most construction that can benefit from this research is in locations with older building stock (i.e., mass masonry). The greatest concentrations are likely on the East Coast and in the Midwest (i.e., cold climates), although these types of buildings are definitely present throughout the country.

This research on the MC of embedded wood members addresses a durability risk associated with this insulation retrofit. If interior insulation retrofits are linked with significant numbers of moisture-related failures, the adoption of this retrofit measure will be set back.

The research covered here was judged relevant by the Building America Standing Technical Committee on Enclosures circa 2011 (when the monitoring project began); it was as a topic for additional research work (see Enclosures STC Strategic Plan: \#32 Gap (Walls): Identify moisture damage risks associated with insulating embedded wood beams or joists in masonry walls; DOE 2011).

\subsection{Cost-Effectiveness}

Load-bearing masonry has a range of thermal properties; however, even a "thick" multiwythe load-bearing masonry wall is likely to have an R-value of R-3.2 to R-6.8; the average is about R-5. Surface heat transfer coefficients ("air films") of another R-1 may result in thermal performance that is comparable to that of a high-end (i.e., triple-glazed) modern window; however, this level of insulation is too low for most practical purposes (considering current energy costs, building durability, and health and thermal comfort issues). Hence, insulation is often added during retrofits and is critical to achieving high performance (per Building America program goals) in any climate with significant heating loads. 
The R-values of uninsulated masonry walls are also substantially lower than modern code requirements for cold climates; for zones 5 and 6, the typical opaque-wall "true" R-value requirements are R-12 to R-17 (as calculated from U-values given in the 2009 International Energy Conservation Code, Table 402.1.3; ICC 2009b).

Thermal insulation follows the law of diminishing returns; the return on investment decreases as insulation thickness increases. Given that these wall assemblies are being changed from uninsulated (base case) to insulated (final) assemblies, the initial 1-2 in. of insulation should be highly cost-effective. Optimization would be a function of insulation cost, energy costs, and climate zone.

BSC's current retrofit recommendations include the use of air-impermeable closed-cell spray foam (ccSPF) as an interior insulation material for mass masonry walls. A typical installed price for ccSPF is roughly $\$ 1 /$ board foot, although prices appear to be decreasing; when normalized by $\mathrm{R}$-value instead of volume this cost is equivalent to approximately $\$ 0.16 / \mathrm{ft}^{2} \cdot \mathrm{R}$. In comparison, standard types of loose-fill fibrous insulation are sold at $\$ 0.02-0.04 / \mathrm{ft}^{2} \cdot \mathrm{R}$; this is a material cost, not an installed cost. If a 1:1 material-to-installation cost ratio is assumed for this estimate, ccSPF still costs about two to four times more than the lowest-cost loose-fill materials. However, as discussed by Straube and Schumacher (2007) and Morelli et al. (2010), the use of airpermeable and moisture-sensitive fibrous insulation in this application results in assemblies with a higher risk of moisture-related failures.

Interior insulation retrofit of mass masonry buildings is generally considered lower-cost (and therefore more cost-effective) than exterior insulation but has the attendant durability risks and performance limitations described earlier.

\subsection{Tradeoffs and Other Benefits}

Basic benefits of the retrofit insulation of uninsulated masonry walls include energy savings and thermal comfort improvements due to radiant surface temperature effects and air leakage reduction. The assemblies under discussion could, unlike the nonretrofitted assemblies, meet requirements for modern energy codes (Section 1.2).

As discussed in Section 1.1 and Section 1.2, the research on embedded wood members is being undertaken to ensure the retrofit of insulation in masonry structures does not cause substantial durability problems in the future. 


\section{Literature Review and Field Observations}

Several practitioners have used in-situ monitoring and simulations to examine moisture risks at embedded members in masonry walls.

\subsection{Dumont et al. (2005) Field Monitoring}

Dumont et al. (2005) monitored the MCs of wood structural members that are embedded in masonry in two low-rise residences that were retrofitted with insulation in Wolseley, Saskatchewan (climate zone 7, "dry" climate), and Kincardine, Ontario (climate zone 6A, "moist" climate). The Wolseley house was insulated with mineral wool with a polyethylene vapor barrier; the Kincardine house was insulated with spray polyurethane foam. The foam insulation encased the wood members where they were seated in the masonry wall.

Data showed that the wood members of the Wolseley house remained at safe MC levels $(10 \%-15 \%)$ throughout the monitoring period. This is not meant as an endorsement of the use of air-permeable insulation with an impermeable interior vapor barrier: this is actually a high-risk assembly. In reality, the lack of moisture load (dry climate/low rainfall) is likely the dominant factor. In contrast, the Kincardine house showed consistently elevated MCs $(20 \%+)$ at several locations. The authors suspected the moisture source was capillary uptake from the wet foundation, but rainwater absorption through the face of the masonry (due to surface detailing) was not eliminated as a possible source. The limited drying to the interior available through spray polyurethane foam was also likely a contributing factor.

\subsection{Scheffler (2009) Hygrothermal Simulations}

Scheffler (2009) used simulations to examine the problem of moisture accumulation at wooden beam ends. He used DELPHIN two-dimensional hygrothermal simulation software, running a wooden beam embedded in brick masonry under steady-state conditions $\left(23^{\circ} \mathrm{F}\left[-5^{\circ} \mathrm{C}\right] / 80 \% \mathrm{RH}\right.$ exterior; $68^{\circ} \mathrm{F}$ [ $\left.20^{\circ} \mathrm{C}\right] / 50 \% \mathrm{RH}$ interior; 90 days). These simulations demonstrated the moisture risks that are associated with insufficient control of airflow or moisture vapor flow (diffusion) from interior sources. This was followed by one- and two-dimensional simulations that used transient weather data (Bremen, Germany; mild, maritime climate with high rain and humidity) that indicated increases in RH and liquid water (condensation) at the beam ends caused by added insulation.

Scheffler also described the historical methods to increase embedded beam longevity, such as charring the beam end to increase moisture resistance and adding exterior-to-interior ventilation at the beam pocket. He discussed current methods to ameliorate these moisture issues, which could be caused by insulation retrofits, including replacing wood floor/ceiling assemblies with non-moisture-sensitive materials (e.g., concrete) and possibly adding heat or ventilation at the wood beam end.

\subsection{Morelli et al. (2010) Hygrothermal Simulations}

Morelli et al. (2010) collaborated with Scheffler to continue examining this issue. They proposed leaving a 12-in. (300-mm) gap in the insulation above and below the floor, which would result in a 30-in. (770-mm) gap (12-in. gap $\times 2$ plus floor depth). Two- and three-dimensional heat transfer simulation showed the heat flow was reduced by $60 \%$ from the uninsulated to insulated cases; the gap case showed only a $45 \%$ reduction. This work was followed by two-dimensional 
DELPHIN hygrothermal simulations of the embedded beam (in a Bremen climate). RH levels in a corner of the beam pocket (and equilibrium wood MC) were compared between cases. The uninsulated wall showed a drying trend, the fully insulated wall showed seasonal RH increases, and the gapped insulation wall showed performance between the two previous cases but with increasing moisture levels. However, these results assumed a relatively high wind-driven rainloading factor. Switching to a lower loading factor caused the gapped insulation assembly to show a general drying trend.

\subsection{Morelli and Svendsen (2012) Simulations and Literature Review}

Morelli and Svendsen (2012) continued the work of Morelli et al. (2010) by showing further simulations with continuous interior insulation versus insulation installed with a gap at the floor beams. This research also resulted in a methodology for assessing retrofit measures on brick masonry walls based on a failure mode and effect analysis.

Morelli and Svendsen also performed an extensive literature review from the 1980s to 2012. They examined several in-situ field studies and found that driving rain typically did not cause moisture problems at beam ends. Some researchers found that cracks in the façade could cause problems, but crack-free façades had acceptable performance. Another researcher examined the effect of interior air leakage at beam ends: at high air-leakage rates, temperatures in the beam pocket were higher and reduced condensation risks. At low air-leakage rates, air-transported moisture was negligible; however, at intermediate flows condensation did occur. That researcher recommended adding localized exterior wall insulation at beam ends or insulating the beam end cavity. Other researchers examined techniques such as adding heat to the beam ends to avoid moisture problems. The results kept wood MCs low, but it is an expensive (and therefore unlikely) retrofit.

\subsection{Rudd (2014) Crawl Space Retrofit Field Measurements}

Rudd (2014) described the retrofit of a crawl space in a circa 1940 multifamily building in the Philadelphia area (zone 4A). The crawl space foundations were ungrouted (hollow) concrete block with a brick veneer (Figure 2, left); above-grade walls were wood frame with a brick veneer. The first-floor framing (sawn lumber) was grouted in place and embedded in the concrete masonry unit wall (Figure 2, right).

As an energy upgrade, the crawl space was converted from conventional vented/unconditioned to sealed and conditioned crawl space, per $\S \mathrm{R} 408.3$ of the International Residential Code (ICC 2009a). Rigid foil-faced polyisocyanurate was installed on the crawl space walls and sealed around the joist ends (Figure 3). A continuously running exhaust fan was added to draw air from the crawl space; it pulls makeup air from the units above and provides a continuous supply of dry, semiconditioned air to the crawl space. 

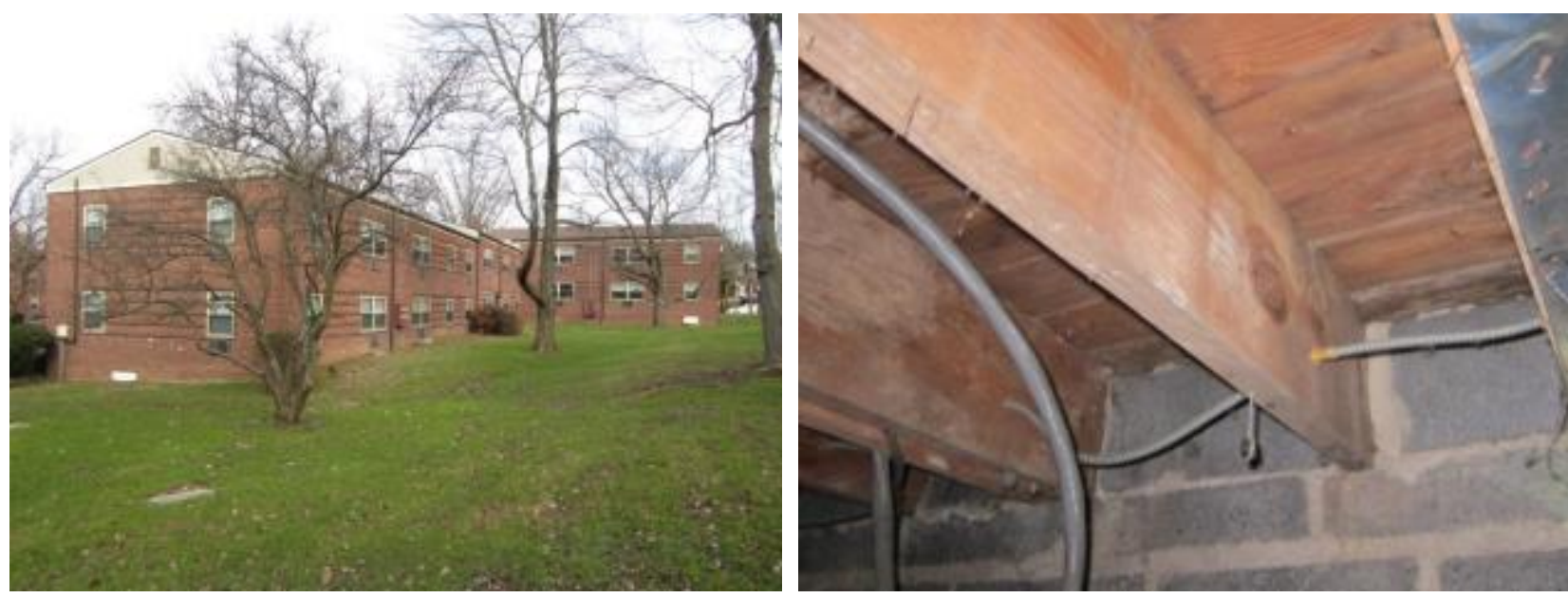

Figure 2. Overview of apartment complex (left); preretrofit joist ends in concrete masonry unit walls (right)
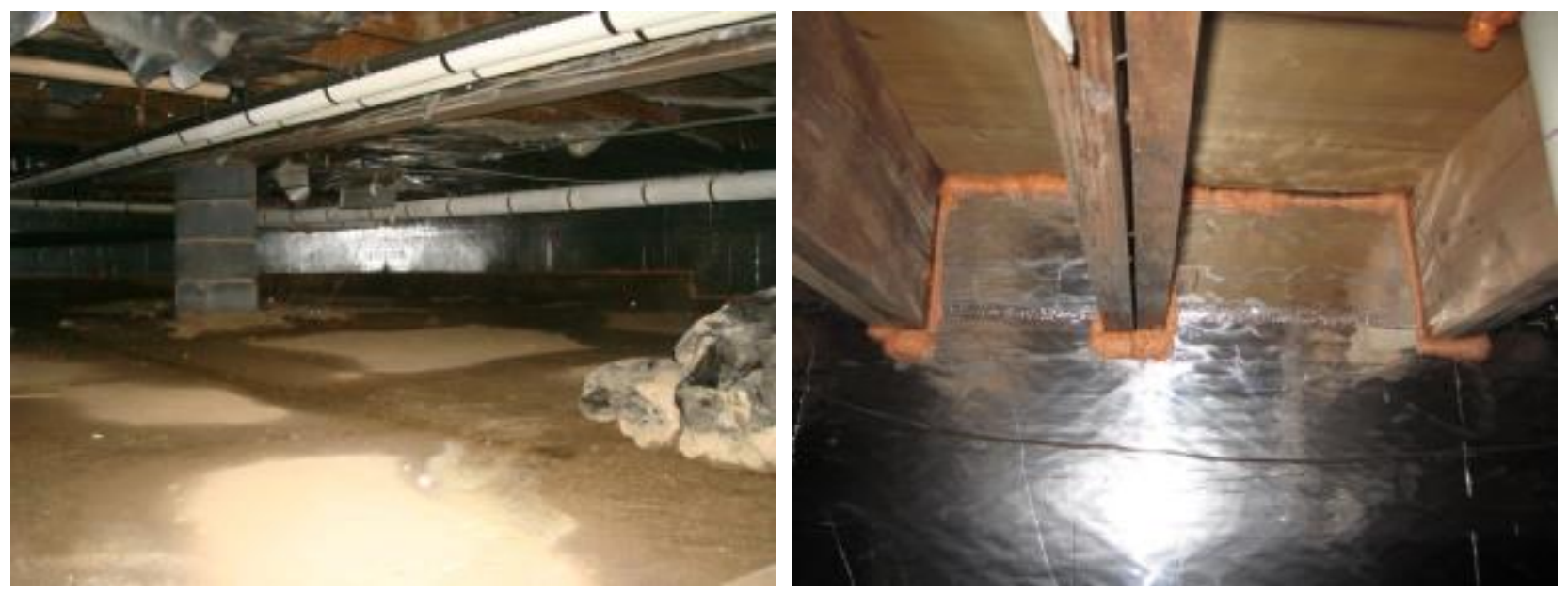

Figure 3. Postretrofit crawl space conditions (left); insulation board sealed at joist ends (right)

Joist MCs were measured: initially, they were $6 \%-10 \%$ in the main space and only $1-2$ percentage points higher near the joist ends. However, the site later flooded (immersing the floor framing), and some joist ends remained at 40\%+ MC. The author recommended cutting back insulation $1 / 2$ in. around the joist ends to facilitate drying. Other joist ends had lower $(10 \%-12 \%)$ MCs.

\subsection{Ueno (2012) Heat Flow and Hygrothermal Simulations}

Ueno (2012) examined this problem by first using three-dimensional heat flow simulations to determine the embedded beam and joist end temperatures with and without interior insulation (Figure 4). Various mitigation techniques, such as heat flow plates or omitting insulation, were also simulated. 

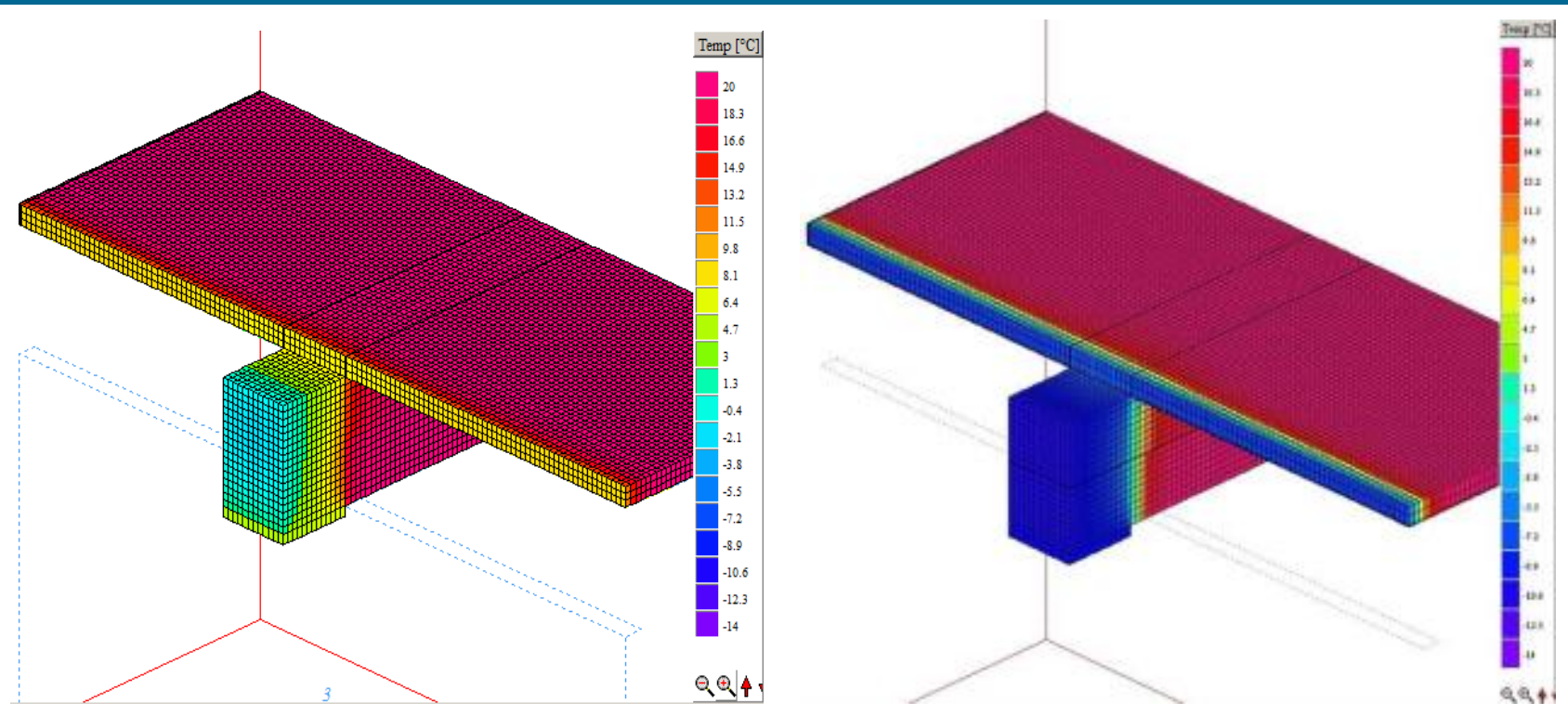

Figure 4. Embedded beam uninsulated case (left); insulated case (right)

Source: Ueno (2012)

These results were then used to inform one-dimensional hygrothermal simulations of embedded beam ends. These simulations gave inconclusive results; the author recommended a possible first step of using of two-dimensional hygrothermal simulations.

However, greater and more defensible insights could be gleaned from in-situ measurements of beam pocket temperatures, RHs, and wood MCs in insulated and uninsulated configurations and various orientations and rainfall exposure levels. Based on Ueno's conclusions, this current research project measured in-situ conditions of embedded wood joists in an interior insulated masonry structure.

\subsection{Field Observations of Embedded Wood Members}

The research team has examined many mass masonry buildings for potential interior insulation retrofits; this section covers some of the field observations from this work.

One common geometry, especially in mill or industrial buildings, is large timber beams (8-10 in. minimum thickness) at a wide spacing (Figure 5, left). The beams are fire cut (slant cut at the end to prevent wall collapse during a building fire; see Figure 30) and embedded in the masonry wall. Signs of water damage at the beam end (Figure 5, right) were relatively rare and were typically associated with roofing failures (on the top floor), water issues near grade, and poorly detailed roof-wall connections (which deposit excess water on the wall). 

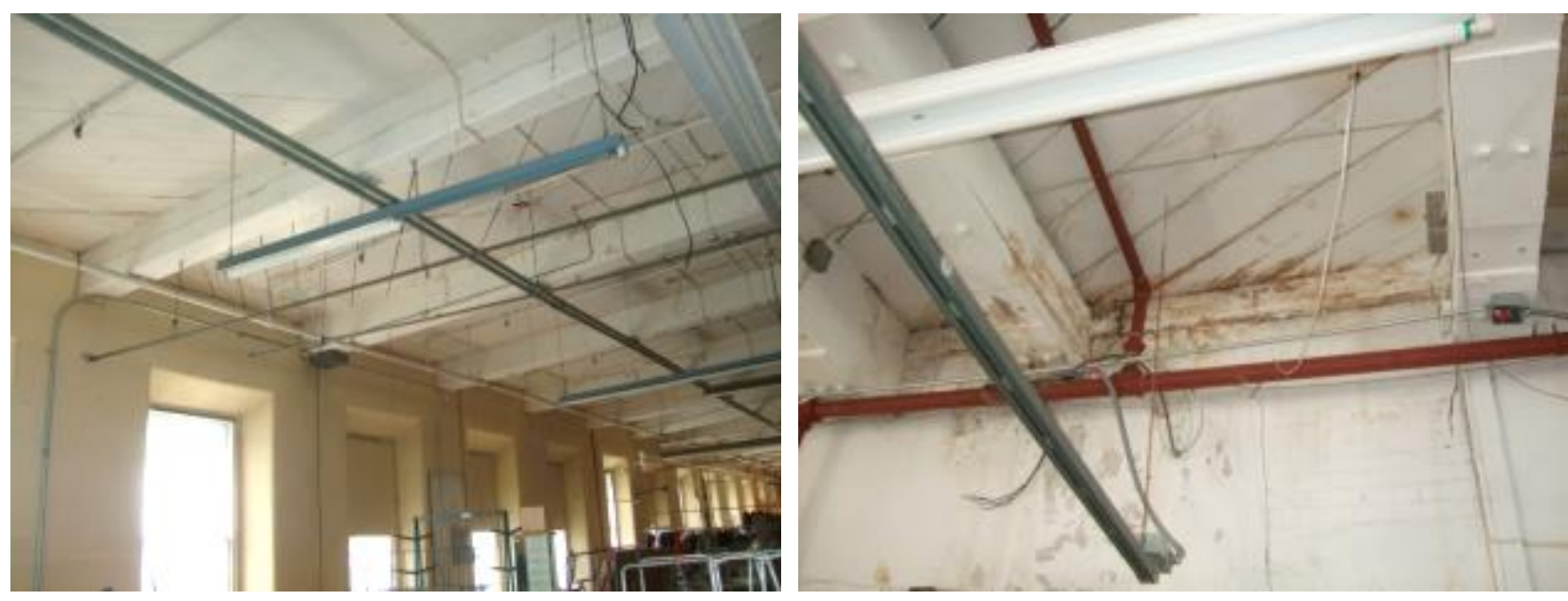

Figure 5. Typical large beam geometry (left); water damage at beam end (right)

These types of beams are typically pocketed with a steel or cast-iron plate to support it at the masonry wall (Figure 6). This plate was presumably installed for structural reasons (to distribute the beam's load on the supporting masonry and form a flat surface), but it also functions as an effective capillary break to eliminate water wicking from the masonry below.
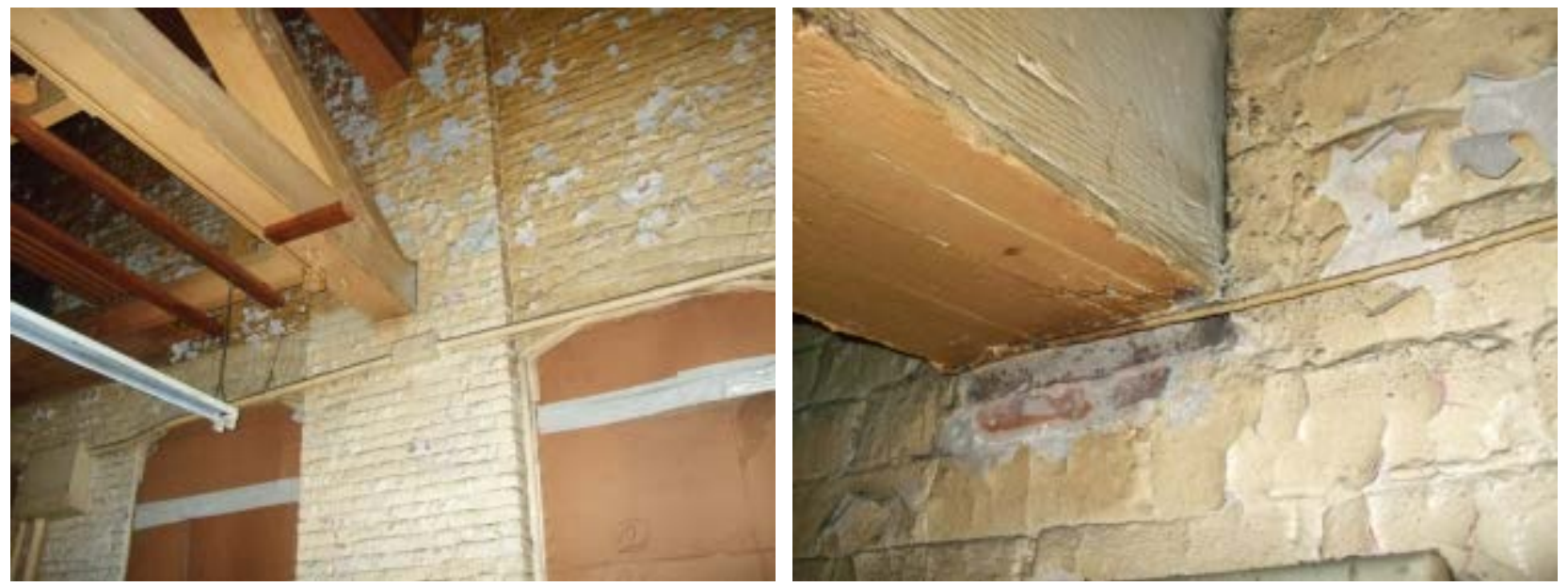

Figure 6. Large timber beam pocket (left); iron or steel bearing plate (right)

The sides of the beam sometimes have an air gap between the wood beam and the masonry; Figure 7 shows a relatively large ( $\sim 3 / 4$-in.) gap. However, these conditions vary widely from building to building; some buildings have masonry tight against the beam. 

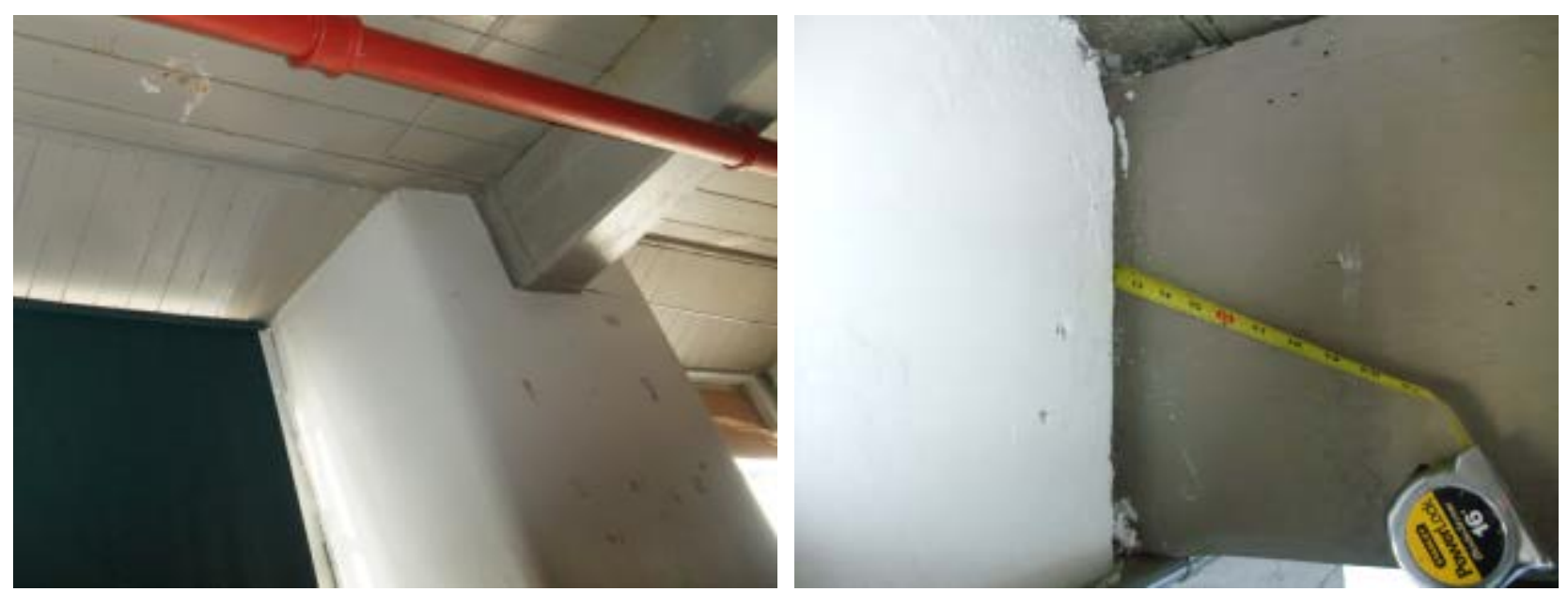

Figure 7. Beam pocket gap on sides; conditions vary by building

One historic design in a Boston-area building clearly acknowledges the risks that are associated with wood beams near grade. Beam pockets were used for most of the building; however, at the basement level (with beam ends near grade), cast-in steel plate saddle hangers were used to support the beam (Figure 8). This detail completely removes the vulnerable wood from contact with the masonry (Figure 9, left). Several areas were stained (Figure 8, right) with paint blowoff; however, measurement of the wood MC showed dry conditions, even at extensively waterstained areas (Figure 9, right). Keeping the wood beam end clear of the wall (with this saddle detail) allows significant drying of any incidental wetting in service.
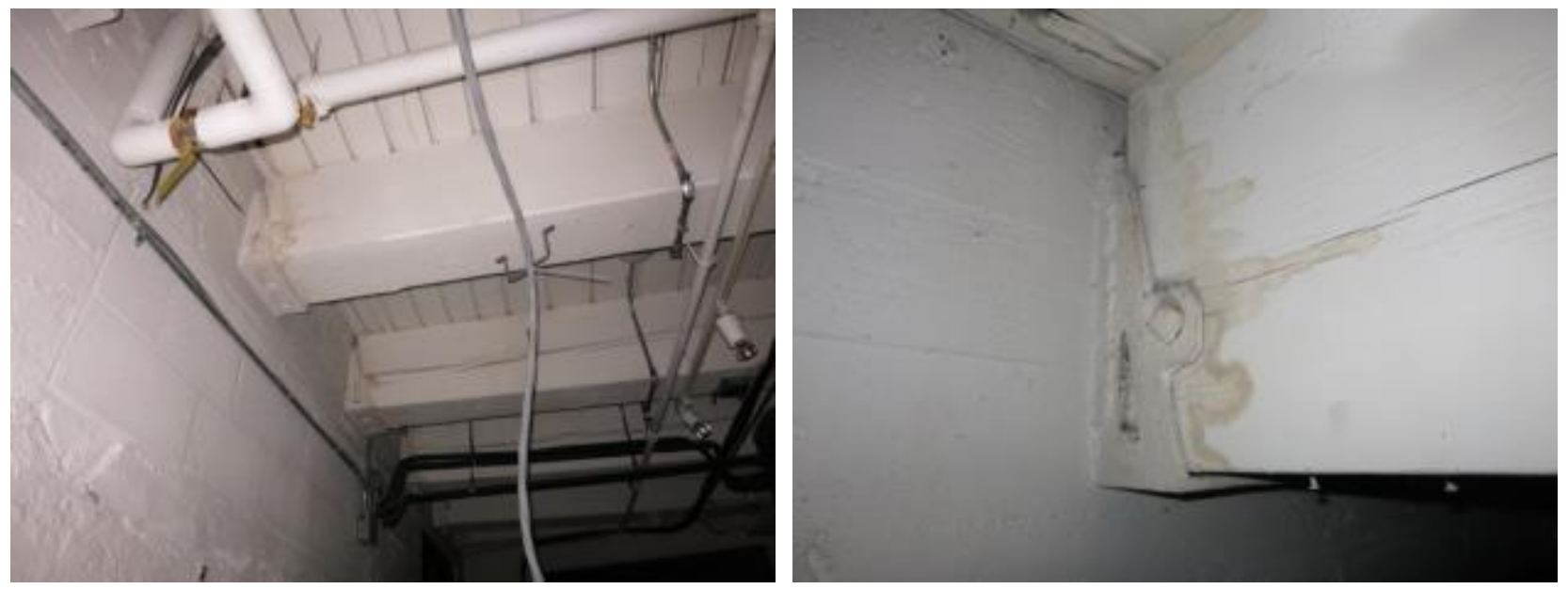

Figure 8. Steel saddle hanger detail, with beam clear of masonry wall at grade

This wetting might have been caused by interior-sourced flooding, based on the water stain patterns (e.g., visible staining between subfloor gaps). Whatever the wetting source, however, this detail allows for greater drying than an embedded beam. 

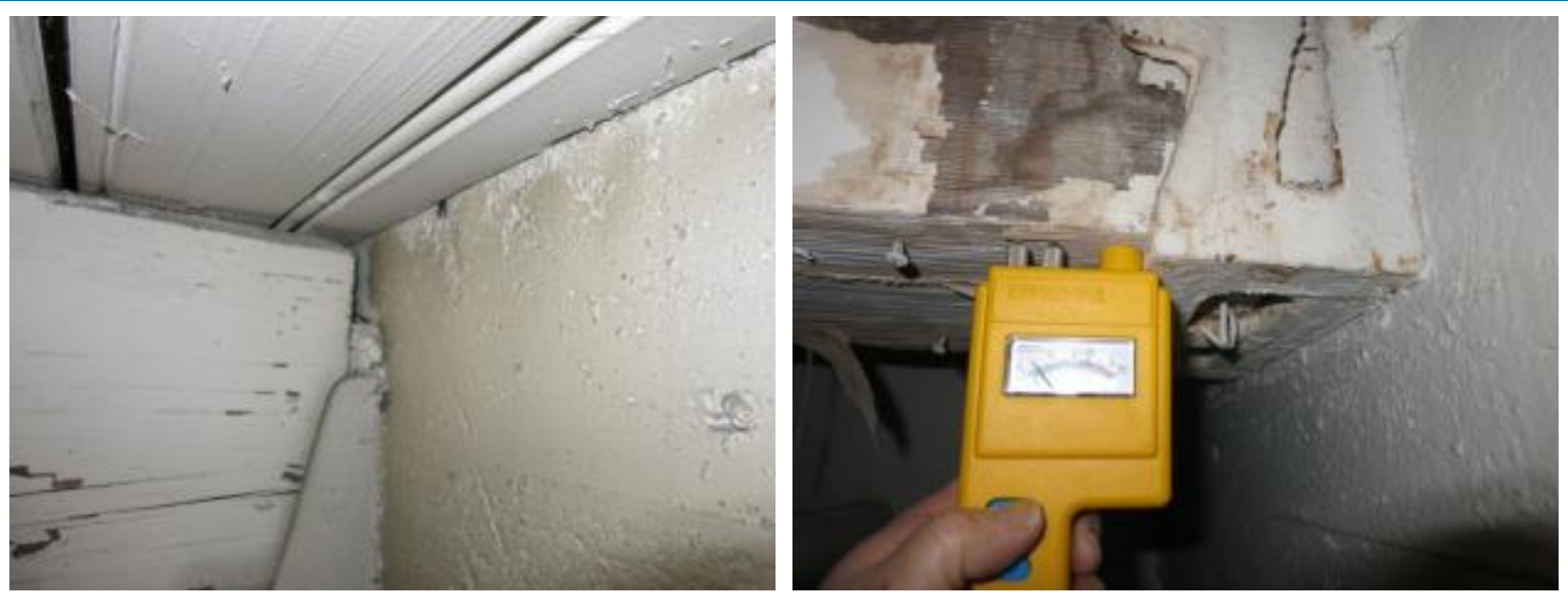

Figure 9. Wood clear of masonry (left); low MC despite wetting stains (right)

Individual joists that are composed of dimension lumber (2-3 in. width) at a close spacing (12-16 in. on center) constitute the other common geometry that is seen in residences and small commercial buildings (Figure 10).
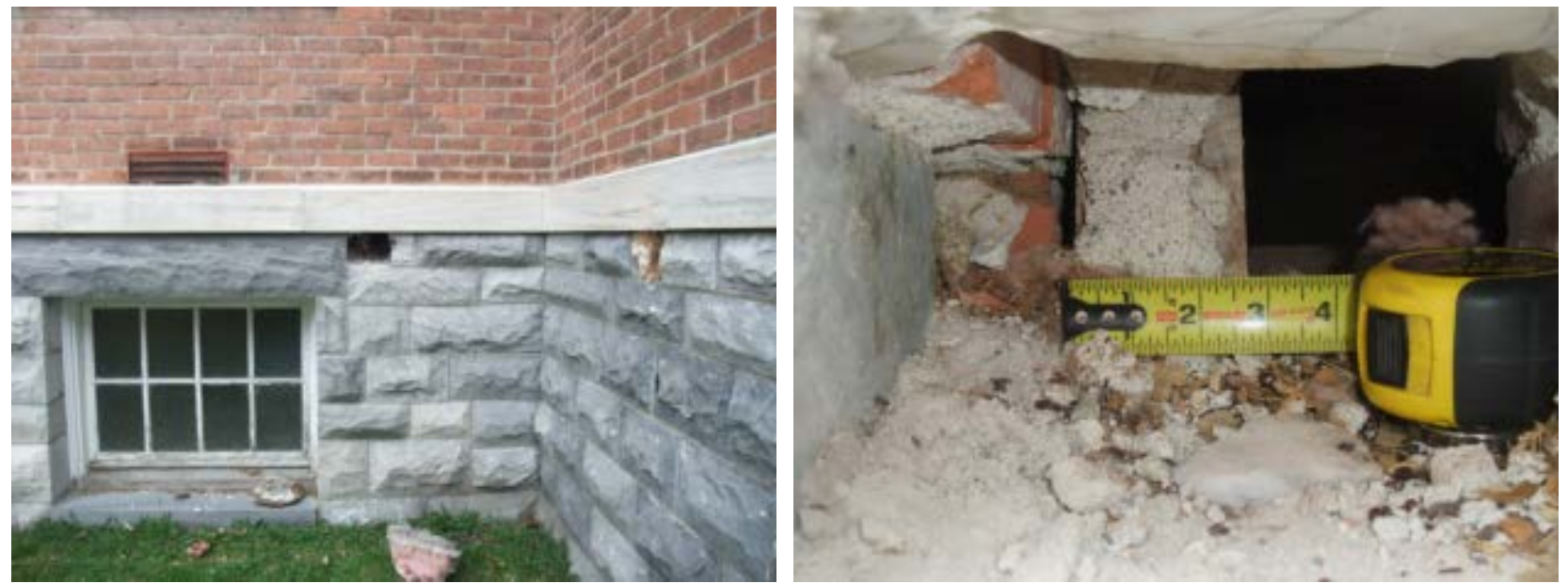

Figure 10. Embedded joist end from exterior showing dimensions and fire cut

These joists are fire cut and typically have no metal bearing plate. Pocket conditions vary, but grouting the joists into the pocket is not uncommon.

One high-risk condition for embedded beam or joist ends is proximity to grade, or even worse, placement below grade. Below-grade conditions for embedded beams are exceptionally risky: exterior boundary conditions will be $100 \% \mathrm{RH}$ with wetting from capillary uptake and liquid water penetration (rainwater and groundwater).

These risks are demonstrated in demolition at a circa 1850 brick building in the Boston area. The exterior grade rises at the sides of the building, which puts the floor framing below grade (Figure 11). 


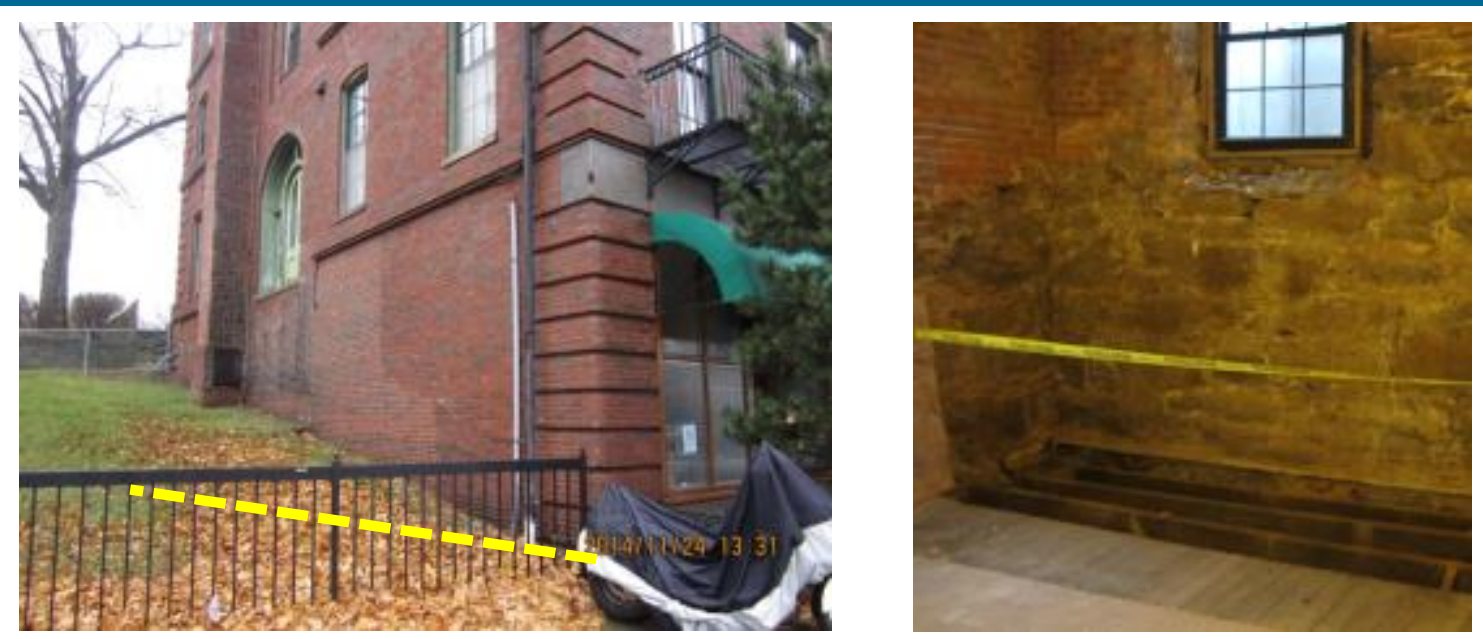

Figure 11. Building exterior grade condition (left); beam interface to below-grade wall (right)

(images courtesy of Chapman Construction)

The floor framing had severely deteriorated at the beam pockets (Figure 12). This floor system had no insulation. This damage had likely been continuing for some time, but it postdates the circa 1980s-1990s renovation (which was being demolished here).
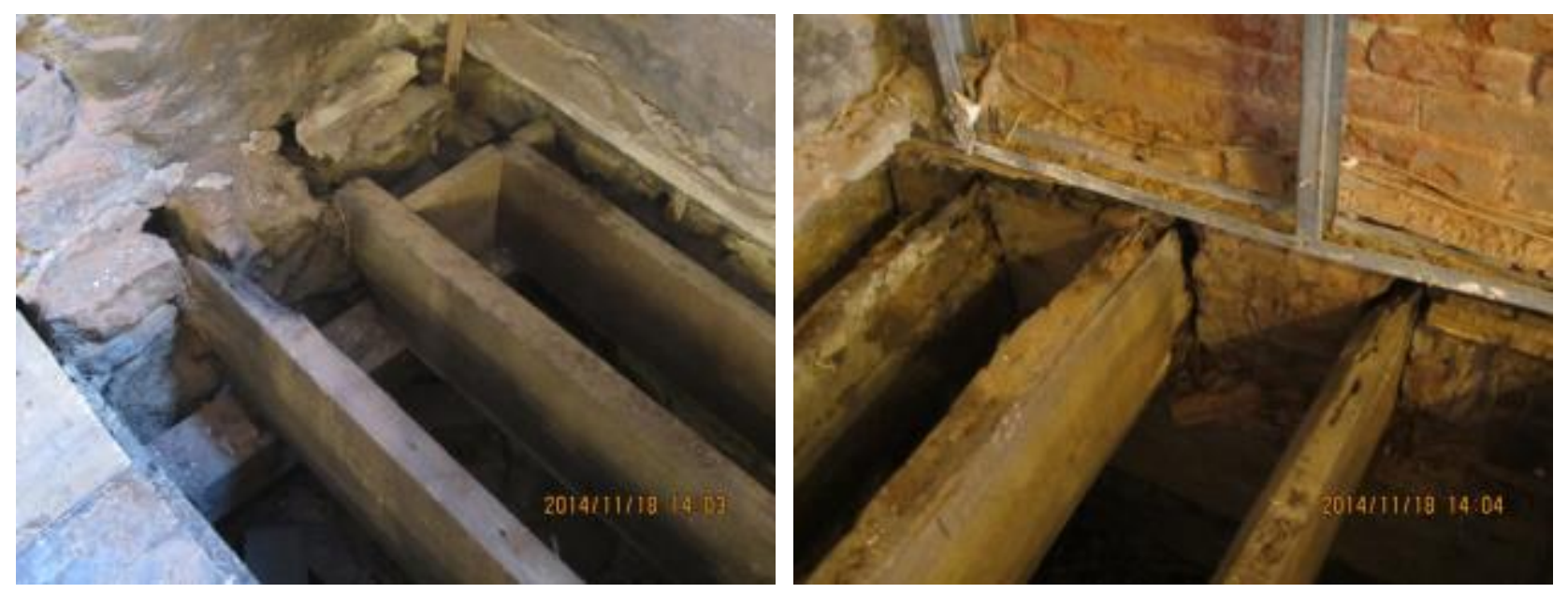

Figure 12. Damage to embedded beams at walls

(images courtesy of Chapman Construction) 


\section{Experimental Design and Sensor Installation}

This section is repeated (with slight edits) from Ueno et al. (2013) to provide a summary of the test assemblies and instrumentation package.

\subsection{Retrofit Project Overview}

The field monitoring work was conducted at an existing brick mass masonry building in Lawrence, Massachusetts (zone 5A), which is being renovated by the Merrimack Valley Habitat for Humanity into ten condominium units (Figure 13 and Figure 14).
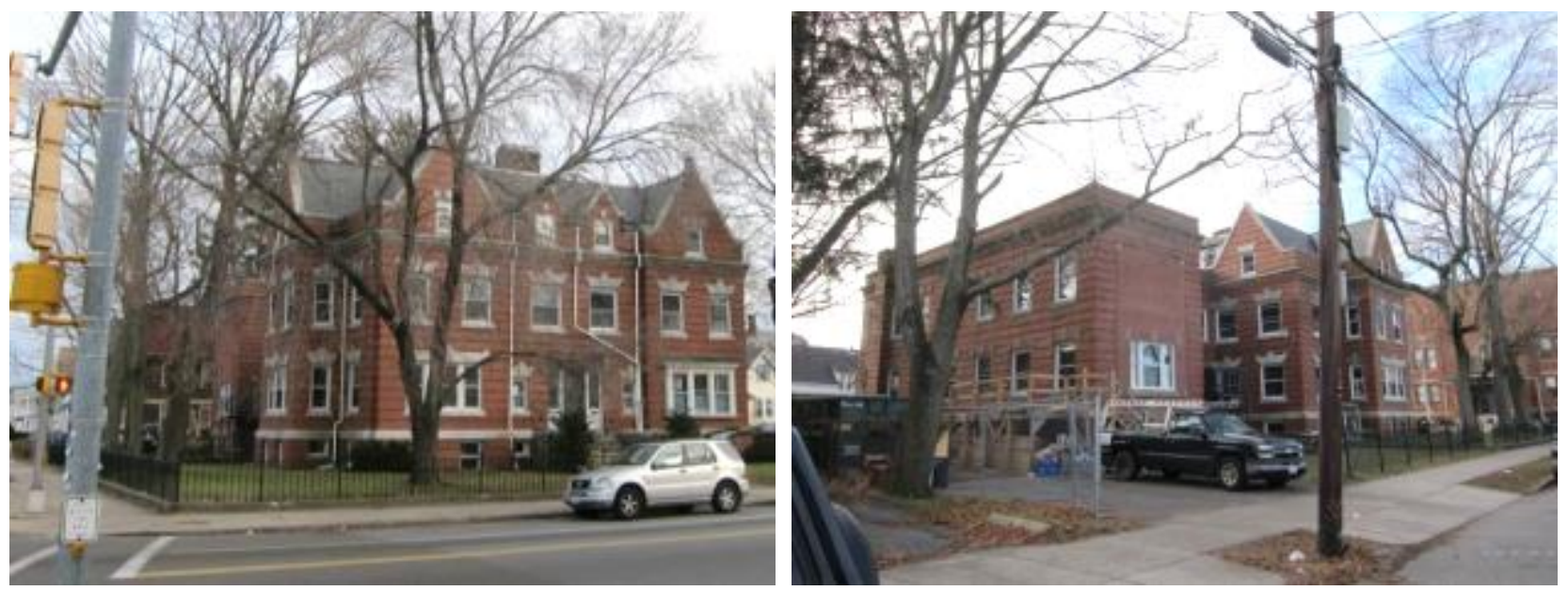

Figure 13. Retrofit building exterior view from west (left); view from north (right)
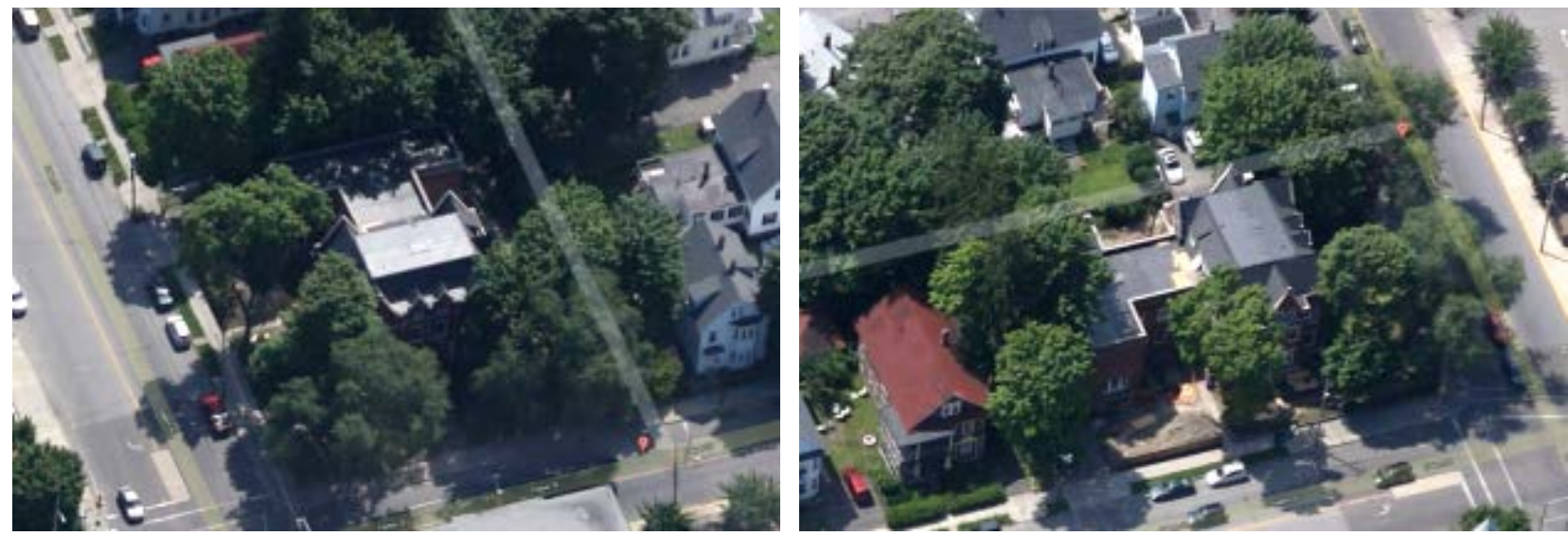

Figure 14. Overhead view of retrofit building from west (left); overhead view from north (right)

The BSC team used methods described in Straube and Burnett (2005) to create a driving rain rosette (Figure 15) with a recent year's weather data (May 2012-May 2013) for the nearest weather station (Lawrence Municipal Airport/KLWM; roughly 2.5 miles east of the site). The figure shows that the greatest driving rain is deposited on the rear face of the building (project East). Adjacent trees shield the building somewhat during nonwinter conditions (Figure 14). 

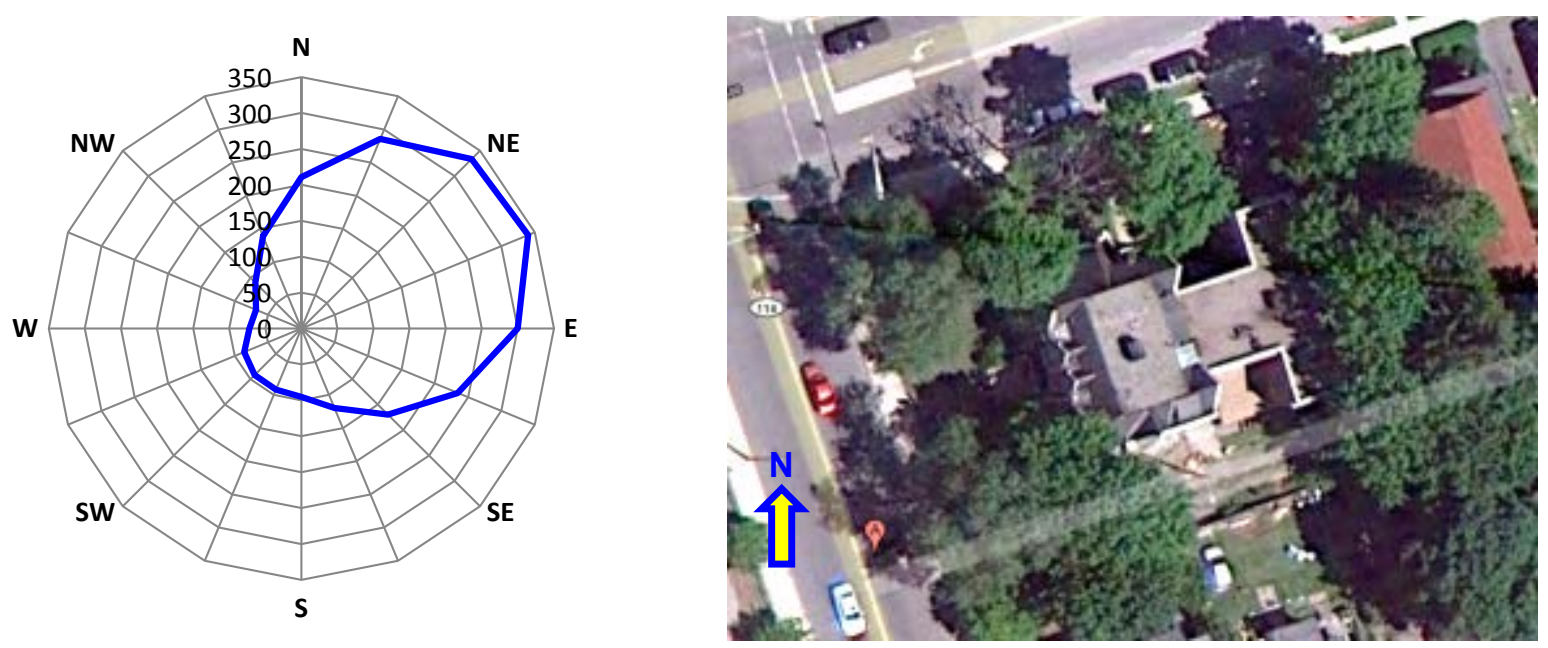

Figure 15. Driving rain rosette for KLWM, rain in mm/year (left); overhead view (right)

The construction of the masonry walls at this project includes multiwythe solid brick and exterior brick with a hollow clay block infill/backup (Figure 16). These photos show conditions after the interior furring, lath, and plaster were demolished. Solid multiwythe brick was used at the original part of the building (west-facing front elevation; circa 1906 construction; see Figure 13, left); hollow clay block was used at the east-facing rear addition (circa 1930 construction; Figure 13, right).
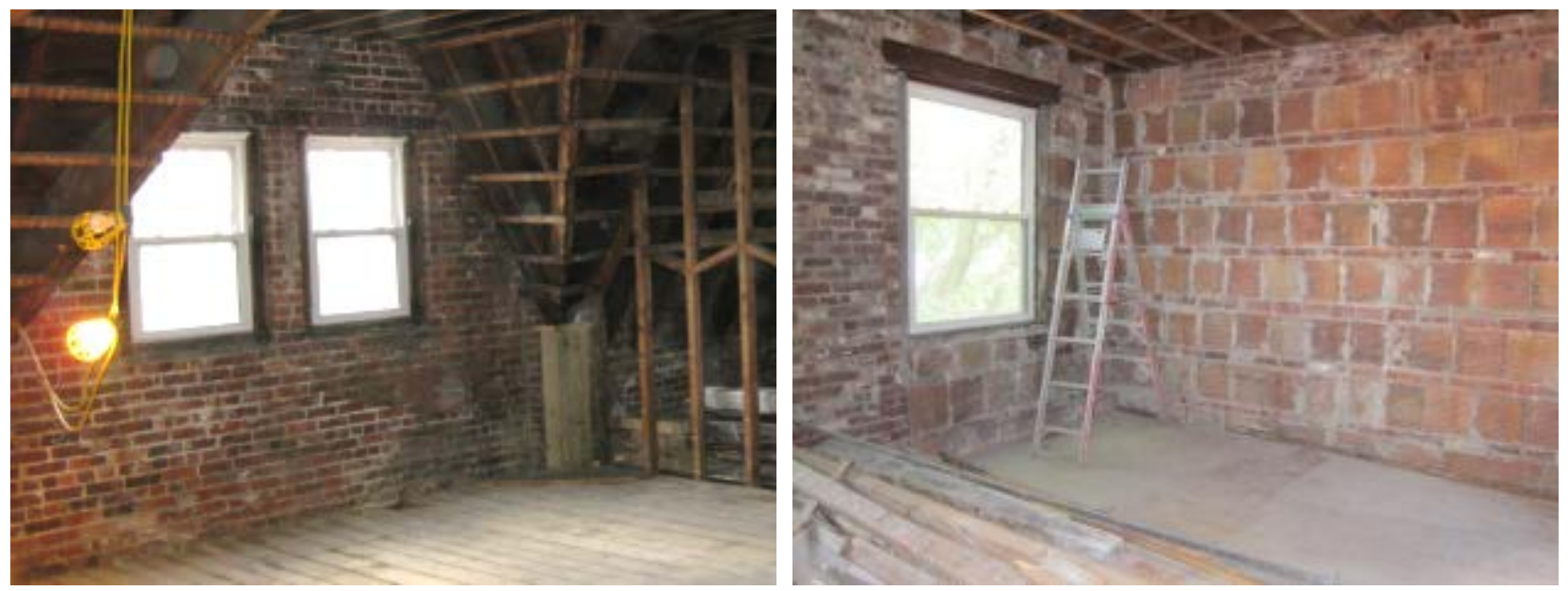

Figure 16. Exterior wall conditions at solid brick (left); hollow clay block infill (right)

Although these assemblies appear from the interior and exterior to be monolithic, the building has a variety of interconnected spaces such as the incompletely filled collar joints between brick wythes (Figure 17, left) and the hollow cores of the clay blocks (Figure 17, right). 

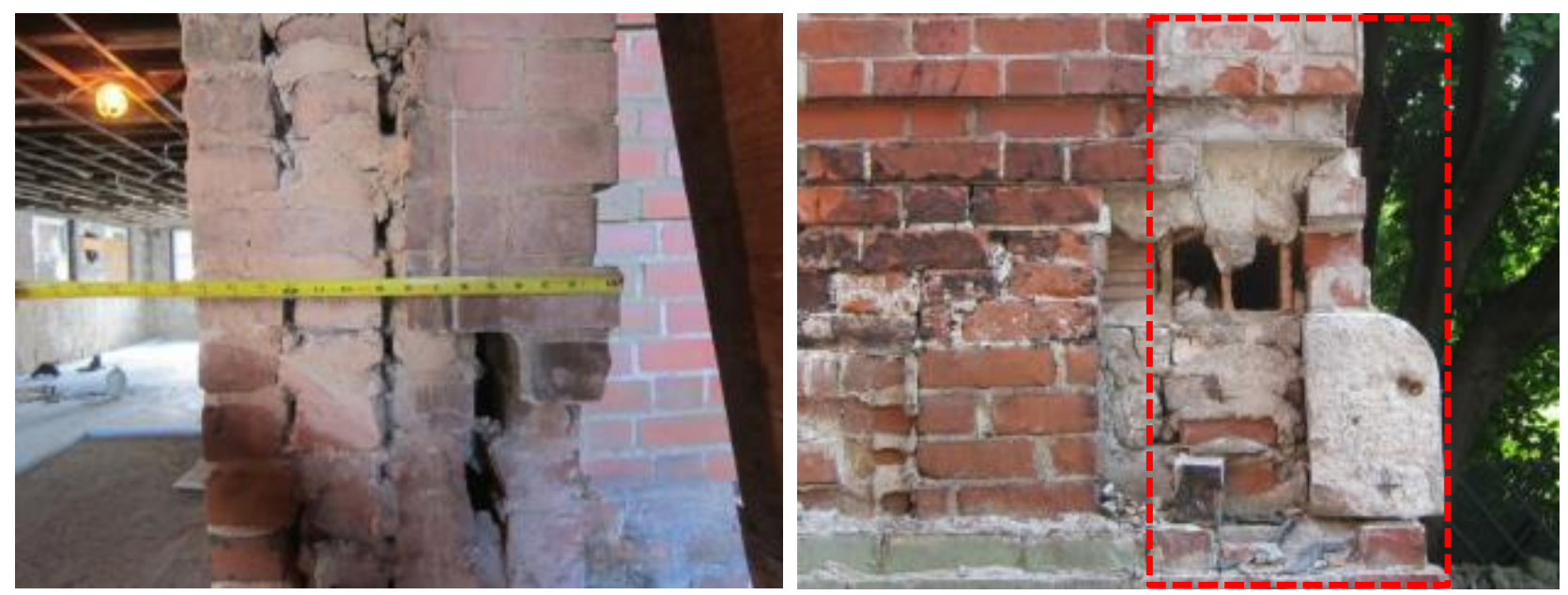

Figure 17. Wall section at solid brick (left); at hollow clay block infill (right) conditions

The building is being retrofitted with interior insulation, which consists of three 2-in. layers of extruded polystyrene (XPS) insulation that is adhered to the existing masonry with polyurethane adhesive (Figure 18, left). The seams are staggered and are taped on the innermost and outermost layers to improve air barrier performance. Wood $2 \times 4$ framing is installed inboard of the XPS insulation for services (Figure 18, right); the cavity is left uninsulated.
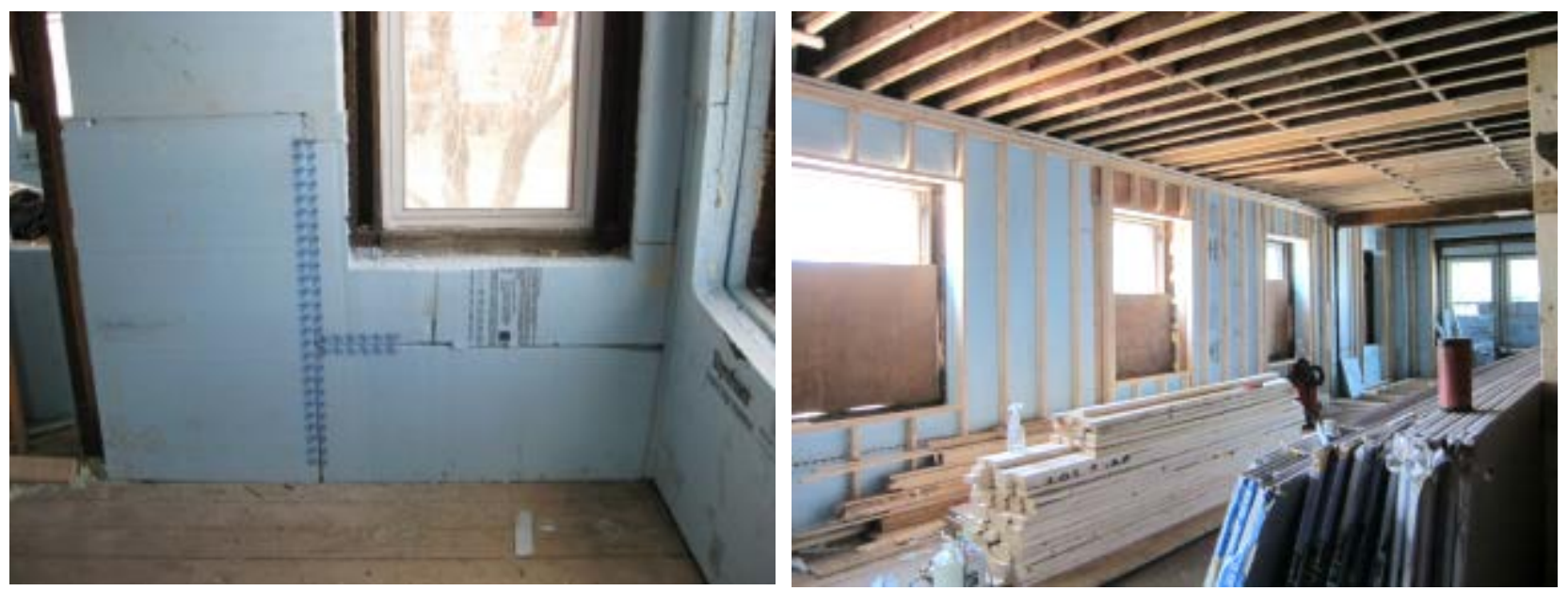

Figure 18. Multiple layers of insulation (left); framing installed inboard of insulation (right)

The embedded wood structure consists of dimension lumber (roughly 2-in. thickness) joists at a close spacing (16 in. on center typical) instead of large, widely spaced timbers or beams. Typical conditions are shown in Figure 19 (left) The insulation approach at the embedded beams is to install scraps of rigid XPS foam insulation with polyurethane adhesive and a clamping jig, per Figure 19 (right). This approach consumes available scrap; a generous space at the perimeter of each block allows effective air sealing with a spray polyurethane foam kit. 

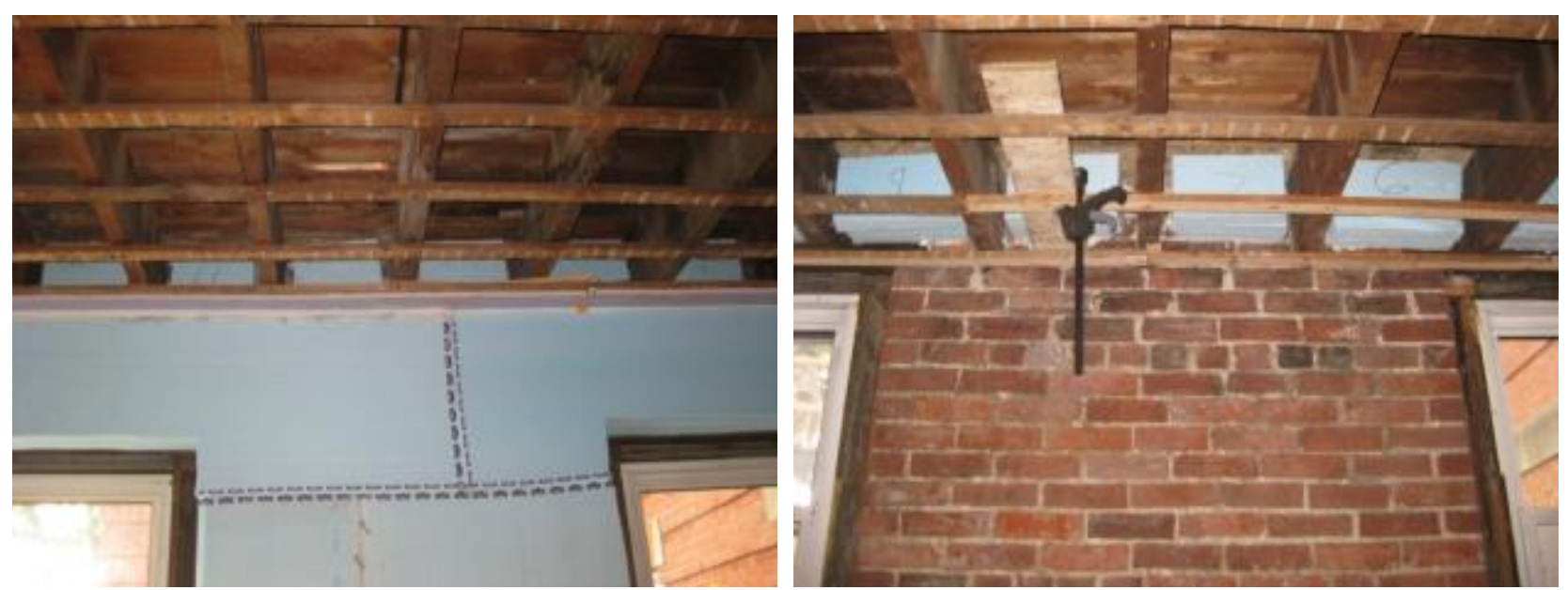

Figure 19. Embedded joist foam blocks (left); close-up showing clamping jig (right)

Figure 20 shows a typical floor-to-floor separation detail with spray foam at the joist space. This detail also needs to meet fire separation requirements, which explains the discontinuities in the insulation (see "New strip of mold resistant fire-rated gypsum board" in the figure).

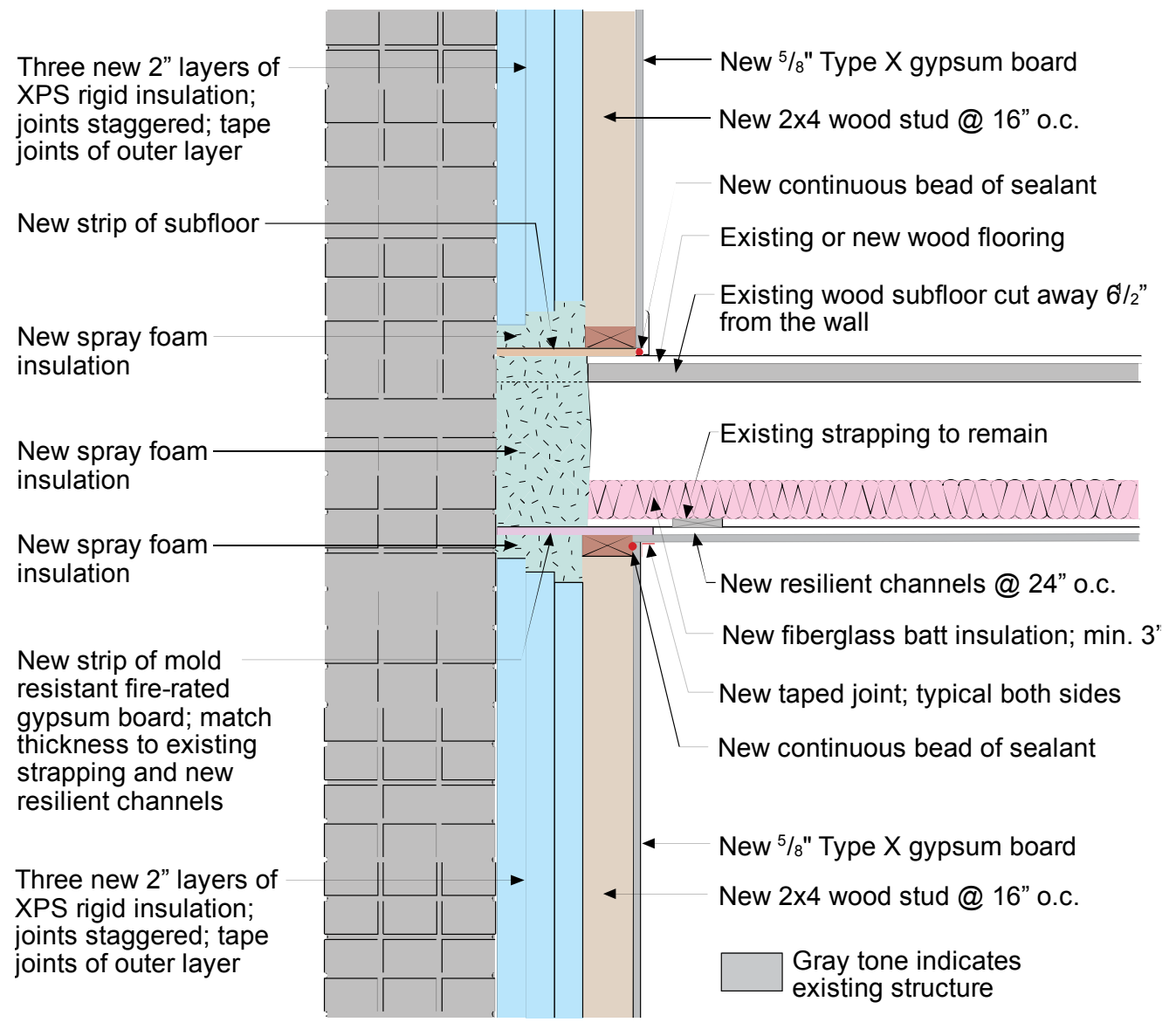

Figure 20. Unit-to-unit floor-to-ceiling assembly at exterior wall; joists perpendicular to wall 


\subsection{Building Monitoring Locations}

To capture a variety of conditions, joists were monitored in multiple locations throughout the building. Variables of interest included cardinal orientations (and thus solar heating/drying as well as wind-driven rain exposure), masonry wall type (solid brick masonry versus hollow clay tile backup), localized wetting exposure, and insulation strategy. The building has 11 monitored joist locations; the logic behind the joist selection is described in more detail in Section 3.3.

The monitored joists are located in the basement ceiling framing and the first-floor ceiling framing; Figure 21 and Figure 22 show the sensor layout on the building plan. The floor plans also show the footprints of the individual condominium units for reference. The monitoring package used at each joist is covered in detail in the Section 3.3.

As discussed earlier, the front/west wing of the building is original (circa 1906) construction with solid brick masonry walls. The rear/east wing of the building is an addition (circa 1930) with hollow clay block backup walls and a brick veneer. The separation between these two wall types is shown in Figure 22 for the first floor. However, the basement-level walls were built with solid brick at both the original wing and the addition, likely for structural reasons.

The nomenclature of monitored joists for this project is [floor]-[orientation][number, if multiple cases]: for instance, BSMT-N1 or FIRST-S.

Basement ceiling joists are monitored on all four orientations, including multiple measurements on some orientations; all are embedded in solid brick masonry. BSMT-N1/N2/N3 are joists with identical exposure; however, each uses a different retrofit strategy (Figure 23 through Figure 26):

- BSMT-N1 is insulated per the remainder of this project, insulated and air sealed with rigid XPS foam and urethane spray foam.

- BSMT-N2 is insulated with air- and vapor-permeable insulation (two R-13 layers of fiberglass batt, or R-26), which captures the effect of insulating, while still allowing airflow.

- BSMT-N3 is left uninsulated, similar to assemblies described in Morelli et al. (2010). 


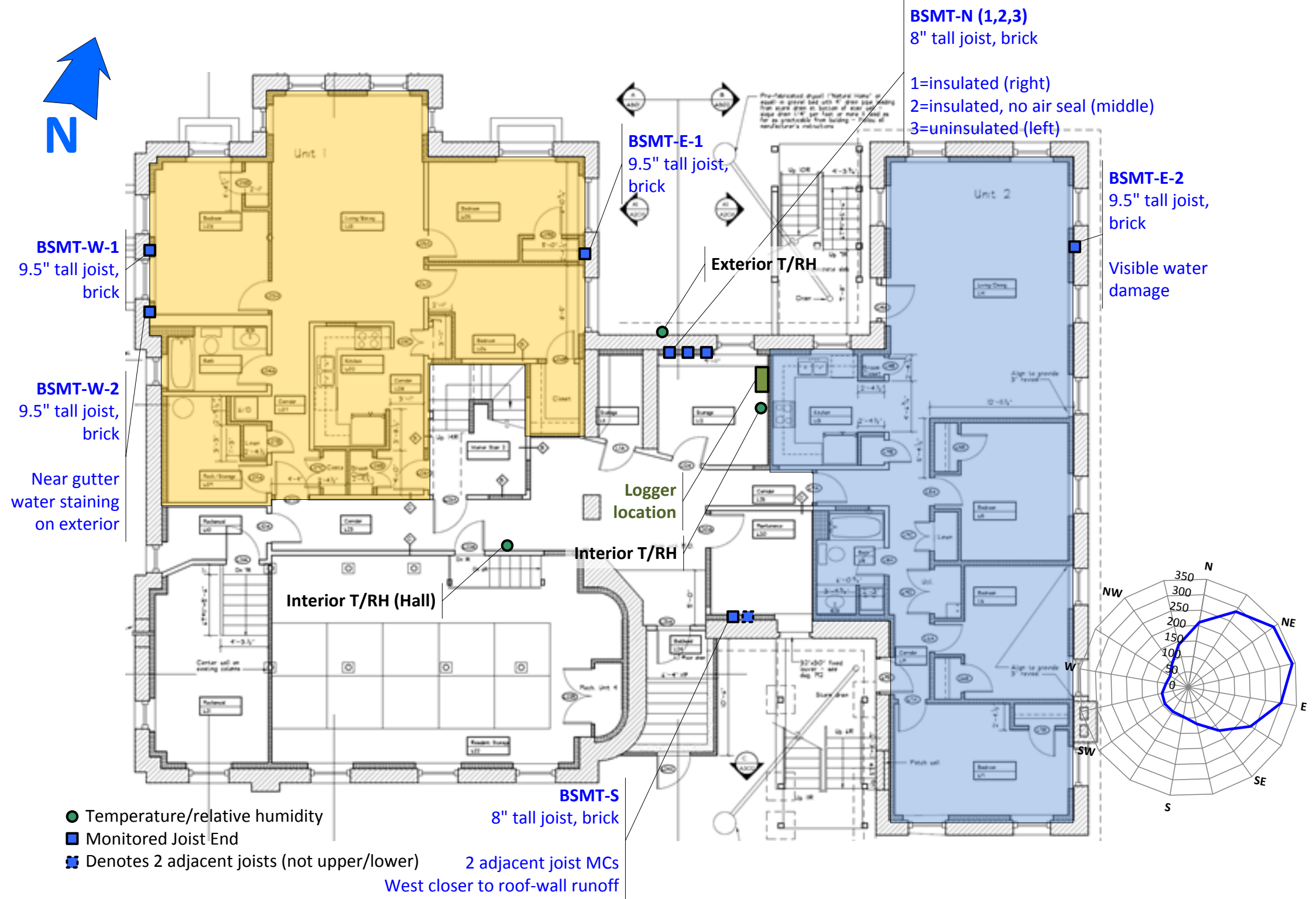

Figure 21. Location of monitored joist ends at basement level (basement ceiling) with driving rain; residential units highlighted 


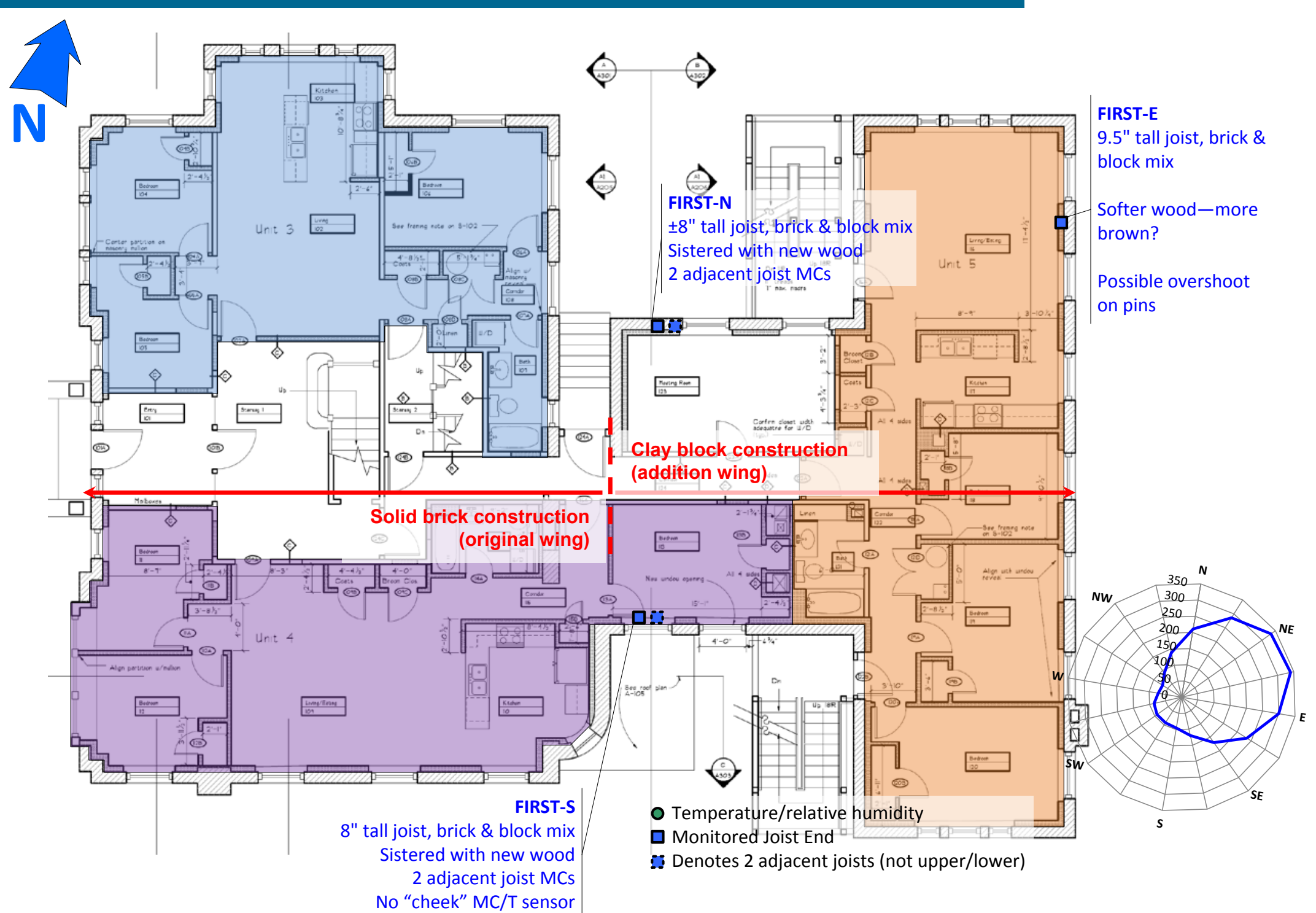

Figure 22. Location of monitored joist ends at first floor (first-floor ceiling) with driving rain; residential units highlighted 


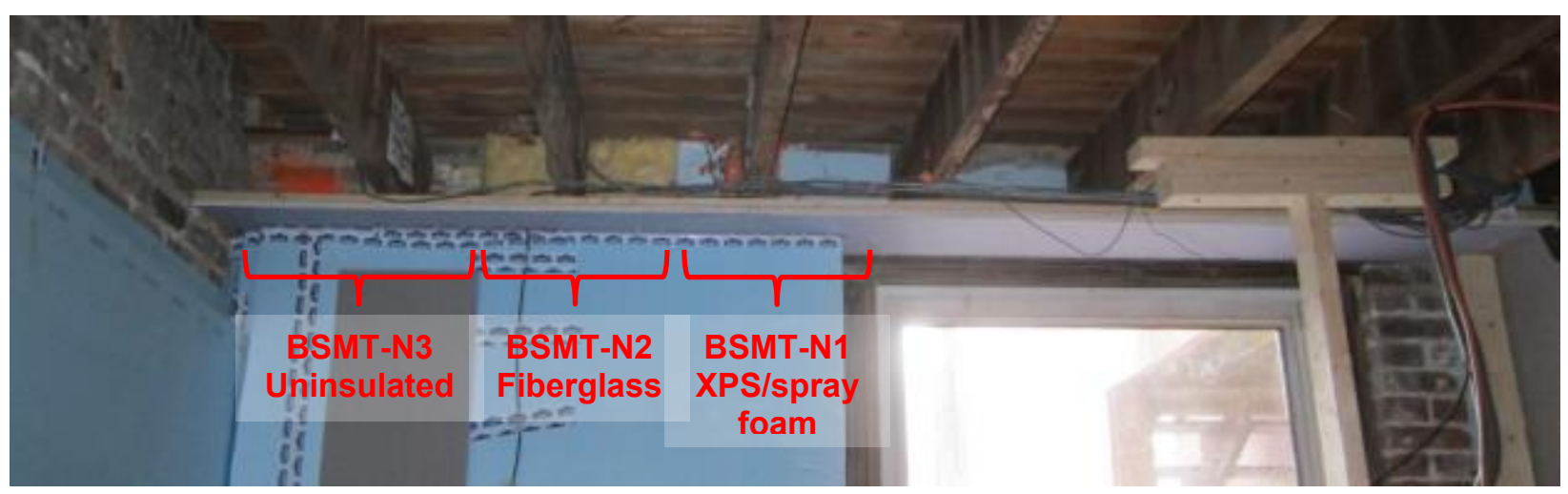

Figure 23. Comparison of insulation strategies for joist ends BSMT-N-1/2/3, predrywall

These test joists were intentionally placed in a common area; therefore, if monitoring indicates that one of these strategies causes excess moisture accumulation, the finished ceiling (gypsum board) can be opened, and the poor performer will be retrofitted with another strategy.
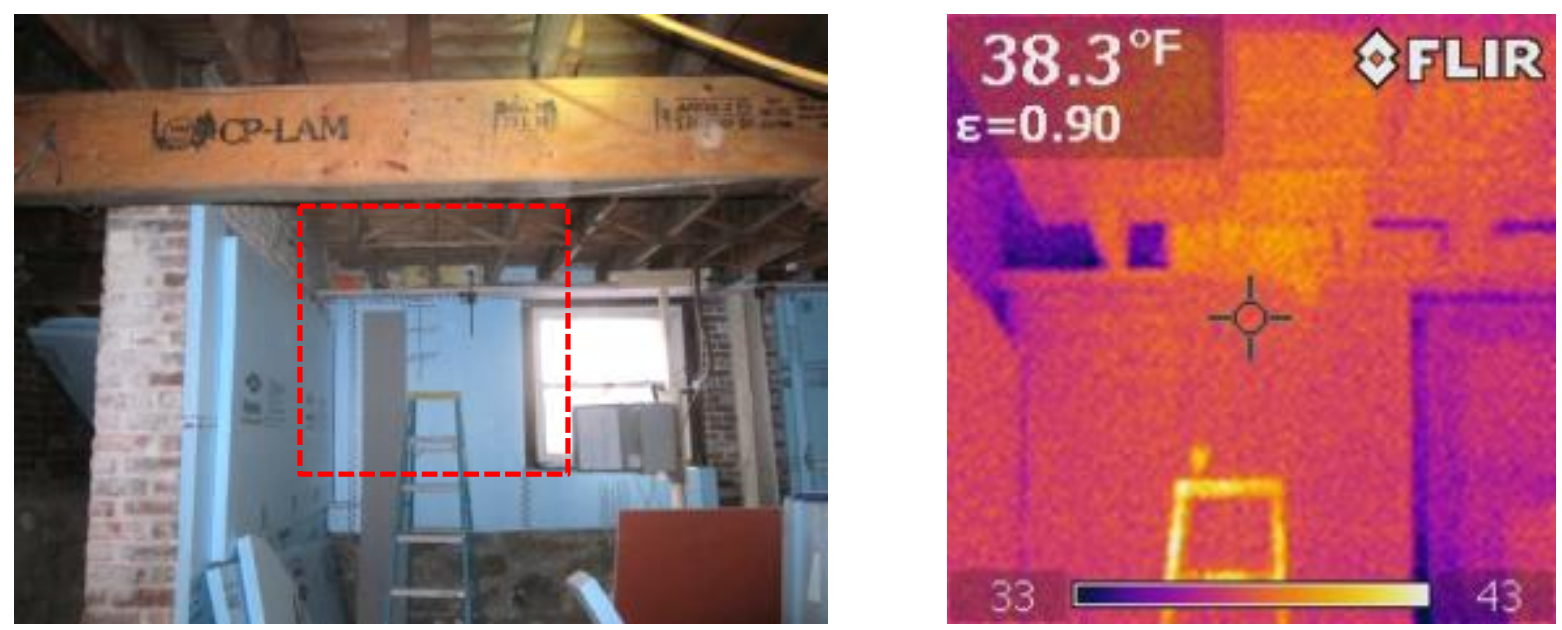

Figure 24. Infrared comparison of BSMT-N1/N2/N3 joist ends (interior unheated)

BSMT-E2 is of particular interest because it shows evidence of previous water penetration (staining of the beam end). The east orientation at the rear of the building also has the highest exposure for driving rain, based on airport weather data. Whether these bulk water issues were resolved during previous renovations, or whether the building has some unknown hidden leakage path, is unknown.

BSMT-W1 and BSMT-W2 are of interest because the site inspection revealed that rainwater was being deposited on the wall at the jog (see Figure 21). BSMT-W1 was set up to capture the mostly dry field of the wall; BSMT-W2 was located close to the jog to determine whether this bulk water was sufficient to cause issues with the embedded joist end moisture behavior. This cardinal orientation has low driving rain exposure (see Figure 15). 

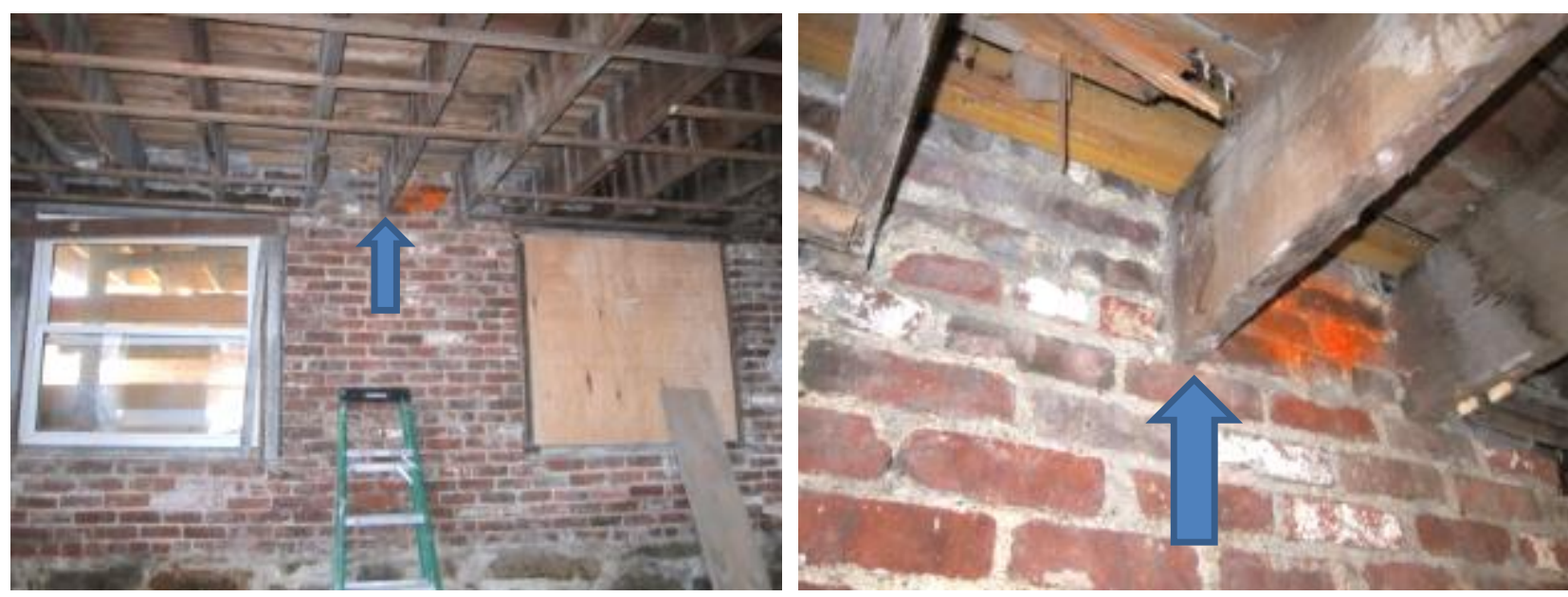

Figure 25. BSMT-E2 joist, showing existing water staining
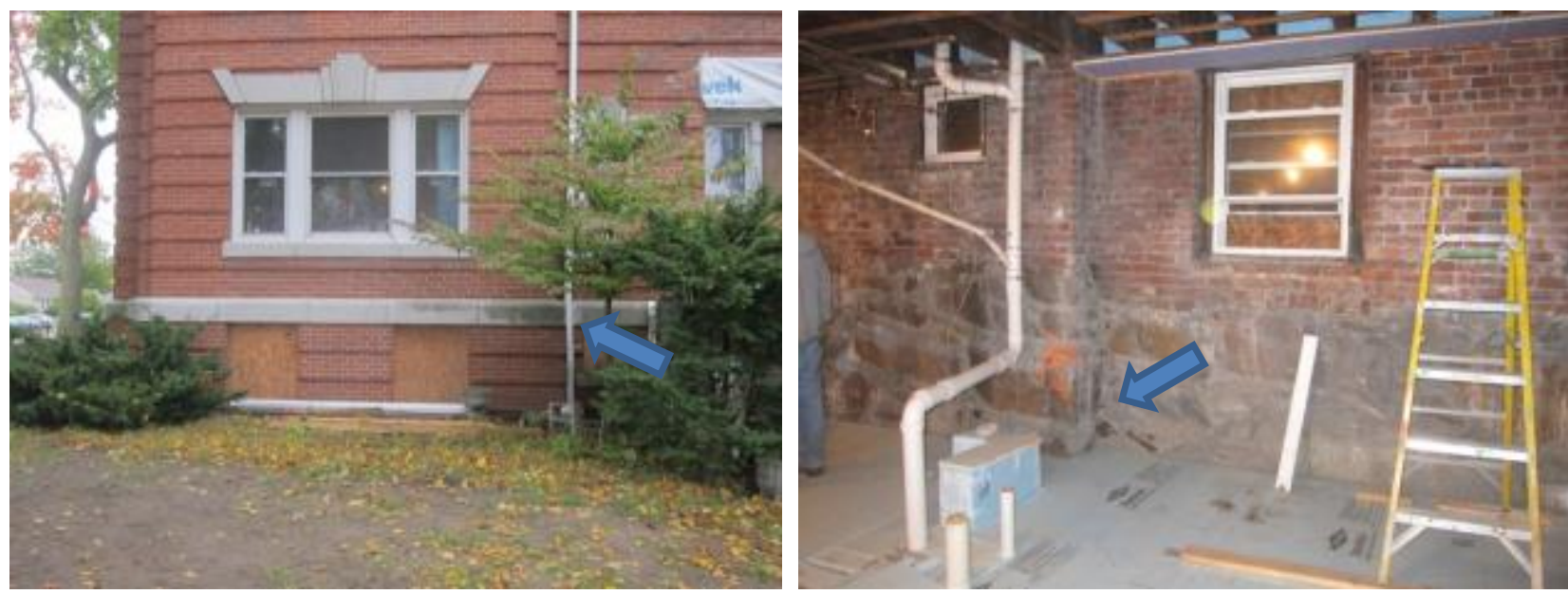

Figure 26. BSMT-W1 and BSMT-W2 joists showing water deposition at wall jog

BSMT-S1 is of some interest because hygrothermal simulation work (Ueno 2012) seemed to indicate that summertime inward vapor drives would cause the south-facing embedded wood members to be vulnerable to moisture accumulation. The possible occurrence and magnitude of this effect were studied by comparing behaviors at different solar orientations.

On the first floor, joists were monitored in the addition (hollow clay block) walls only, because the joists in the original first-floor wing were inaccessible. Figure 27 shows the FIRST-N monitoring locations, and that the hollow clay block backup walls were actually constructed with alternating layers of block and brick.

First-floor monitoring was installed in north, south, and east-facing joists. The east-facing joist appears to be a different species: the wood is noticeably softer and is a different color (see Figure 28). This difference in wood species may affect MC measurements via electrical resistance.

The insulation was installed first at the floor joists at the front (west) wing, which contains BSMT-W1, BSMT-W2, and BSMT-E1. Those joists were insulated and air sealed to the 
perimeter of the foam blocks with a two-component spray foam pack (Figure 29). The remaining joists were insulated on an ongoing basis during construction.
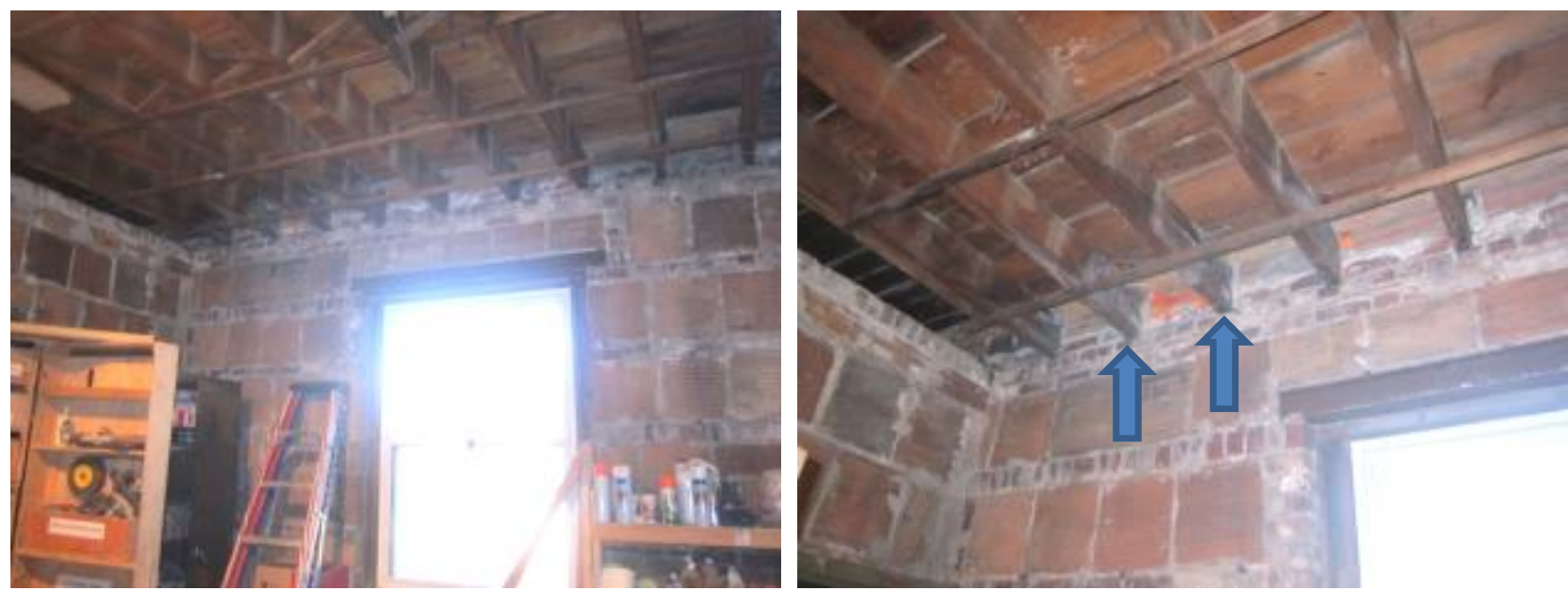

Figure 27. FIRST-N joists showing brick and clay block wall construction
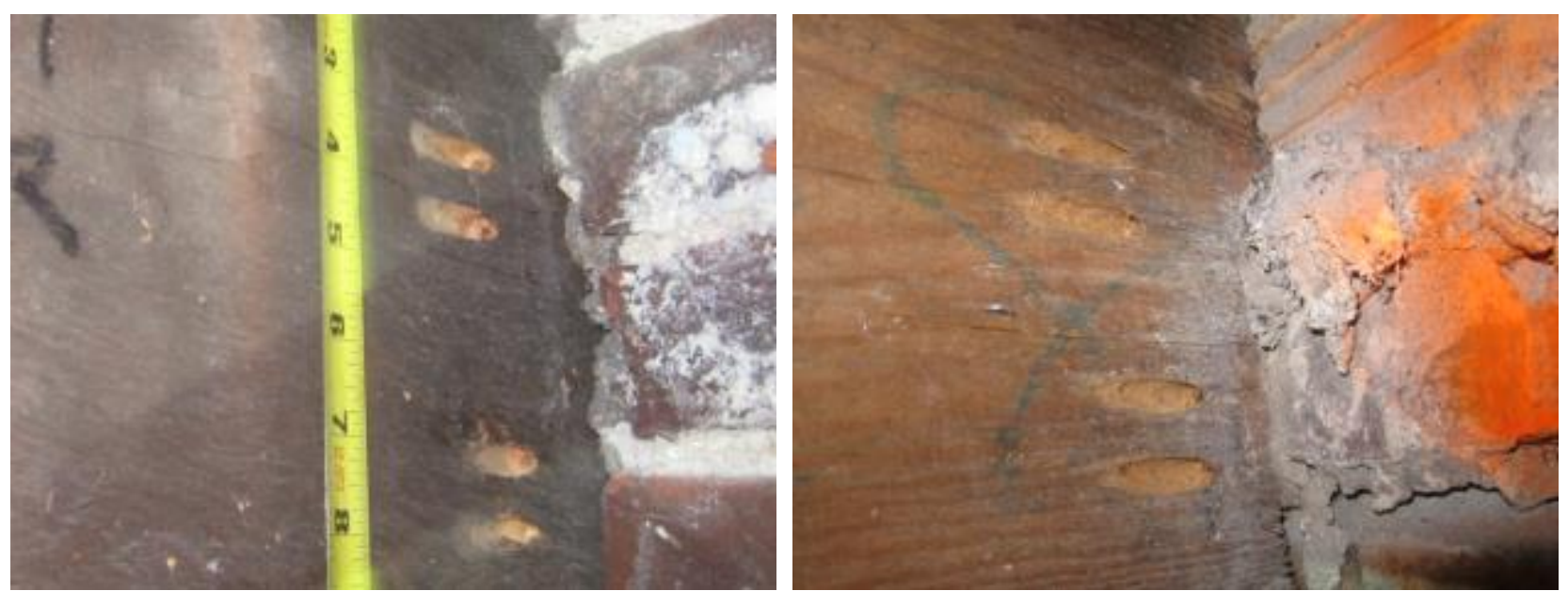

Figure 28. Wood color comparison at BSMT-E1 joist (left); FIRST-E joist (right)
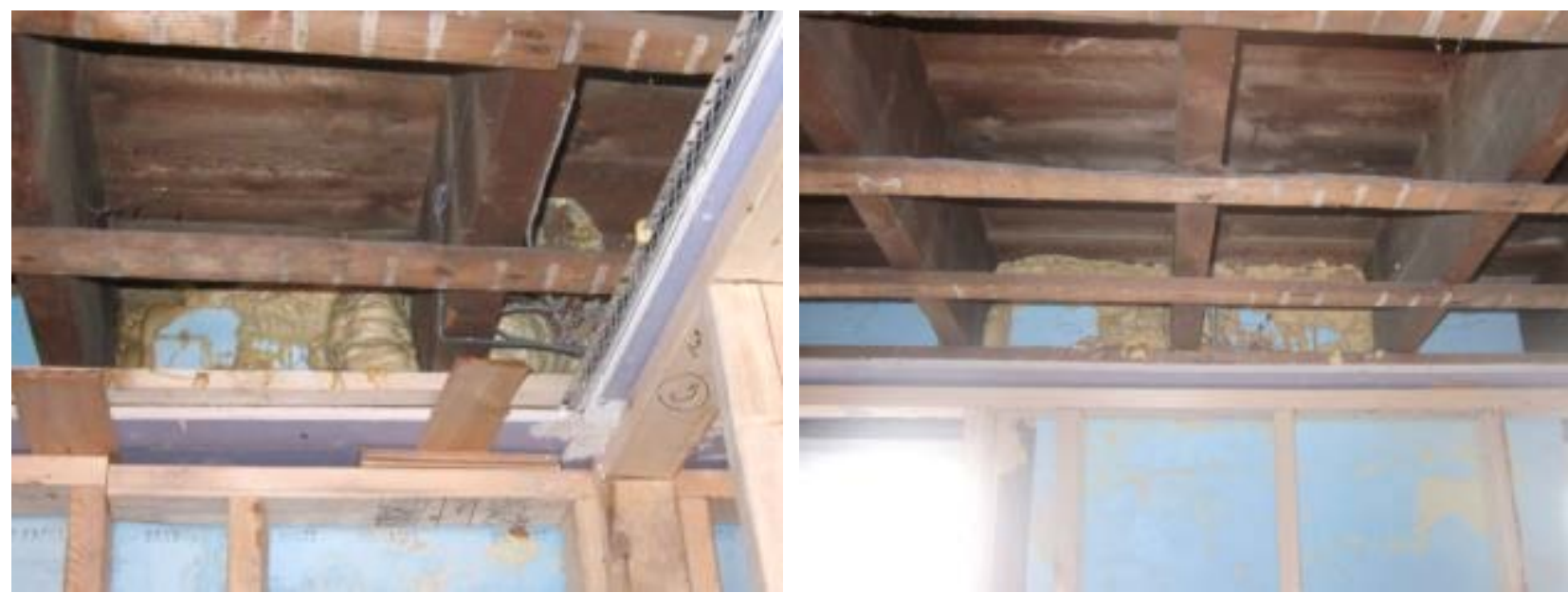

Figure 29. Two-component spray foam air seal at joists BSMT-W1 and BSMT-E1 


\subsection{Joist Sensor Package}

Three types of sensors were used to monitor conditions within the assembly: temperature, $\mathrm{RH}$, and electrical resistance-based wood MC. Details about these instruments are provided in Appendix A and Appendix B. The specifics of these sensors are covered in detail by Straube et al. (2002).

The sensor package installed at each joist is shown schematically in Figure 30. The ends of the joists are fire cut, or cut at an angle so a fire that burns through a joist will not collapse the masonry wall by levering the structure upward and outward.

\section{Sensor Key:}

- Relative humidity/temperature

$\square$ Moisture content/temperature

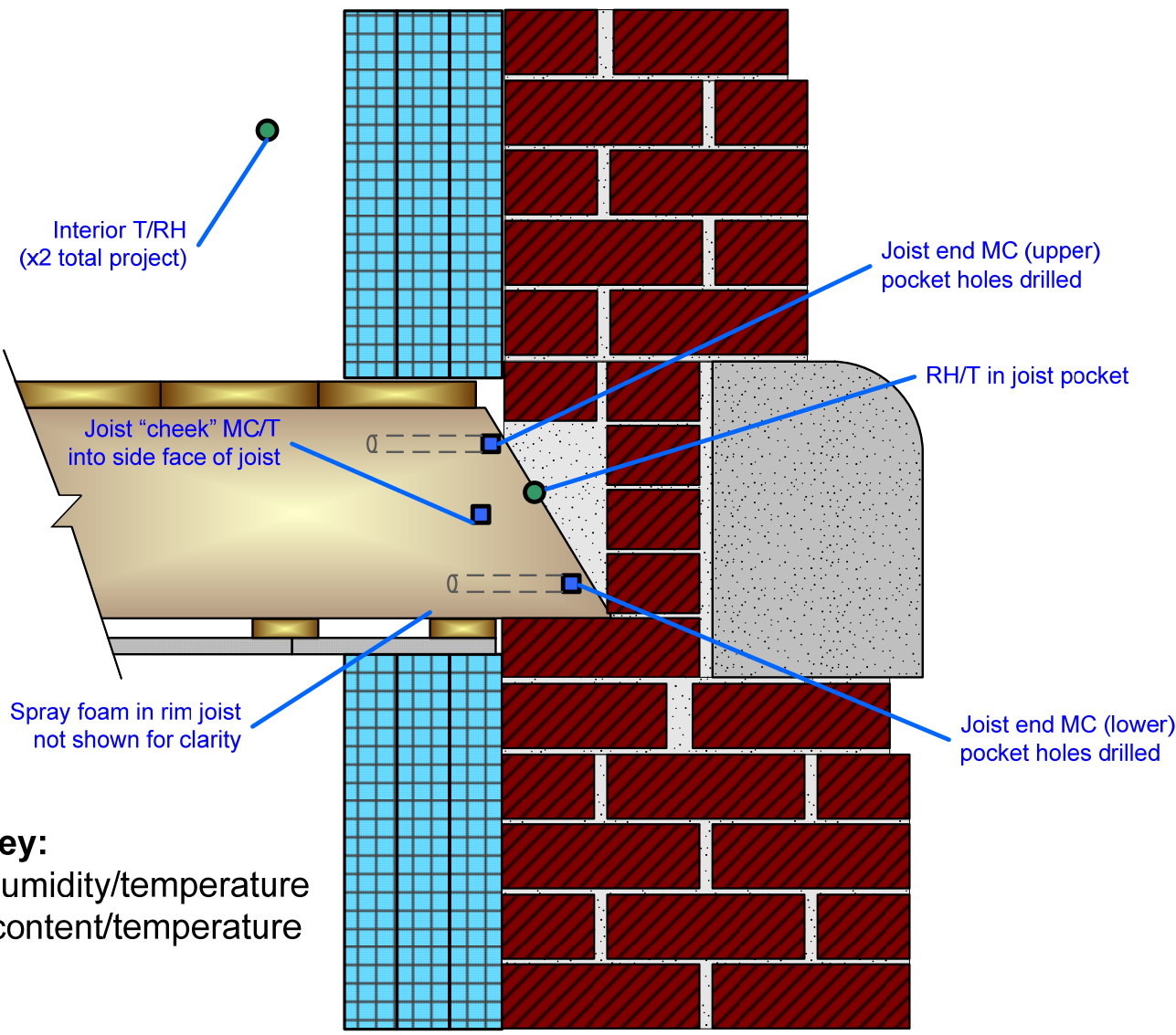

Figure 30. Schematic of typical joist end sensor monitoring package

- The MC at the embedded end of the joist is monitored by two sets of extended electrical resistance pins, which are driven from the interior side through pilot holes. MCs are typically measured at low and high locations at each joist end. This is intended to determine whether MCs are higher where the joist is seated into (and in direct contact with) the mortar and masonry walls. The pins are driven to measure MC at the outermost 1 in. of the beam.

- In some cases the upper sensor was omitted, because the upper location was not embedded in the masonry. In those cases, two lower MC sensors were installed in adjacent beams. These cases are signified by a blue square with a dotted outline in Figure 21 and Figure 22; this was done at BMST-S, FIRST-N, and FIRST-S. 
- The side face or cheek of the joist is also measured for $\mathrm{MC}$ and temperature. This was done primarily as a reference check: it provides a third reference point for MC measurement anomalies, which might be due to wood species differences. It also provides limited spatial resolution: it might indicate the extent of moisture migration when the deeply embedded end of a joist shows high MCs. This cheek location is concealed within the interior insulation after the spray foam is installed.

- A temperature and RH sensor is installed within the pocket where the joist is embedded in the masonry wall. Installation of this sensor was not necessarily consistent, because many of these joists were grouted in place with mortar that had a limited air gap. Other joists had a distinct air gap. The lack of an air gap increases the vulnerability of an embedded wood member, because the wood is in direct capillary contact with the moisture-absorbent masonry on the sides and at the bottom.

The underside of the joist has no capillary break at its seat in the wall. This contrasts with the practice of using a steel or cast-iron bearing plate for larger timber beams.

The joist ends were monitored using 6 in. long sharpened stainless steel pins attached to wire leads (Figure 31, left). First, the end of the joist was examined to determine the angle of its fire cut and the location of the end of the joist (Figure 31, right).
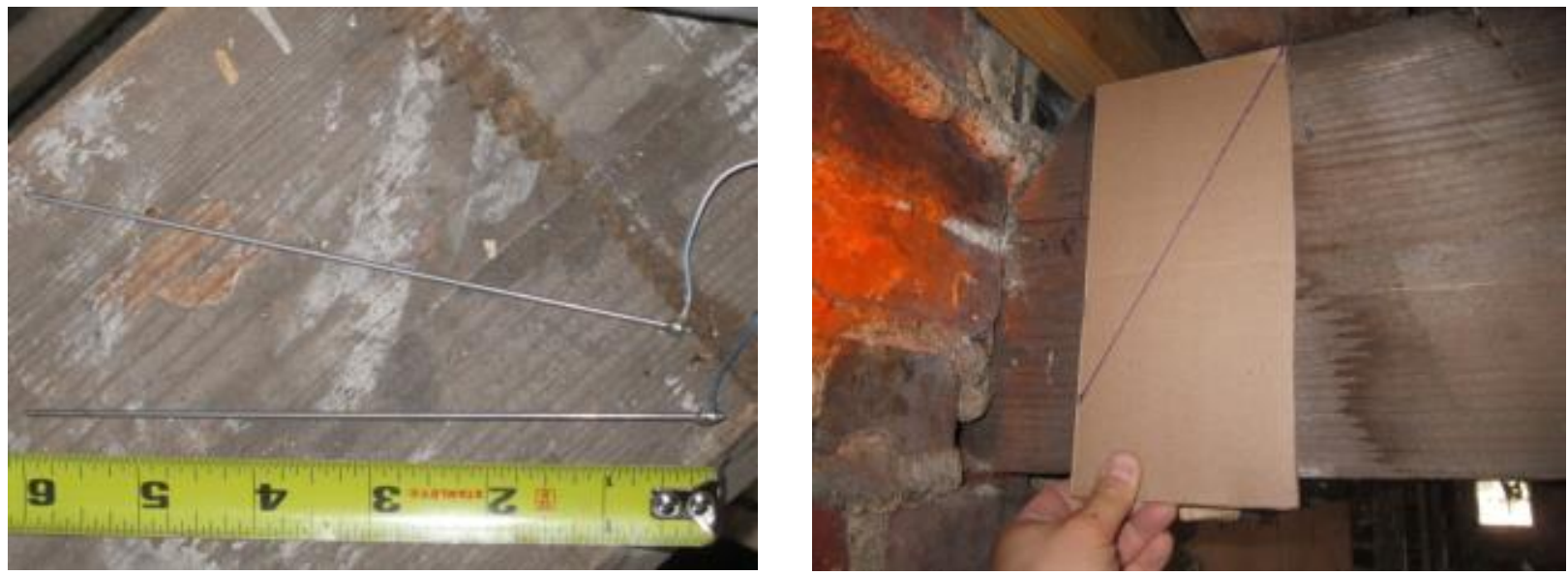

Figure 31. 6-in. extended MC pins (left); determining drilling depth (right)

Then a pocket hole jig was used to drill a pilot hole at a shallow angle in the beam (Figure 32, left). A $1 / 8$-in.-diameter hole was drilled for clearance for the pin, but the joist end was left undisturbed so the pin would be driven directly into the wood fibers with frictional contact. Figure 32 (right) shows the upper and lower joist end MC measurements and the cheek MC/ temperature measurement.

The pocket holes for the joist end MCs were sealed from interior air and water vapor with a vapor-impermeable synthetic rubber caulk (Figure 33, left). The joist pockets were air sealed from the interior with a combination of can-based expanding foam (Figure 33, right), and the spray foam kit used around the rigid blocks of foam mentioned earlier (Figure 29). 
The temperature and RH sensors were installed in any available airspace between the joist and the masonry. In some cases space was readily available to insert the sensor (Figure 34). In other cases some mortar around the beam had to be demolished to install the sensor.
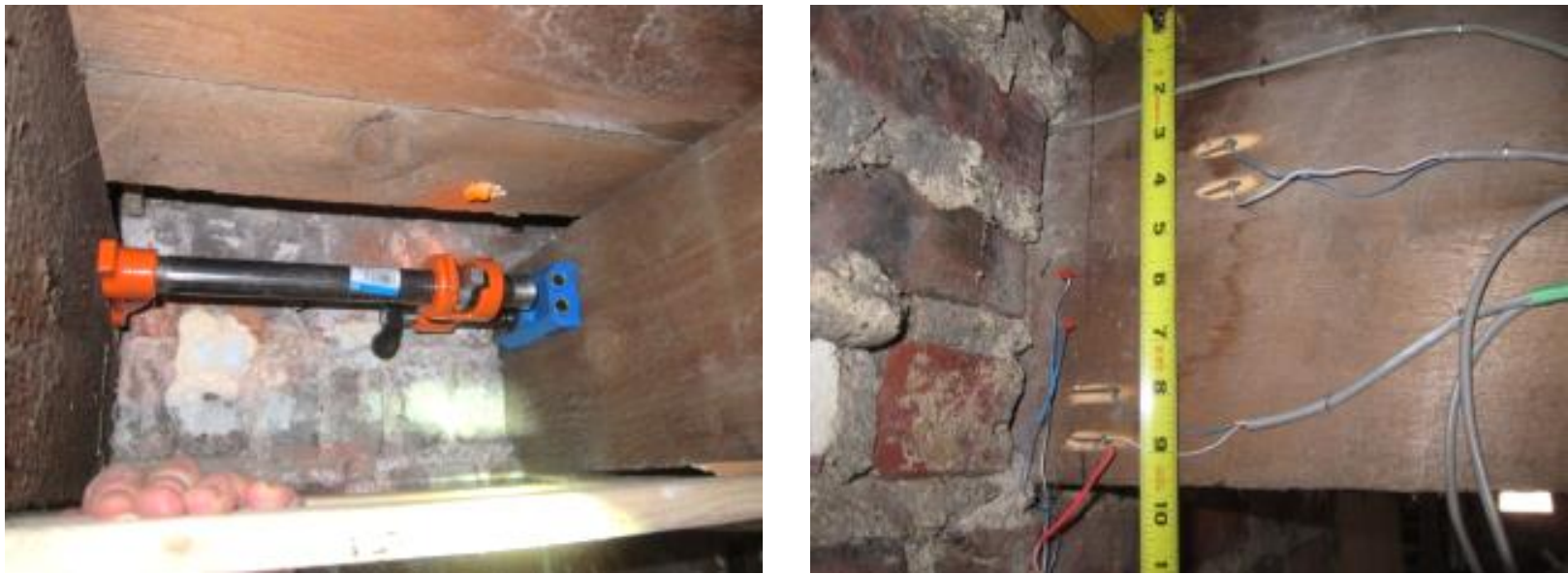

Figure 32. Pocket hole jig (left); installed MC pins (right)
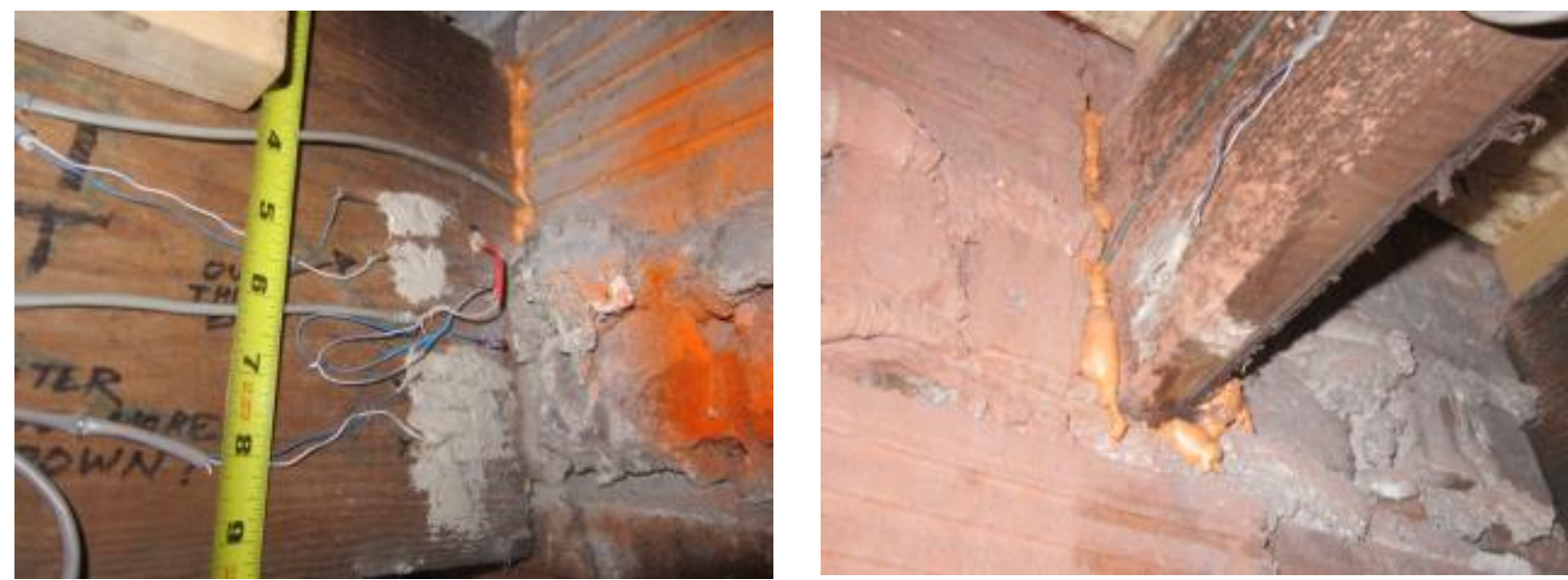

Figure 33. Caulked pocket holes (left); air seal at joist pocket (right)
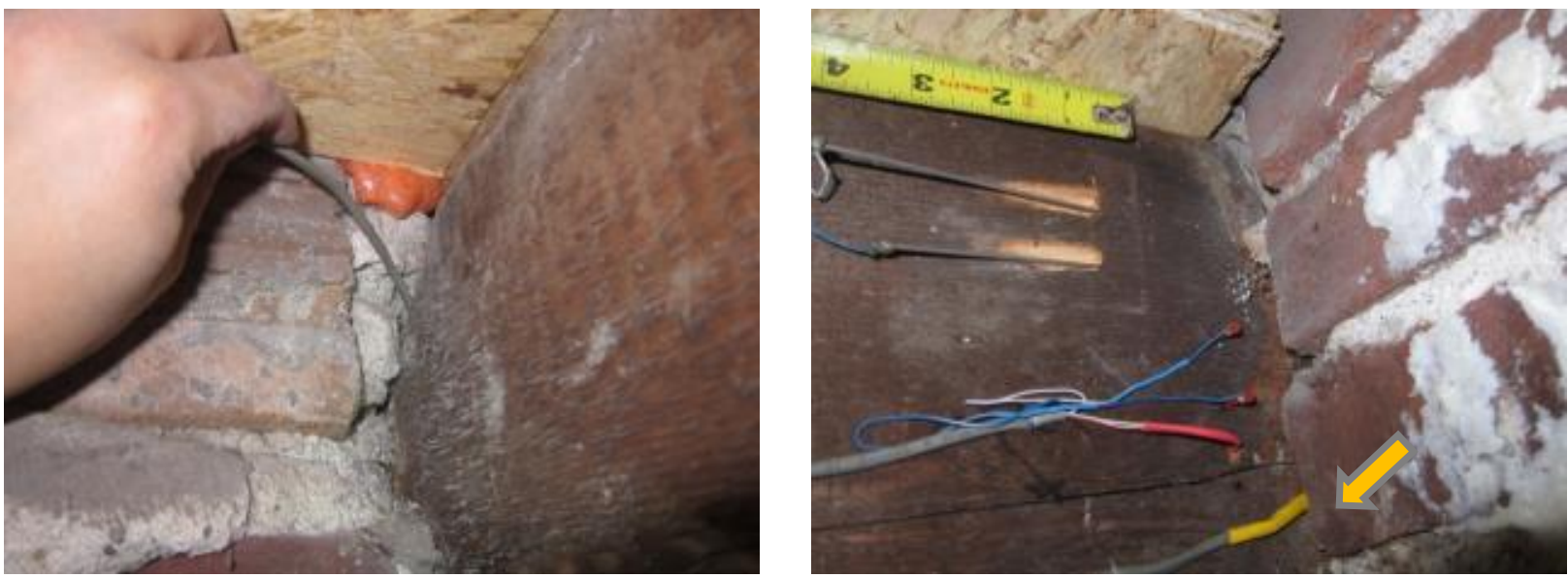

Figure 34. Installation of pocket RH sensor (left); installed RH sensor (right) 
The condition of the masonry joist pocket could be observed directly at several north-facing openings in the addition section where a beam had been removed (Figure 35). Mortar or grout was packed between the brick and the wood joist during installation; mortar was also packed in the angled space behind the fire cut. However, an airspace adjacent to the joist at the hollow clay block would likely increase drying.
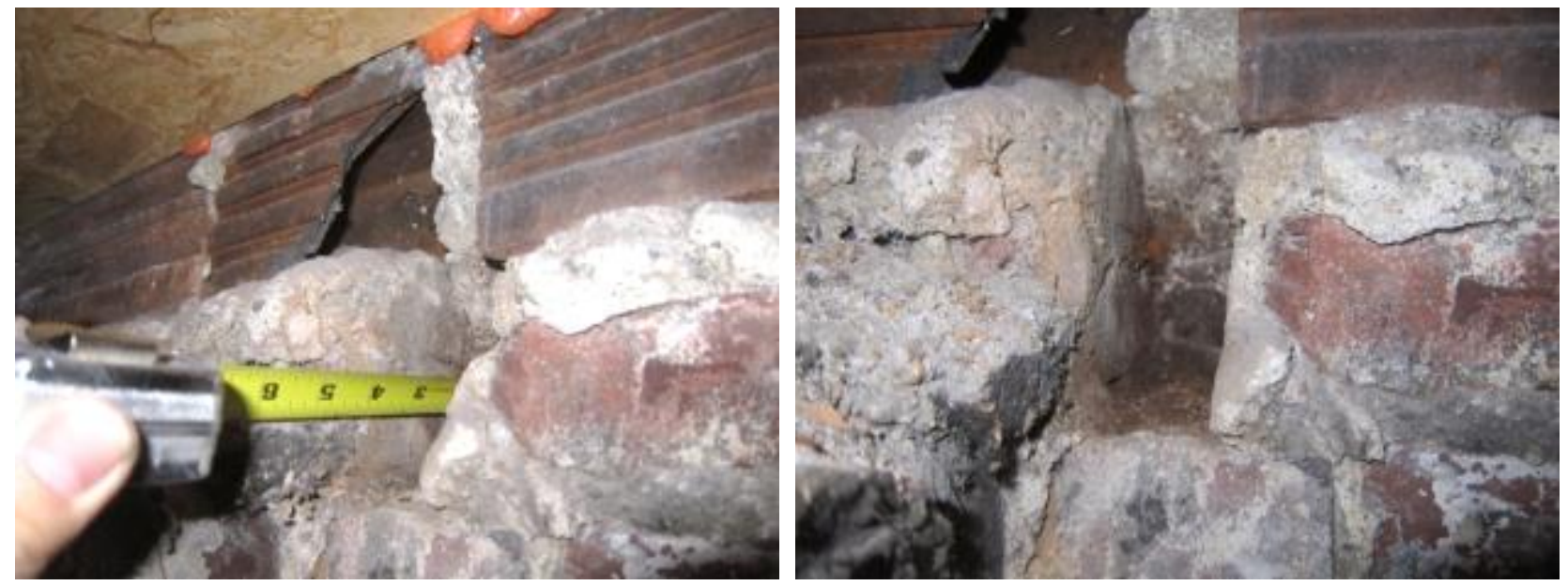

Figure 35. Conditions in joist pocket at north-facing building at addition

\subsection{Additional Sensors and Data Collection Logistics}

Interior temperature and $\mathrm{RH}$ conditions were measured at two locations (Figure 21). One interior temperature and RH measurement was taken directly below the data acquisition system (data logger; labeled "T Logger"); the other is in the common hallway at the front of the building (Figure 36, right; labeled "T Hallway"). Both are on the basement level, which was chosen because most of the sensors are on this floor. During construction, the front of the building was heated with temporary construction heat (vented to the exterior); the rear sometimes ran near ambient conditions. The two interior sensors measure these two conditions.

An exterior temperature and RH sensor (Campbell Scientific HMP60 Temperature and Relative Humidity probe; Figure 36, left) provides outdoor conditions that are synchronized to the joist end measurements; it is located within a solar radiation shield on the north side ground floor of the building. Additional outdoor weather data (including precipitation, wind speed, and wind direction) are being collected from on-line sources for comparison; the nearest weather station is Lawrence Municipal Airport (KLWM).

Data were collected by a Campbell Scientific CR1000 measurement and control system that was installed in a basement storage room (Figure 37), as described in Appendix A. Extension cables were run from the sensor locations to the data collection system before the interior finishes were applied. Data were measured at 5-minute intervals; average values were recorded hourly. No battery backup for the data logger was provided; however, the unit has nonvolatile memory and resumes data collection after a power failure. Data were downloaded during site visits by direct connection rather than remote downloads. 

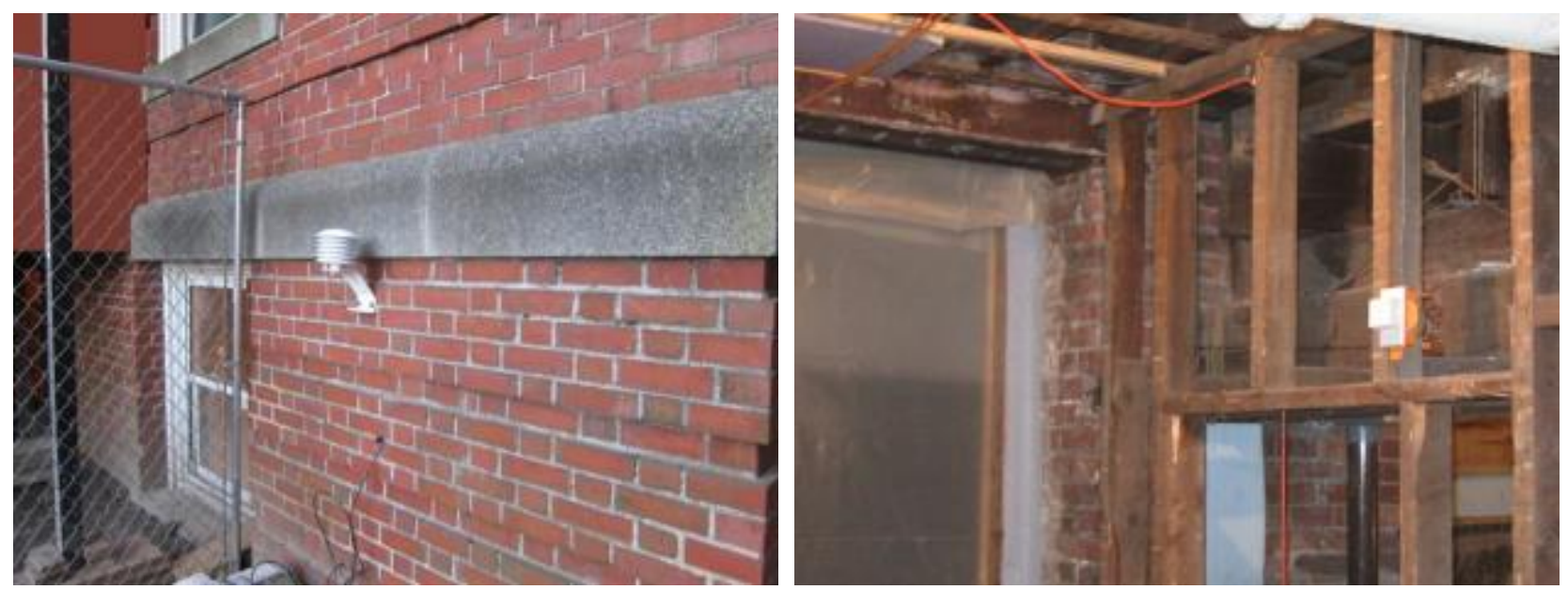

Figure 36. Exterior (left) and interior hallway (right) temperature and RH sensors
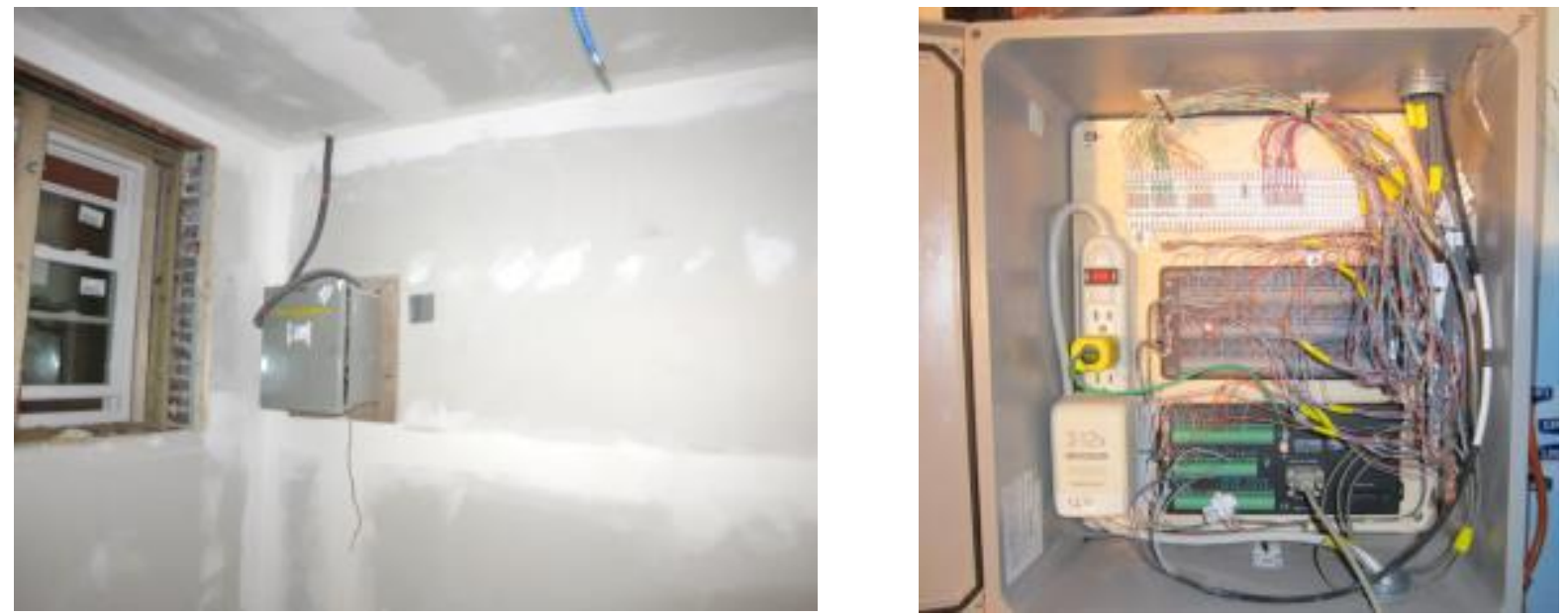

Figure 37. Data acquisition system showing placement (left) and wiring connections (right)

\subsection{Wood Species Identification}

A sample of a wood joist was sent to the U.S. Department of Agriculture Forest Products Laboratory (Center for Wood Anatomy Research) for species identification. The specimen was identified as Abies sp. (a single species from the "true fir" genus). However, microscopy alone cannot distinguish between the true fir species. Douglas fir (Pseudotsuga menziesii) is not a true fir. The heartwood of true firs is classified as "slightly resistant to nonresistant to decay" (the lowest of four categories), per the Forest Products Laboratory (FPL 2010).

Examination of the geographic distribution of true firs revealed most are native to the West Coast; the only common East Coast true firs are the Balsam and Fraser firs. Balsam fir (Abies balsamea) grows principally in New England, New York, Pennsylvania, and the Great Lakes states; Fraser fir (A. fraseri) grows in the Appalachian Mountains of Virginia, North Carolina, and Tennessee. Given that native lumber would be a more likely building material in New England circa 1906 and 1930, Balsam fir was assumed for the analysis. However, the wood members used in the building may well be a mix of woods based on what was available at the lumber yard and how lumber was graded at the time. 


\section{Monitoring Results}

\subsection{Data Overview and Boundary Conditions}

Data have been collected from mid-December 2012 through April 2015 (roughly 28 months), which captures three winters and two summers. The limitations to the collected data follow:

- The building is still under construction; its ongoing renovation is nearing completion in spring to summer 2015. Thus, much of the building was at cold interior temperatures (e.g., construction heating) during the winters as opposed to typical interior heating set point temperatures.

- Most joists received interior insulation (their final completed state) partway through monitoring. However, this can be useful as a before-and-after comparison.

Interior and exterior temperatures are shown in Figure 38; they include site-collected temperature ("T ambient") and airport weather station data ("T KWLM") for reference.

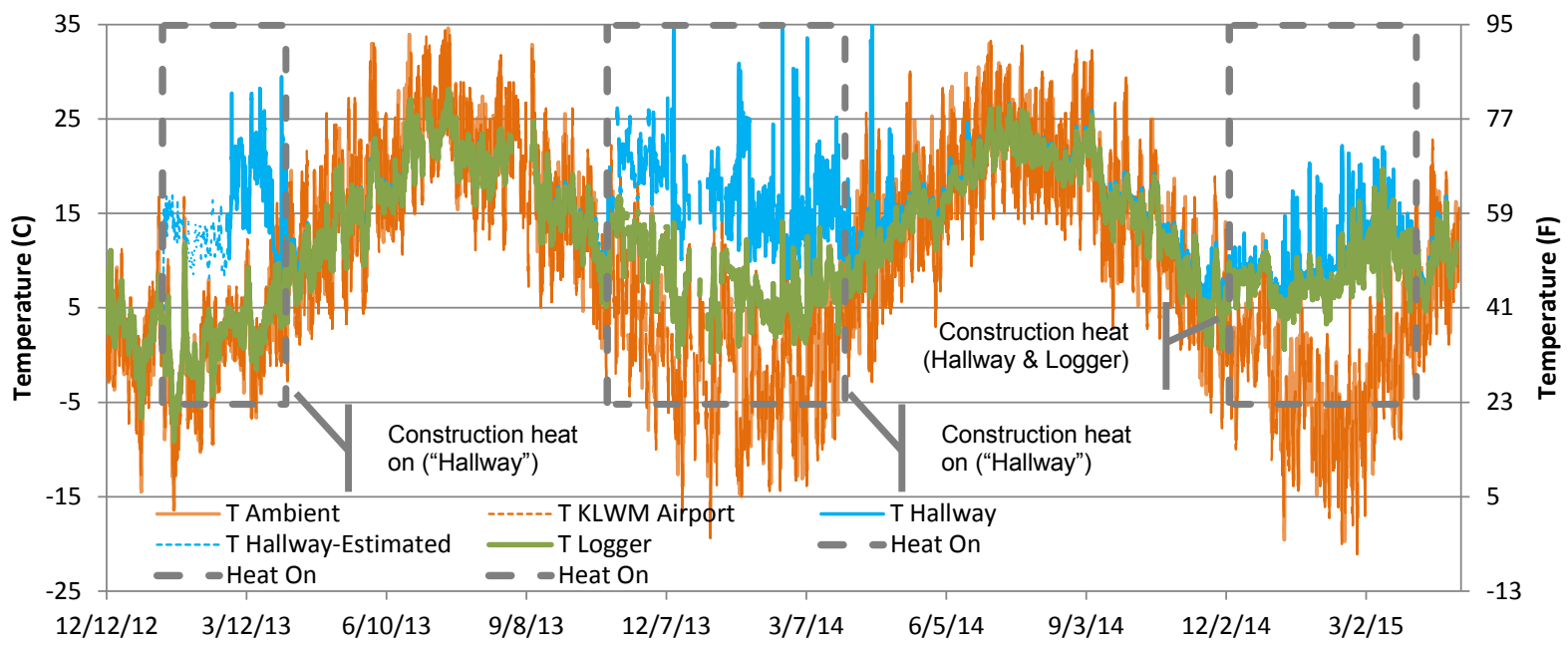

Figure 38. Interior and exterior temperatures (Lawrence/KLWM airport data for comparison)

During unheated periods (spring, summer, and fall), interior conditions roughly tracked exterior conditions with damping due to thermal mass. Intermittently operated construction heating was added to the front of the building in January 2013, which resulted in interior temperatures that were warmer than ambient. However, winter temperatures varied widely because construction heat operated intermittently (the site was open 3 days per week). Winter conditions varied as follows:

- Winter 2012-2013: "T Hallway" was $50^{\circ}-75^{\circ} \mathrm{F}\left(10^{\circ}-24^{\circ} \mathrm{C}\right)$. This temperature was partly estimated ("T Hallway-Estimated) using a cheek temperature (side of a joist) at the front of the building. Basement conditions near the logger ("T Logger") were close to ambient conditions.

- Winter 2013-2014: "T Hallway" was similar to the previous winter; "T Logger" was warmer than the first winter due to progress on insulation and air sealing. 
- Winter 2014-2015: Both “T Hallway" and "T Logger” were 50 $-75^{\circ} \mathrm{F}\left(10^{\circ}-24^{\circ} \mathrm{C}\right)$, which shows further progress on construction.

Exterior and interior RH measurements are shown in Figure 39. Summertime interior RH levels were 55\%-90\% (high dew point and cool conditions). Wintertime RH levels were 30\%-70\% in the unheated spaces and $10 \%-50 \%$ in the intermittently heated spaces (substantial air leakage and little interior moisture generation). The construction heating system (a natural gas unit heater) vented to the exterior and was not a source of interior moisture.

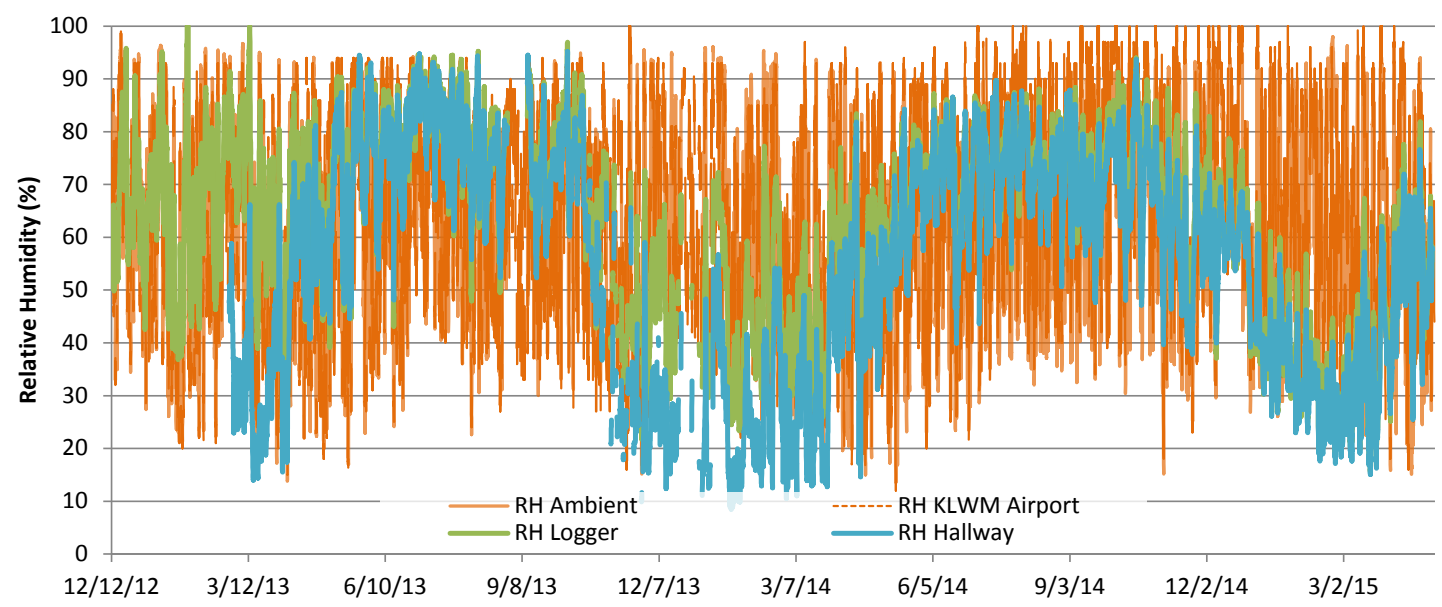

Figure 39. Interior and exterior RH measurements (KLWM data for comparison)

Figure 40 shows these data plotted as dew point (absolute air moisture content), which is a more useful metric than RH. Interior dew points ("DP Logger" and "DP Hall") roughly track exterior conditions, as would be expected given the high air leakage rate and low occupancy during construction.

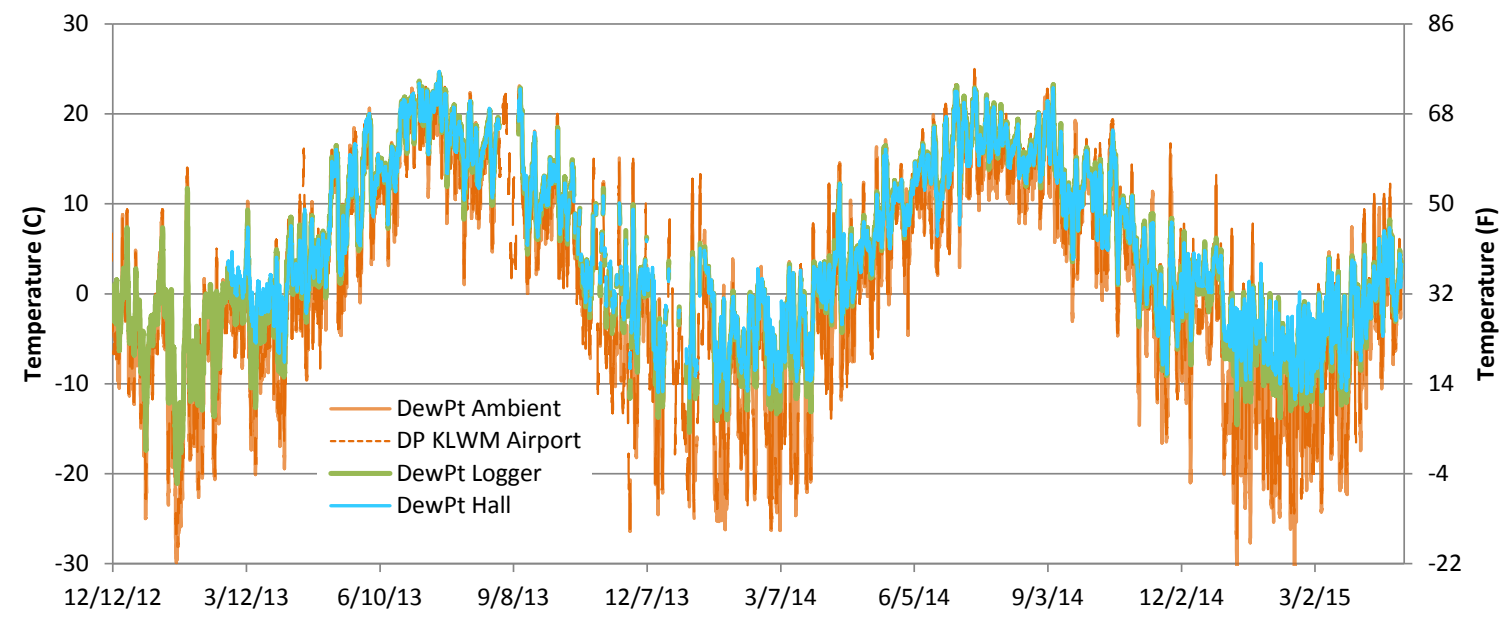

Figure 40. Interior and exterior dew point temperatures (KLWM data for comparison)

Interior dew point conditions did not correlate to exterior dew points exactly; wintertime dew points were higher than ambient because of some building airtightness (which improved as construction progressed), and adsorption and desorption of interior materials. The low interior 
wintertime dew points were drier than expected during occupied wintertime conditions (e.g., $35^{\circ} \mathrm{F}\left[2^{\circ} \mathrm{C}\right]$ dew point is equivalent to $68^{\circ} \mathrm{F}\left[20^{\circ} \mathrm{C}\right]$ and $\left.30 \% \mathrm{RH}\right)$.

Of course, hygroscopic materials (such as wood joists) react to $\mathrm{RH}$ rather than absolute humidity (as reflected by dew point). Given interior humidity measurements of $40 \%-90 \%$ (due to cold temperatures), wood within the building would be expected to operate at $8 \%-20 \% \mathrm{MC}$. Of course, joist pockets were operating at colder conditions than the main space and were coupled to the potentially wet masonry wall. These pockets were therefore likely to have even higher MCs than wood in the interior space.

\subsection{Moisture Contents and Wood Durability}

The results below are shown in terms of wood MC; some background is useful to interpret the durability risks associated with various moisture levels. Traditional guidance is to keep wood MC lower than 20\% to inhibit decay fungi (Carll and Highley 1999; FPL 2010); optimal growth occurs at 25\%-30\% MC. Decay fungi become active at MC levels higher than $28 \%$ (Straube and Burnett 2005); serious decay occurs only at levels higher than the wood's fiber saturation point or about 30\% MC (FPL 2010). However, the MCs should be interpreted with temperatures in mind. Biological activity is inhibited at low temperatures, so high MCs in midwinter pose lower risks than in warmer seasons. Sustained high MCs at moderate temperatures (e.g., summertime) pose the greatest durability risks.

\subsection{Joist Moisture Content Measurements: Minimally Heated Wing Basement}

Graphs in this section cover the joist ends on the basement level in the rear wing of the building (highlighted in Figure 41). This area was unheated for most of the monitoring period; limited construction heating occurred during the final winter (Figure 38).

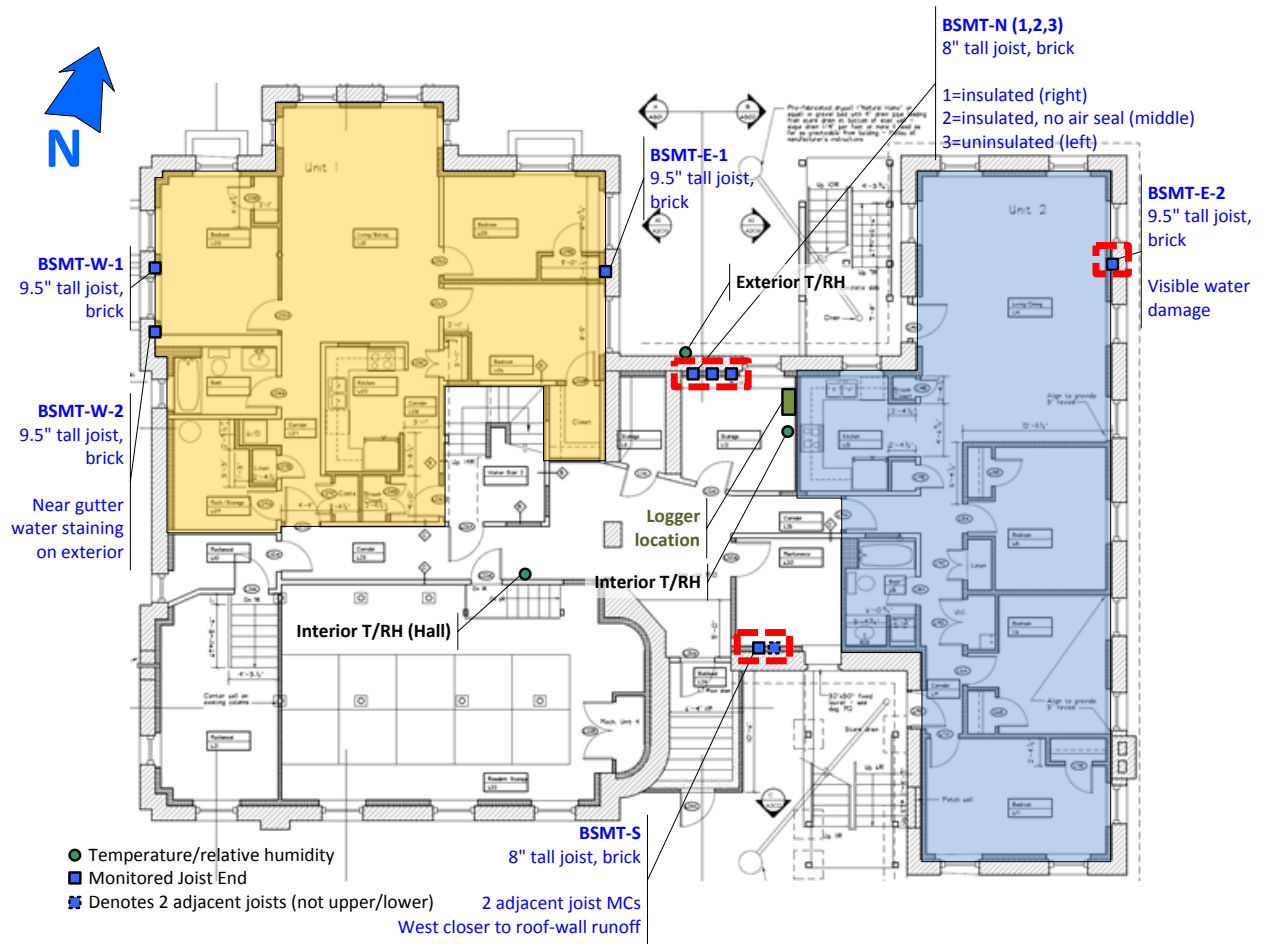

Figure 41. Basement unheated wing joist end measurements highlighted 
The joist MC measurements are plotted on the left-hand axis of Figure 42: they include the lower and upper joist end locations and the cheek MC (as a comparison point). The RH measurement in the joist pocket is plotted on the right-hand axis (in green). The wood species correction factors for Balsam fir $(a=0.900 ; b=0.350$, per Straube et al. 2002) were applied to the MC measurements.

Figure 42 through Figure 44 include graphs for the basement-level north-facing joists. The interior conditions at these joists were measured by the "T Logger" sensor.

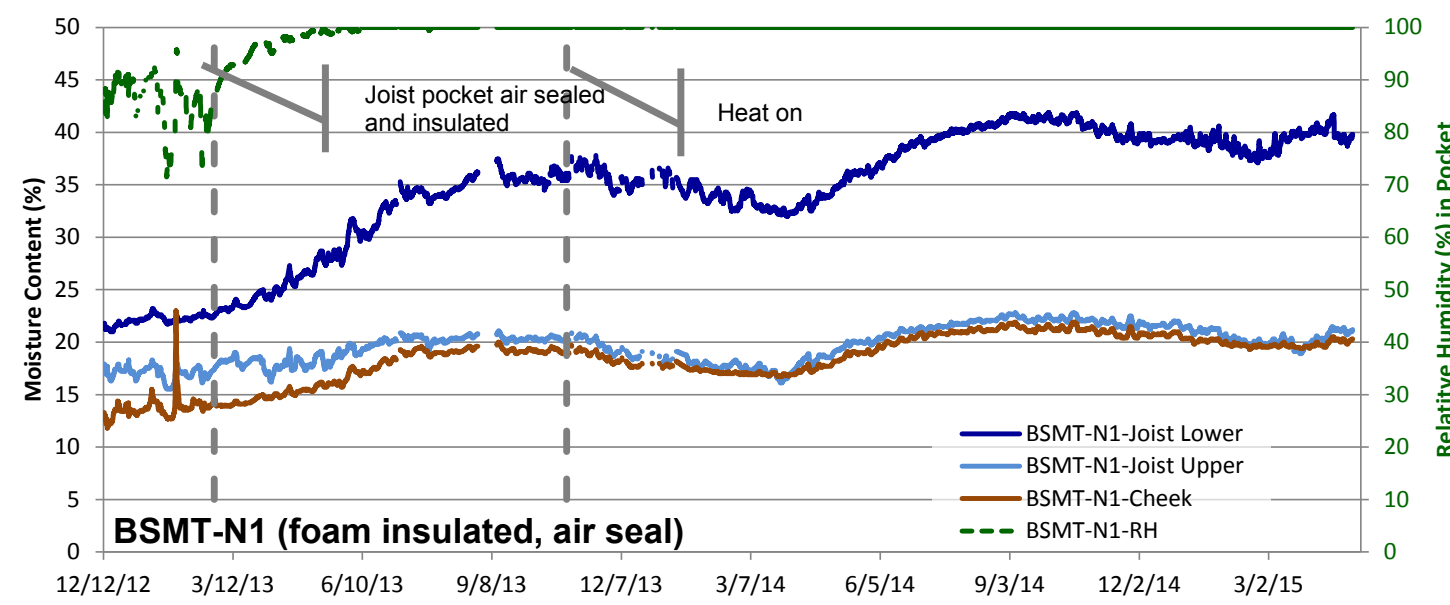

Figure 42. BSMT-N1 (insulated) joist end MCs and RHs

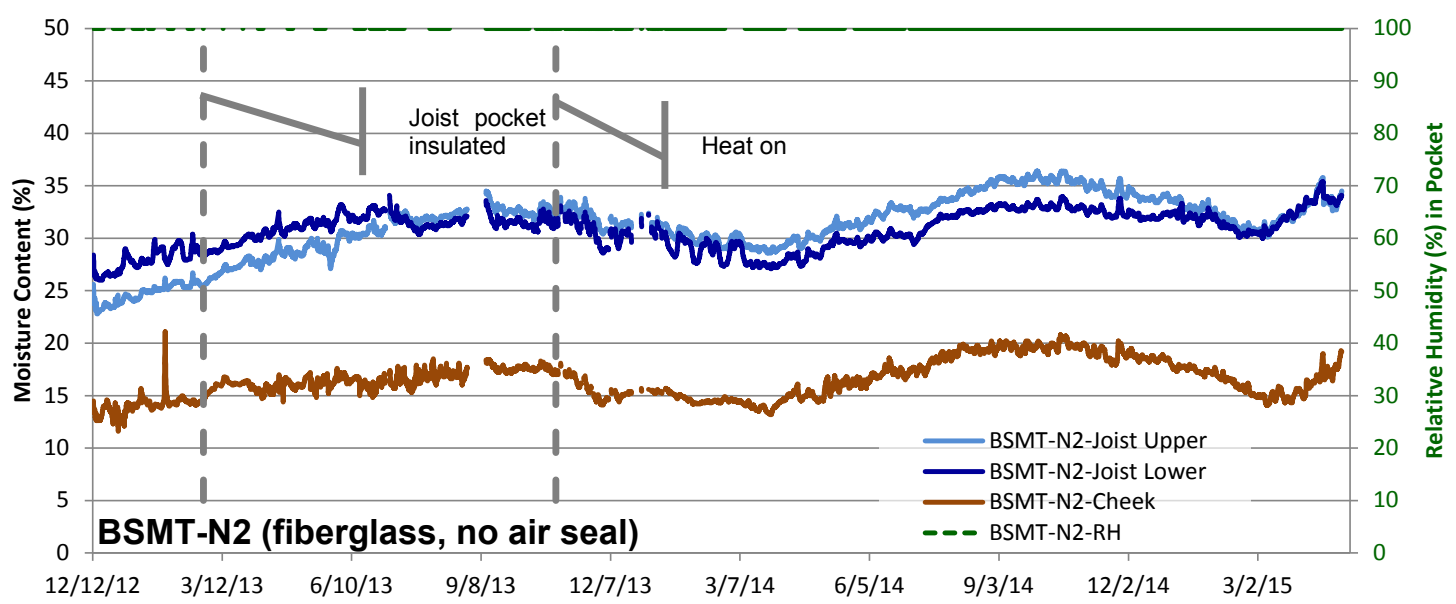

Figure 43. BSMT-N2 fiberglass) joist end MCs and RHs 


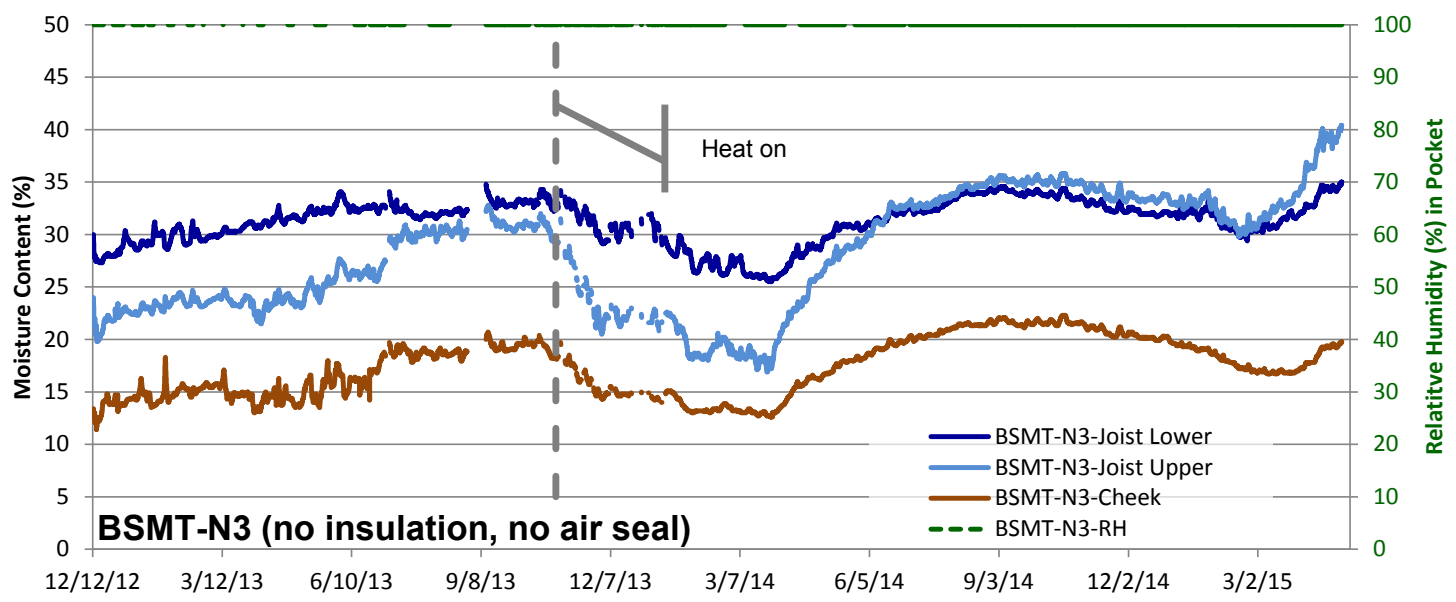

Figure 44. BSMT-N3 (uninsulated) joist end MCs and RHs

The joist pocket RH measurements showed high levels of either constant 100\% (BSMT-N2 and BSMT-N3), or a quick rise from $80 \%$ to constant $100 \%$ (BSMT-N1). The reason for the RH difference between BSMT-N1 and BSMT-N2/N3 was not evident from visual or infrared observations (Figure 24). Temperature measurements showed that the largest differences between joist ends were $1^{\circ} \mathrm{F}\left(0.5^{\circ} \mathrm{C}\right)$, and visual inspection of the temperature and $\mathrm{RH}$ sensor installation showed no significant installation differences between the three joists.

MC measurements typically showed that the lower joist end ("Joist Lower") was wetter than the upper joist end ("Joist Upper"). This can be attributed to direct contact with the masonry pocket, gravity drainage of bulk water, deeper embedment (and less drying) at the bottom of the beam (versus greater drying at the top of the beam), and a larger air pocket at the top of the beam. The cheek measurement was drier than the joist end measurements in all cases.

The joist end $\mathrm{MC}$ levels were higher than recommended for durability: lower joist ends were $20 \%-40 \%+$ (BSMT-N1 joist lower was wettest by far), and upper joist ends were typically 15\%-36\%. Joist cheek MCs were safer (10\%-22\%). The high moisture levels might reflect unheated or "mothballed" building conditions (previous 2 years of operation). However, no damage to the beam ends was evident during sensor installation.

MCs demonstrated a distinct seasonal cycle: peaks occurred during late summer and early fall (September). More importantly, MCs dropped when heat was introduced in October 2013, especially in N3 (uninsulated). An outward temperature gradient would result in outward drying of the beam end; summer conditions have an inward temperature and water vapor gradient.

Moisture levels did not differ markedly between the three joist ends: although N1 (insulated) had very high "lower" MCs, measurements at other parts of the joist were drier than N2 and N3. High MCs were found at all three joist ends.

The MCs were plotted with driving rain deposition on the north wall, which was calculated using methods from Straube and Burnett (2005) (Figure 45) from late 2012 to mid-2014. Distinct rain events showed no discernable responses in the measured data. 


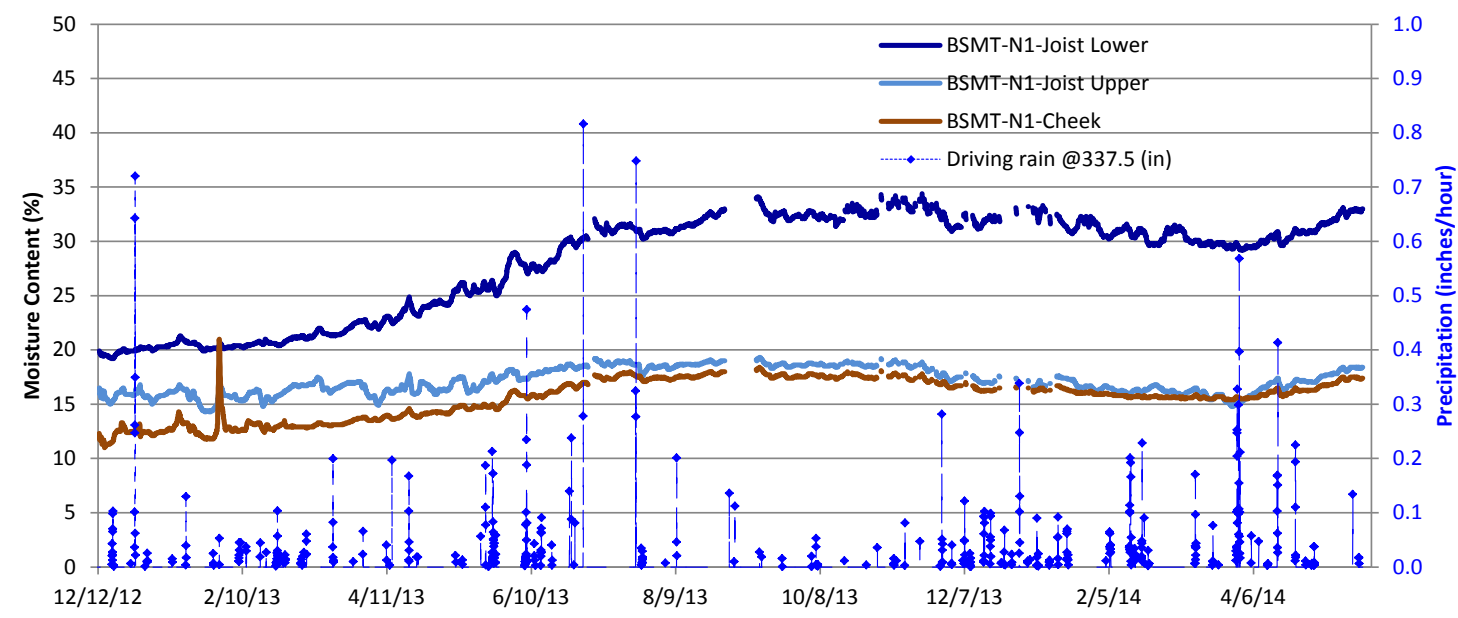

Figure 45. BSMT-N1 joist end MCs with calculated driving rain

Measurements from the east-facing joist from the rear of the building (BSMT-E2) are shown in Figure 46: the sensor measurements underwent a step change downward in August 2013 (highlighted in gray). Given the parallel and sudden shift of all three MC levels, it was clearly a sensor (electrical) issue as opposed to a true MC change. Previous work has shown that MC pins can be short-circuited by wet masonry. Construction activity repeatedly damaged sensors (given the monitoring of an active jobsite), which required return trips for repair. This was often manifested as failures or electrical anomalies in the data. Based on these facts, data before August 2013 were disregarded.

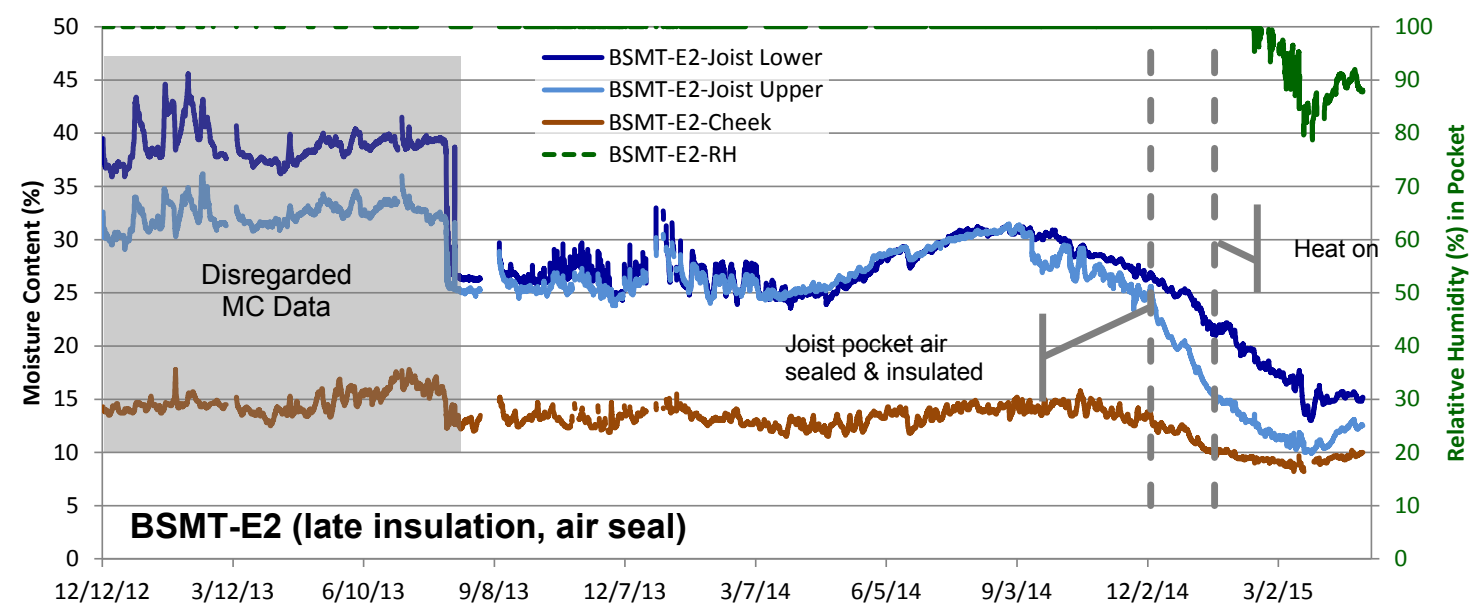

Figure 46. BSMT-E2 joist end MCs and RHs

BSMT-E2 was in a part of the building that had minimal wintertime heating (similar to BSMT$\mathrm{N} 1 / \mathrm{N} 2 / \mathrm{N} 3$ ) and was insulated and air sealed late in the construction process (December 2014). It had similar patterns to the previous graphs, including high peak MCs $(25 \%-31 \%)$, cheek measurements that were drier than the embedded joist ends, a seasonal swing (with peak in summer), and drying into the winter (especially with the addition of heating). $\mathrm{RH}$ also dropped from its continuous $100 \%$ in the final winter, which was consistent with a drop in the joist end MCs. 
The south-facing basement joist is plotted in Figure 47; it also had minimal wintertime heating (the same interior conditions as BSMT-N1/N2/N3). MCs were substantially lower $(\sim 10 \%-16 \%)$ than the north- and east-facing basement joists, and the RH in the joist pocket was markedly lower (seasonal rise and fall of $\sim 70 \%-100 \%$ ). This is attributed to the warmer temperatures due to solar gain on this orientation. These drier conditions are a function of solar heating, which is evident if north and south temperatures are compared (Figure 48 for part of winter 2012-2013). The south side was slightly but consistently warmer in winter, and joist end temperatures converged as outdoor temperatures rose.

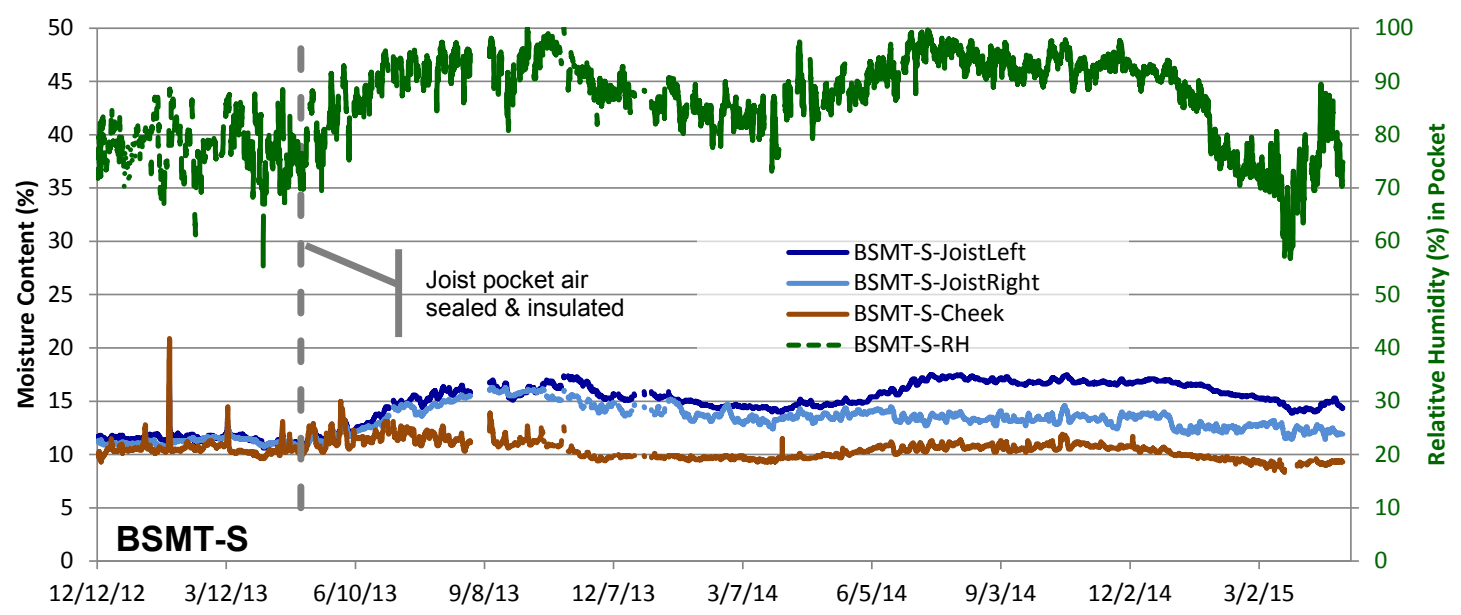

Figure 47. BSMT-S joist end MCs and RHs

The BSMT-S joist end measurements are a left/right pairing, not an upper/lower pairing; both are in the lower joist position.

Similar patterns to previous monitoring are seen, including cheek versus pocket MCs and seasonal moisture patterns (summertime peaks).

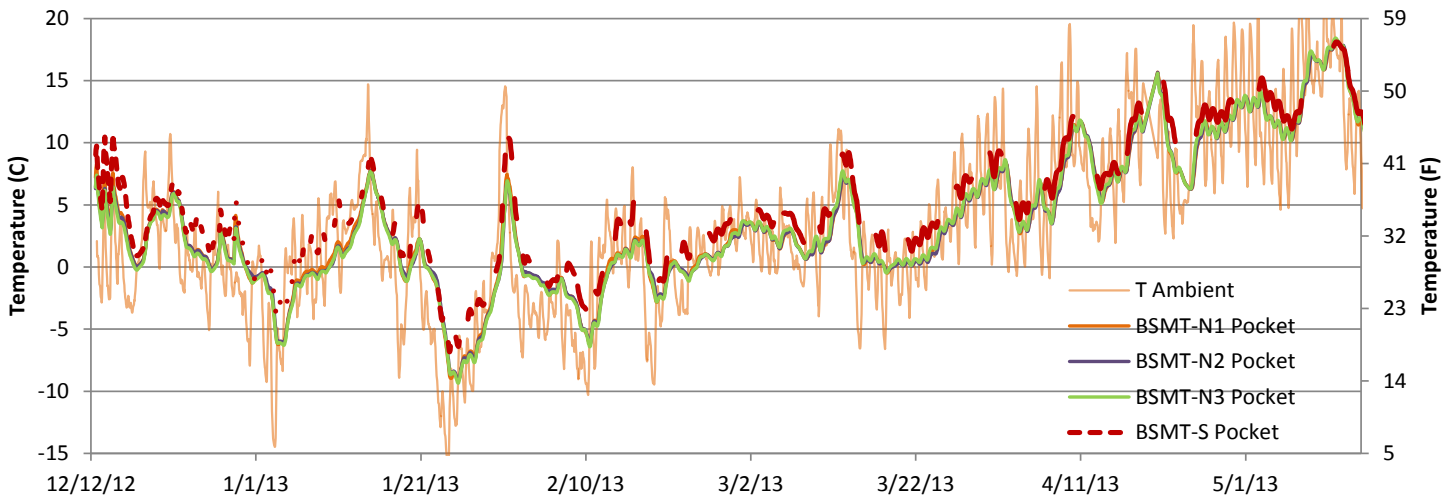

Figure 48. Basement North and South joist pocket winter temperature comparison

A close-up of summertime 2013 joist pocket temperature data (Figure 49) shows that north and south temperatures converged in warmer weather (note the change in temperature scale). The thermal mass of the masonry wall mostly damped out diurnal temperature swings at the joist end pocket and causes a phase shift. 


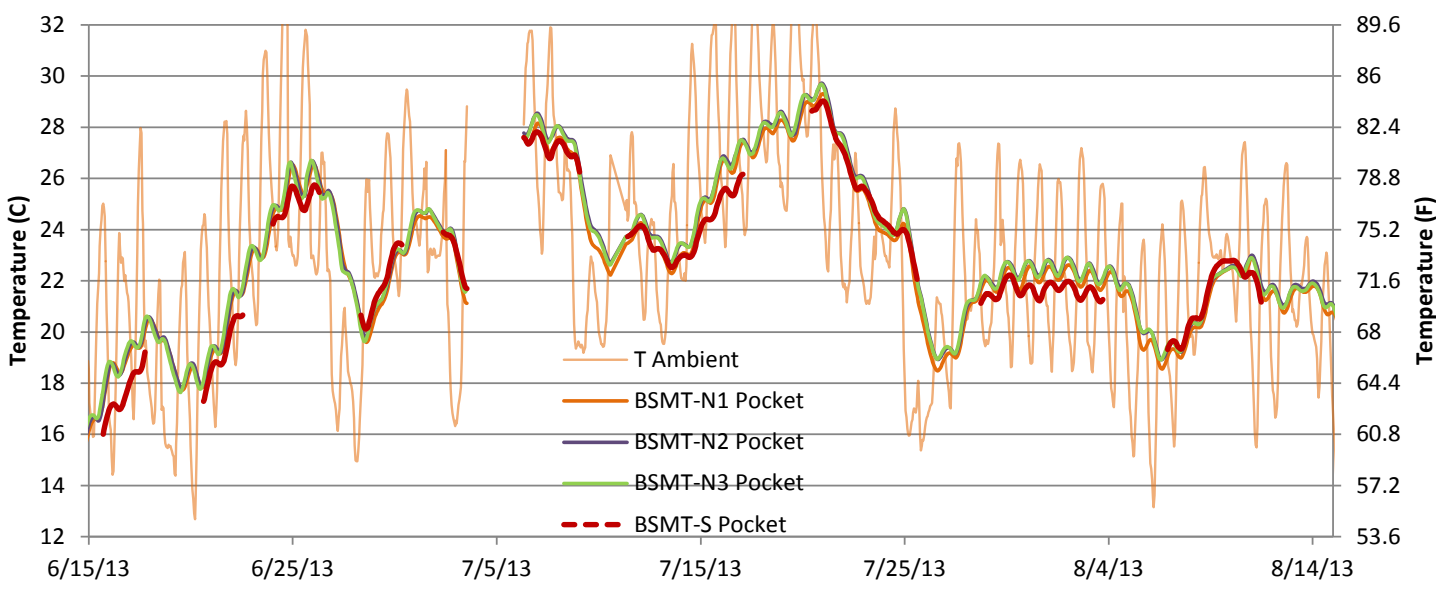

Figure 49. Basement North and South joist pocket summer temperature comparison

\subsection{Joist Moisture Content Measurements: Unheated Wing First Floor}

Graphs in this section cover the joist ends on the first floor (highlighted in Figure 50) at the rear of the building. During this period, this wing was running under essentially unheated conditions (albeit warmer than the basement). The joist ends on this floor were primarily installed in a hollow clay block backup wall, although some solid brick was mixed in to the wall assembly.

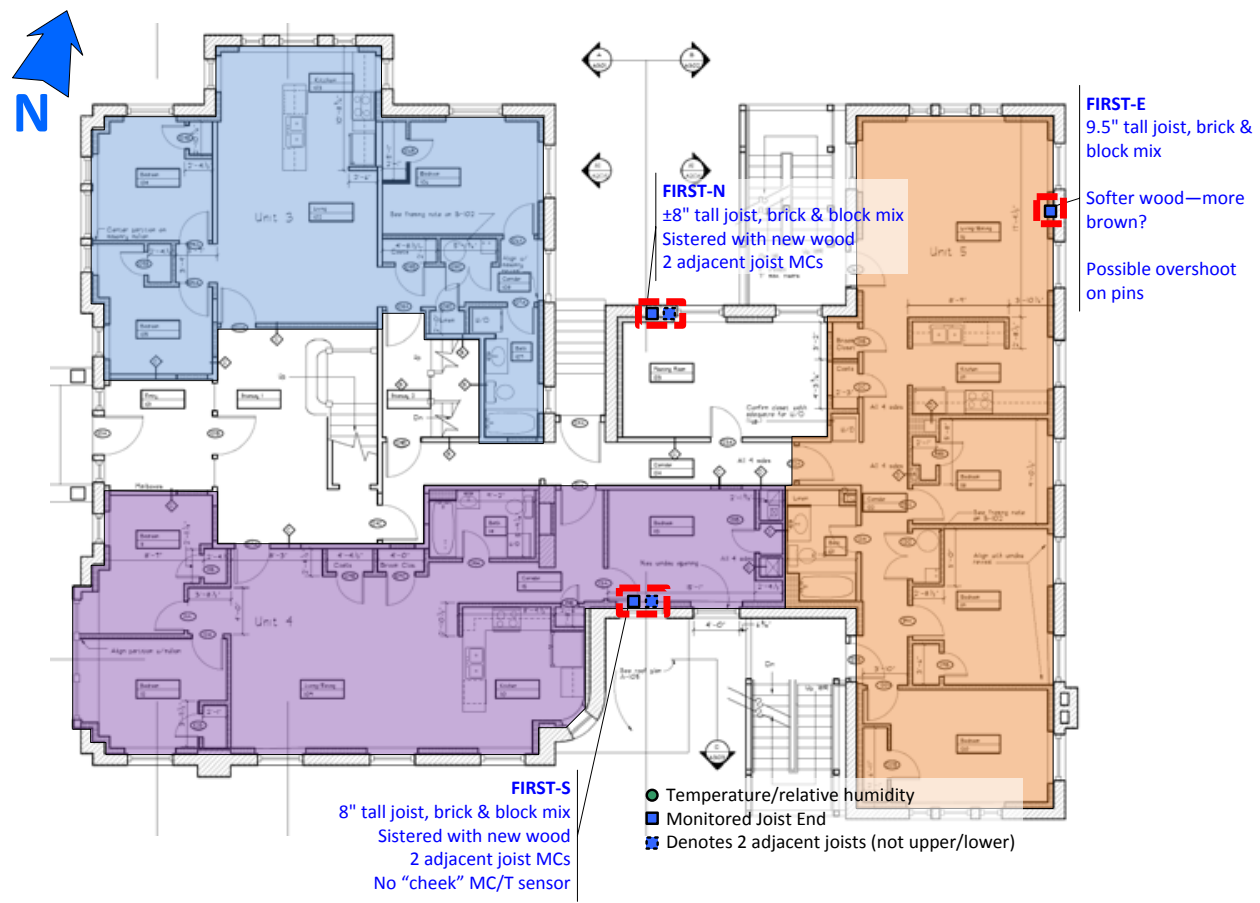

Figure 50. First-floor unheated wing joist end measurements highlighted

The north-facing joists (left/right pair) measurements are shown in Figure 51; the left-facing joist (FIRST-N-JoistLeft) had initial measurements in the $60 \%+$ range (off the graph). The MCs gradually fell over time and reached a range that was consistent with the other joists by winter 2013-2014. This was far higher than any other measurements in the building; the reason for this 
anomaly has not been positively determined, but electrical issues are suspected (as opposed to massive moisture loading of a single joist).

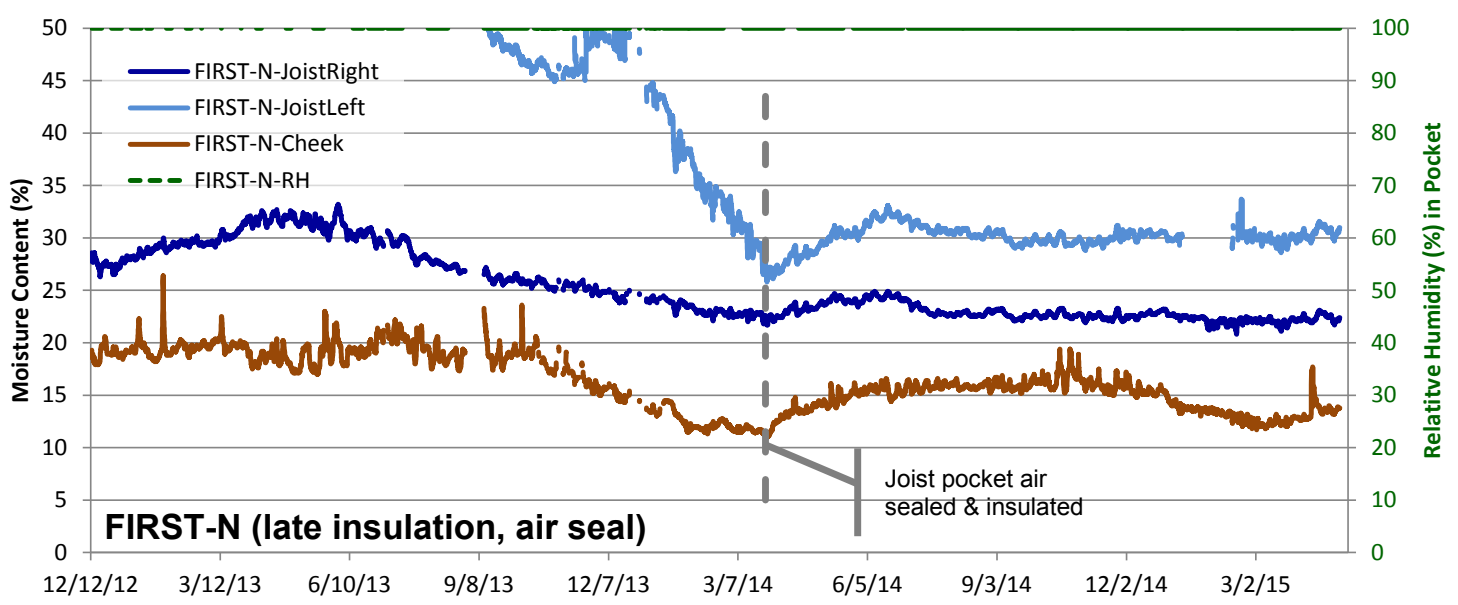

Figure 51. First-N joist end MCs and RH

Figure 51 shows that the beam pocket $\mathrm{RH}$ remained at $100 \%$ throughout these measurements. Similar to previous measurements, the cheek MC was lower (drier) than the joist end MC. The right joist pocket MC (FIRST-N-JoistRight) showed a seasonal rise and fall throughout the monitoring period (it was wetter in spring and summer and showed a general drying trend).

The joist pocket was insulated and air sealed in late March 2014; all MCs began to rise (consistent with cutting off drying to the interior seen in other joist pockets) and then exhibited a slight seasonal rise and fall pattern.

The first-floor east (FIRST-E) sensors had low MCs of about 9\%-15\% (Figure 52); this joist was the softer brown wood (possibly a different species) noted earlier. However, the measured pocket RHs (45\%-95\%) were consistent with lower MC measurements. These low MCs occurred despite a high driving rain exposure on this orientation. This location had noticeably higher summertime temperatures (due to solar gain) than the east-facing joists on the basement level.

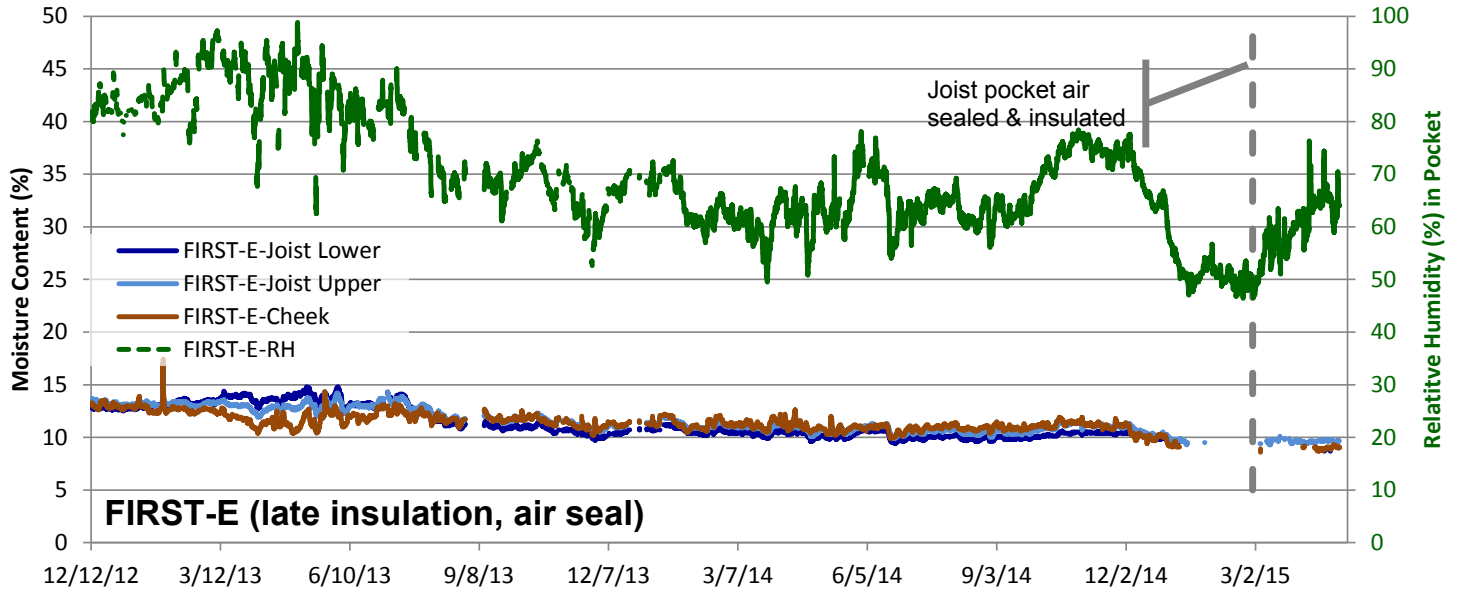

Figure 52. First-E joist end moisture contents and RH 
This joist pocket was insulated and air sealed late in construction (February 2015); an associated rise in pocket $\mathrm{RH}$ occurred, although the change could be associated with seasonal variations.

The south-facing joist MCs (Figure 53) were also low (9\%-15\%); RH measurements were consistent with MCs (50\%-80\% RH, brief spike to $100 \%$ in November 2013). This RH spike was checked against rain events, but no correlation was found. This joist had no cheek measurement.

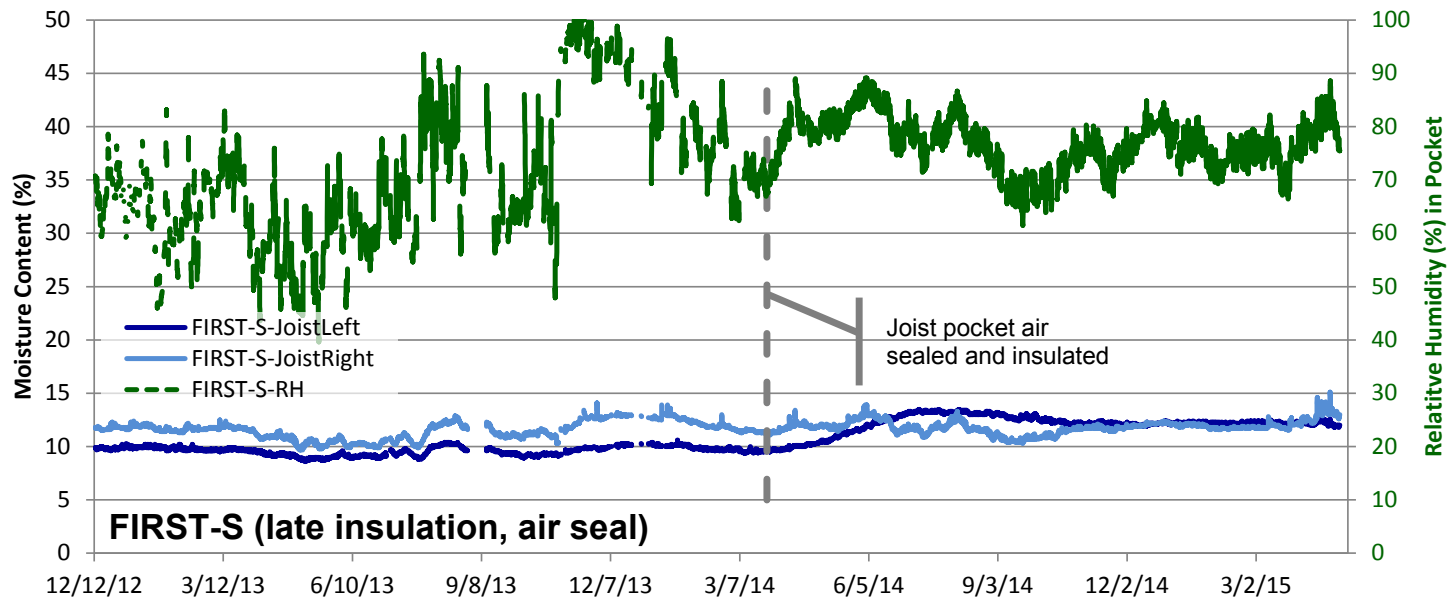

Figure 53. First-S joist end MCs and RHs

MCs rose slightly after the joist end was insulated and air sealed (March 2014); RH measurements became noticeably more stable after this work was completed.

\subsection{Joist Moisture Content Measurements: Heated Wing Basement}

Graphs in this section cover the joist ends on the basement level in the area that received construction heat during all three winters. Typical wintertime interior temperatures were $50^{\circ}-75^{\circ} \mathrm{F}$ $\left(10^{\circ}-24^{\circ} \mathrm{C}\right)$ (per the T Hallway sensor shown in Figure 38$)$ but with a wide swing. The locations of these measurements are highlighted in Figure 54.

The east-facing joist (BSMT-E1; Figure 55) showed some sudden changes in the joist end MC, which likely indicated a sensor electrical anomaly rather than a valid MC shift. These shifts were correlated against interior and exterior conditions, including calculated driving rain; no causes were obvious. Overall, BSMT-E1 Joist Upper had data that will be disregarded, but BSMT-E1 Joist Upper had data that looked reasonable after June 2013. The cheek measurement, however, looks reasonable; unfortunately, it shows a pattern of seasonally rising MCs (peaks in summer), of $10 \%$ to $29 \%$. 


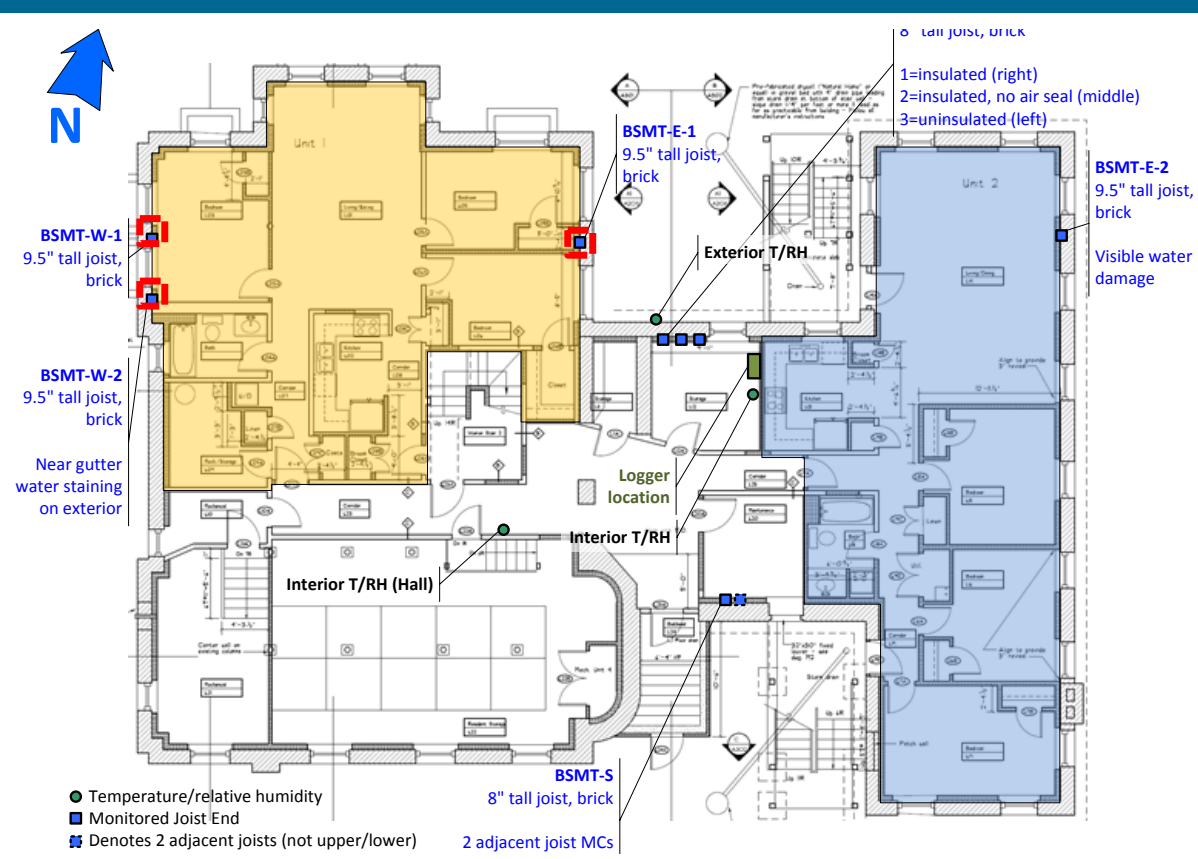

Figure 54. Basement heated wing joist end measurements highlighted

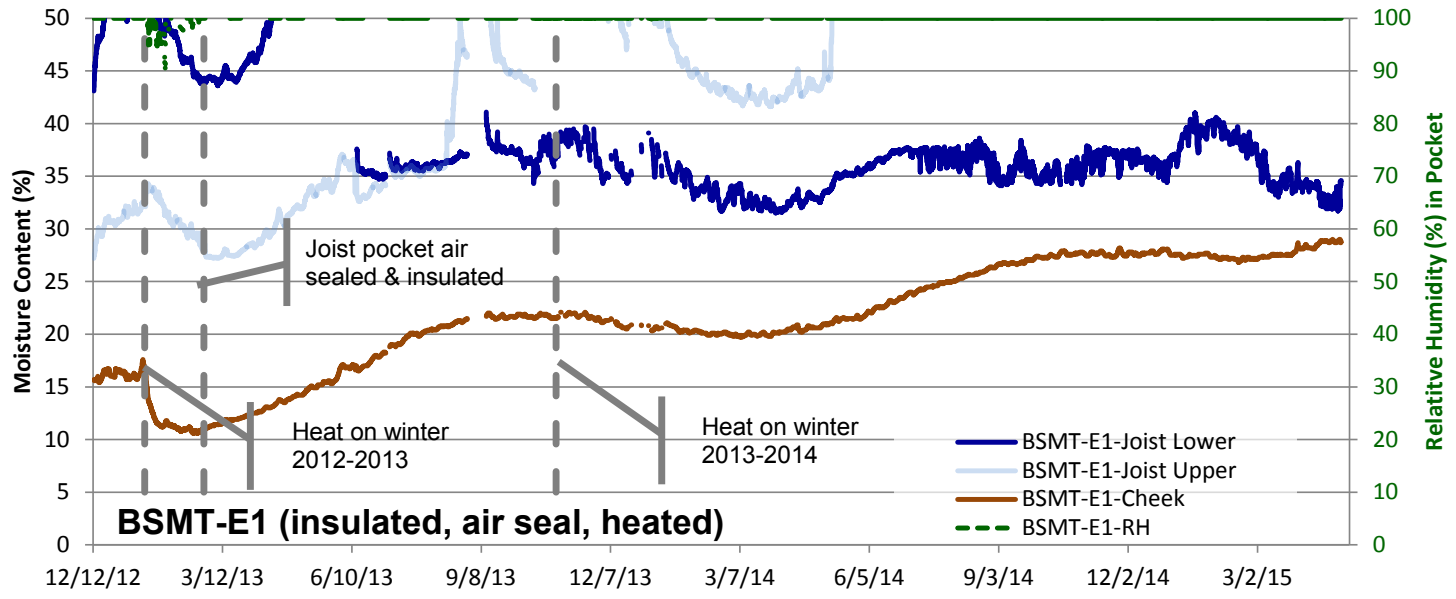

Figure 55. BSMT-E1 joist end MCs and RHs

Despite a low confidence in some of these MC measurements, the RH measurements (almost constant 100\%) were consistent with high MCs. In terms of exposure, even though this joist faces east, this location is blocked from solar gain by the adjacent wing (see Figure 54).

Although the MC measurements exhibit uncertainty, some shifts can be correlated with various events. In January 2013, interior construction heating was started, and all MCs fell, especially at the joist cheek (which has the greatest exposure and the most drying available). The RH in the joist pocket also shifted slightly off $100 \%$. However, after the joist pockets were air sealed and insulated with spray foam in February 2013, the RH increased back to a constant $100 \%$, and the MCs began to rise again. The cheek MC also increased: it was buried within the spray foam insulation, so it was isolated from interior conditions. 
The west-facing joists (BSMT-W1 and W2) have similar-or even more pronounced-seasonal patterns (Figure 56 and Figure 57).

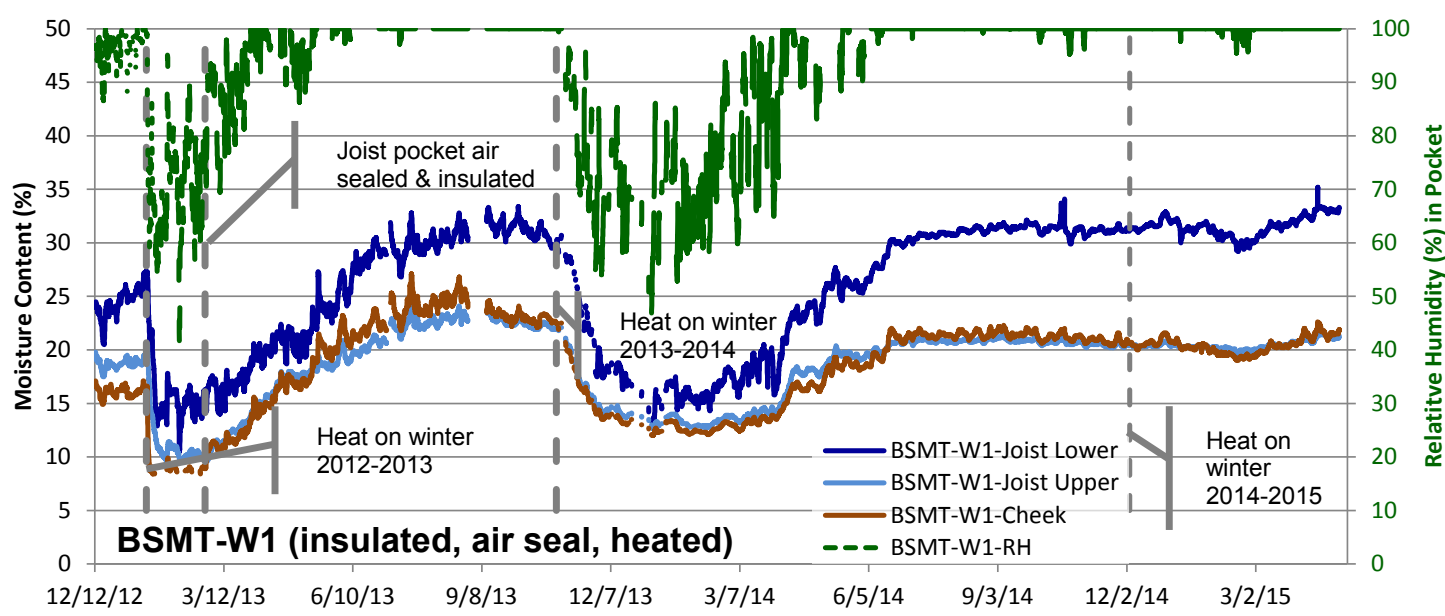

Figure 56. BSMT W1 joist end MCs and RHs

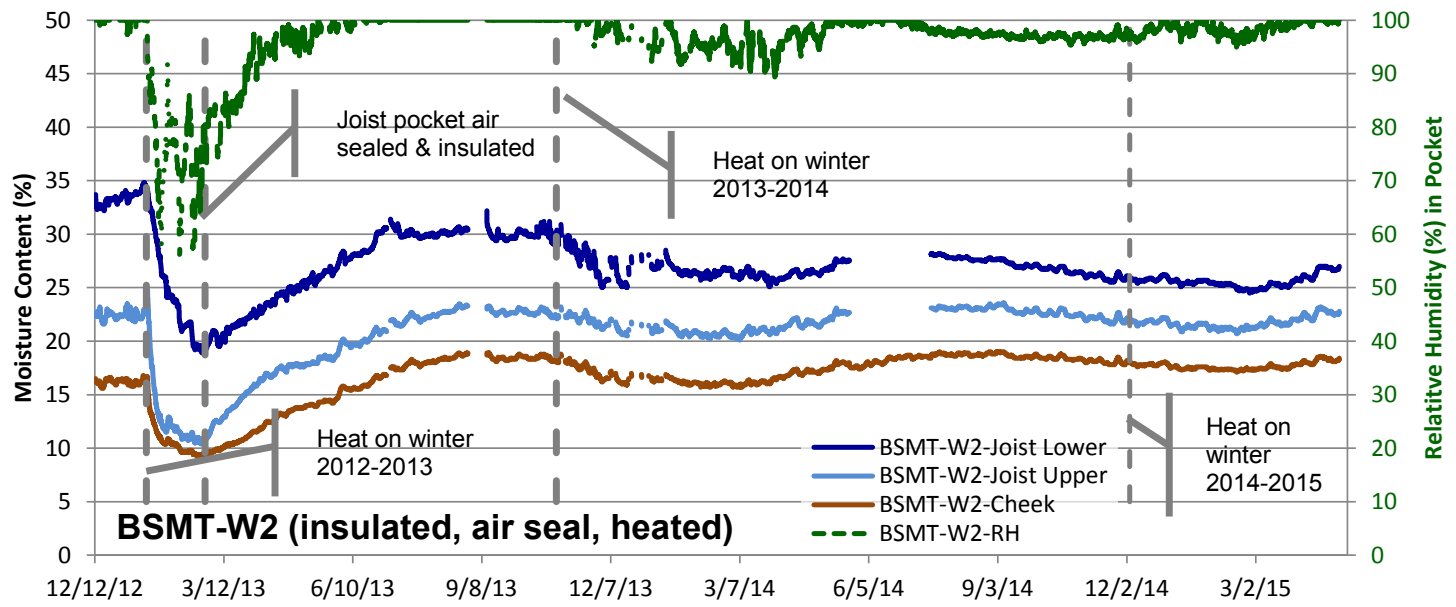

Figure 57. BSMT-W2 joist end MCs and RHs

Similar to BSMT-E1, MCs showed a sharp decrease (drying) when construction heating was introduced in January 2013; RHs dropped simultaneously. Sealing the joist pocket (February 2013) correlated with a rise in MCs and RHs, but the rise was also consistent with the seasonal (summertime) pattern. Again, in winter 2013-2014, construction heating caused the joist ends to dry. In spring 2014, MCs and RHs rose again. However, in winter 2014-2015, the drying associated with wintertime heating was barely perceptible, if it was occurring. Part of this may have been due to the installation of interior gypsum board (ceiling and wall), which would have decoupled the insulated joist end further from the interior space.

The difference in RHs and MCs between east- and west-facing joists might be ascribed to the temperatures in the pocket (Figure 58). 


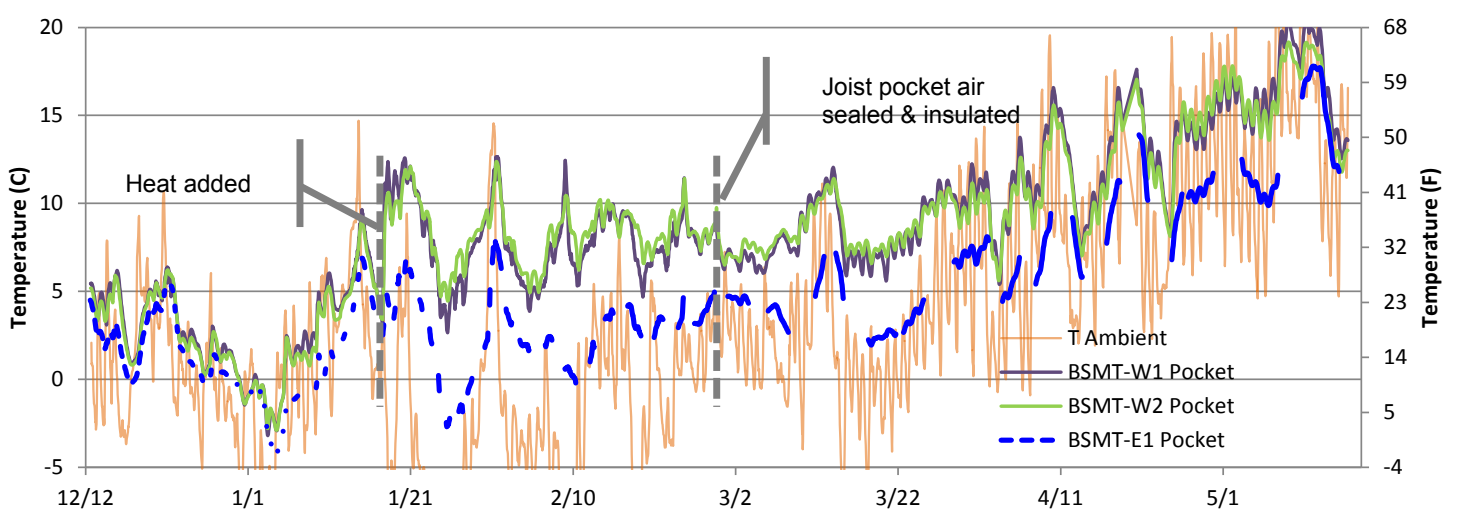

Figure 58. Basement West and East joist end winter/spring temperature comparison

The west-facing joist pockets were consistently warmer than the east-facing joist. The eastfacing joist was shaded from solar gain by the adjacent parts of the building (see Figure 54); the west-facing joists were well exposed to the afternoon sun. This temperature difference increased as heat was added: the space heater for the front of the building was closer to the west-facing joists (front) than the east-facing joist. The temperature difference continued after the wintertime heating was shut off. 


\section{ASHRAE 160 Analysis}

ASHRAE Standard 160 (ASHRAE 2009) provides guidance on moisture analysis for building envelope design, including the moisture performance evaluation criteria. The failure criteria (defined as the risk of mold growth) were redefined in addendum (a) (ASHRAE 2011), as follows:

6.1 Conditions Necessary to Minimize Mold Growth. In order to minimize problems associated with mold growth on the surfaces of components of building envelope assemblies, condition shall be met: a 30-day running average surface $\mathrm{RH}<80 \%$ when the 30-day running average surface temperature is between $5^{\circ} \mathrm{C}$ $\left(41^{\circ} \mathrm{F}\right)$ and $40^{\circ} \mathrm{C}\left(104^{\circ} \mathrm{F}\right)$.

Materials that are naturally resistant to mold or have been chemically treated to resist mold growth may be able to resist higher surface relative humidities and/or to resist for longer periods as specified by the manufacturer. The criteria used in Addendum a to Standard 160-2009 the evaluation shall be stated in the report.

For reference, this research team and other practitioners (Arena et al. 2013; Arena 2014) have found ASHRAE 160 criteria to be unrealistically stringent and conservative because the criteria overestimate the risks of mold growth.

The BSC team used ASHRAE 160 criteria and the RHs and temperatures at the joist end pocket to analyze the collected data. Thirty-day running averages were calculated for each hour and the resulting pass/fail results tabulated. In a strict intepretation of Standard 160, a single failing hour would nominally constitute an assembly failure.

The results are plotted in Figure 59: hours that failed ASHRAE 160 are denoted by points; the outdoor temperatures (30-day rolling average) are plotted for reference.

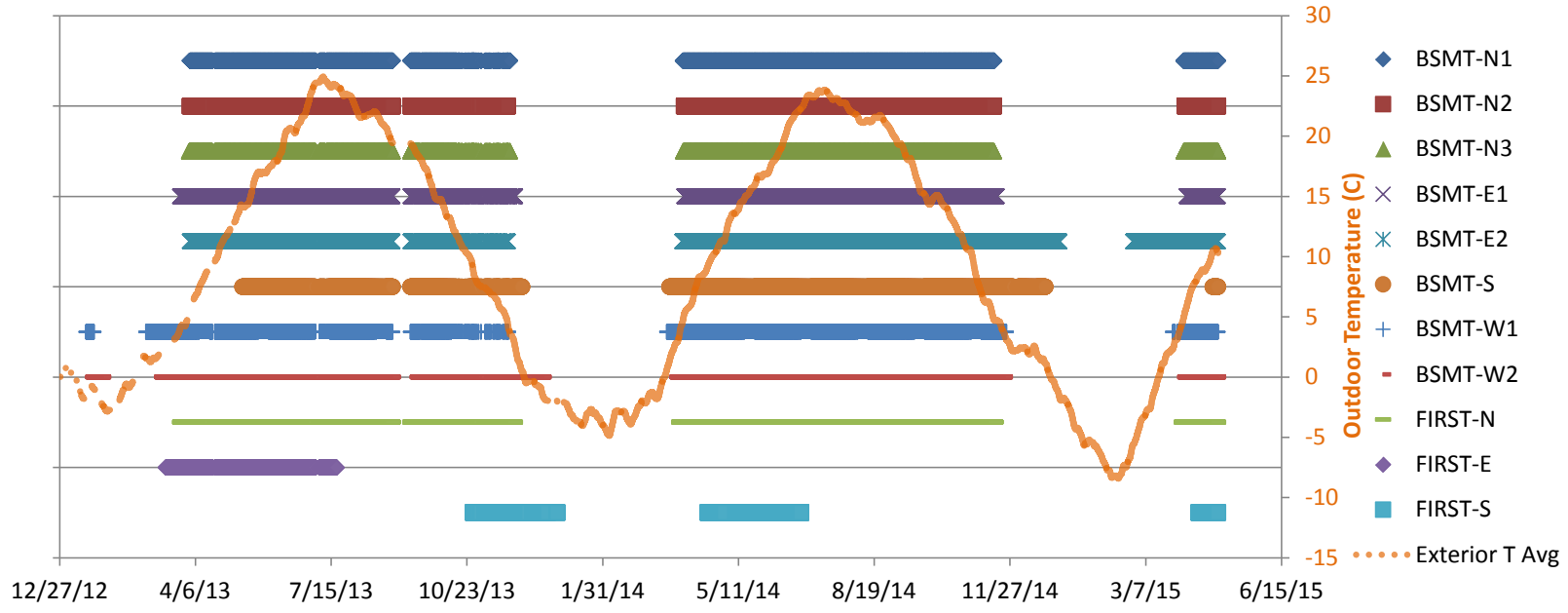

Figure 59. ASHRAE 160 failing hours for joist ends, with exterior temperature 30-day average

The results are not surprising, given that many of the joist end pockets remain at a constant $100 \%$ RH throughout the monitoring period. Therefore, they fail ASHRAE 160 criteria whenever 
temperatures are sufficiently warm to sustain mold growth. As shown in Figure 59, most joist ends have failure conditions at all times except during winter conditions when temperatures remain below $41^{\circ} \mathrm{F}\left(5^{\circ} \mathrm{C}\right)$. The discontinuity seen in August-September 2013 was a section of missing data, not a period of dry conditions.

For reference, the same data were tabulated (with a percentage of failing hours) in Table 1.

Table 1. Number of Hours Failing ASHRAE 160 and Percentage of Hours at Failure

\begin{tabular}{c|c|c|}
\hline Joist End & \# Failing Hours & \% of Hours \\
\hline BSMT-N1 & 10,159 & $63 \%$ \\
\hline BSMT-N2 & 10,108 & $63 \%$ \\
\hline BSMT-N3 & 10,155 & $63 \%$ \\
\hline BSMT-E1 & 10,403 & $64 \%$ \\
\hline BSMT-E2 & 11,310 & $70 \%$ \\
\hline BSMT-S & 10,499 & $65 \%$ \\
\hline BSMT-W1 & 11,567 & $72 \%$ \\
\hline BSMT-W2 & 11,932 & $74 \%$ \\
\hline FIRST-N & 10,450 & $65 \%$ \\
\hline FIRST-E & 2,890 & $18 \%$ \\
\hline FIRST-S & 2,206 & $14 \%$ \\
\hline
\end{tabular}

Two joist ends show a relatively low fraction of failure hours that warrant a closer look:

- FIRST-E (rear face of building, 1930 addition, hollow clay block wall): joist pocket RH levels dropped and remained lower than $80 \%$ during the first summer (August 2013). The joist end MCs were consistently safe $(8 \%-15 \%)$ throughout the monitoring period.

- FIRST-S (side of building, 1930 addition, hollow clay block wall): joist pocket RH levels varied higher and lower than $80 \%$ with intermittent wetter conditions (see Figure 53). However, the joist end MCs were consistently safe $(9 \%-15 \%)$ throughout the monitoring period.

BSMT-S is an interesting case, because it had ASHRAE 160 failures as bad as other joists but with low wood MCs. At that joist, MCs were 10\%-18\%, but RHs seldom fell lower than $80 \%$. However, the joist pocket was not a constant $100 \%$ RH, like many other pockets. 


\section{Joist End Samples}

Wood joist samples were collected in September 2014 to allow for species identification (and thus greater accuracy for resistance-based MCs). The samples came from two joist ends that remained embedded in the masonry wall in the rear addition section (Figure 60); sometime after May 2012 the construction crew removed the joist for structural and access reasons.
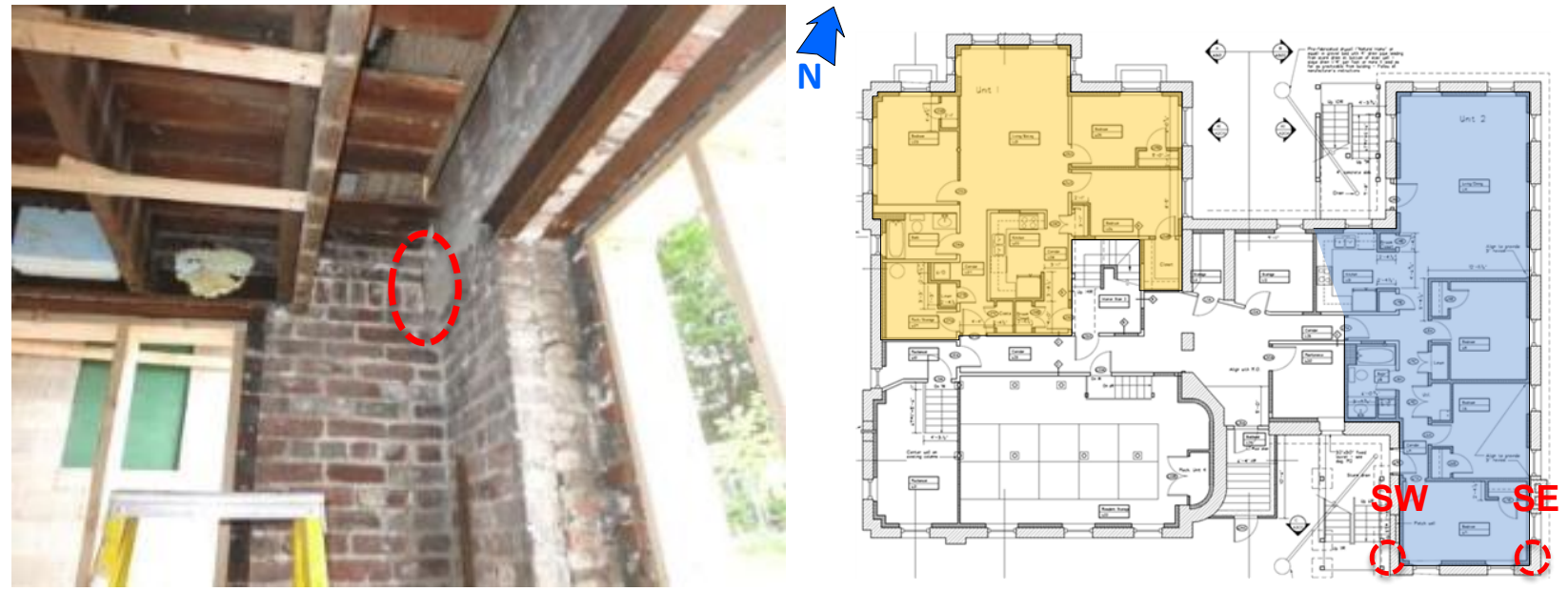

Figure 60. Joist end stub in southeast corner (left), plan showing stub locations (right)

The joist end stub that remained in the wall is shown in Figure 61, left; the wood was cut off flush with the masonry surface, and the removed joist was originally tight against the exterior south wall. The pockets are in the southwest and southeast corners. The joist pocket (Figure 61, right) shows that at least in this case, mortar was infilled around the fire cut (sloped) joist end, which left a minimal airspace around the joist pocket.
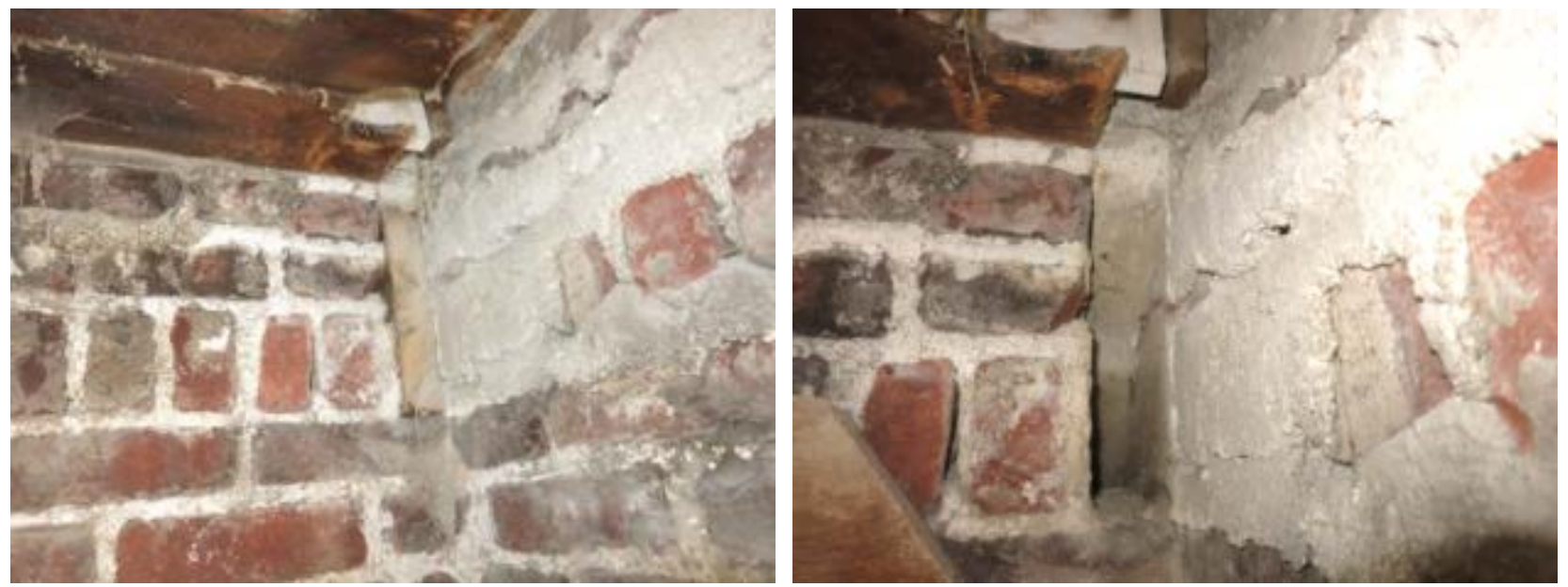

Figure 61. Joist end stub embedded in wall (left); joist pocket showing mortar (right)

One of the two joist ends was damp to the touch and had a distinctly moldy odor when it was removed from the wall. However, when the wet joist end was probed with a screwdriver, it was structurally intact; it showed no evidence of rot, decay, or punkiness. Both joist ends had evidence of earlier water staining. 
The MCs of these joist ends were measured with a resistance (pin-based) MC meter (Delmhorst BD-10) to examine the spatial MC pattern (Figure 62 and Figure 63). The MCs are color coded (red high risk, yellow some risk, green safe) in the photos. The MCs of the underside (horizontal bearing surface) of the joist ends are indicated by rotated text. Some MCs are notated $40 \%+$; this is the upper measurement limit of the meter.

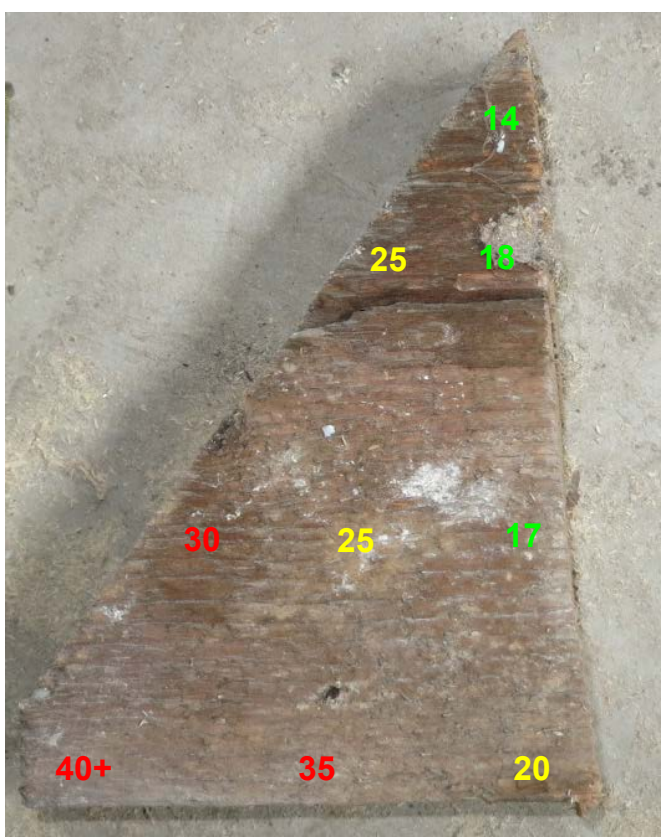

Inboard Face

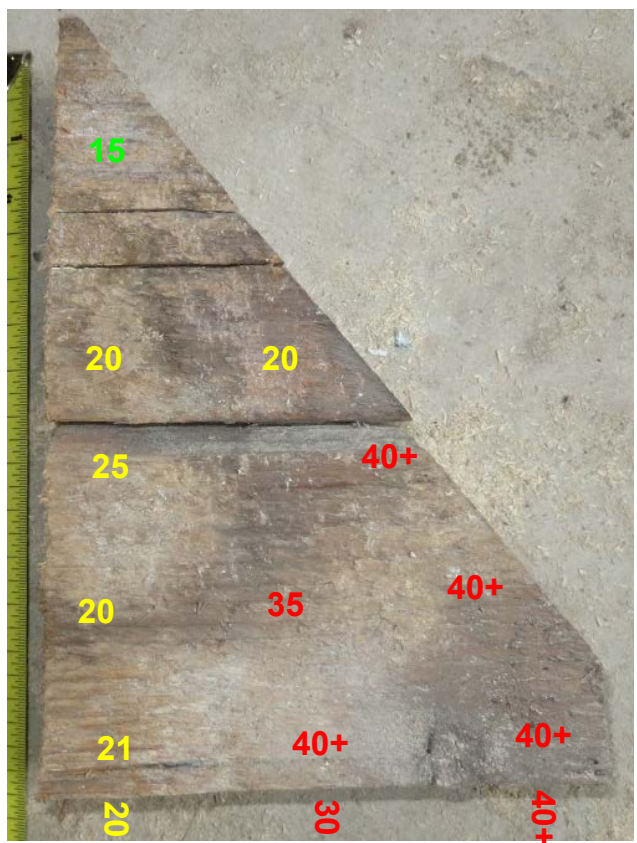

Outboard Face

Figure 62. Joist end stub MCs: southeast corner/east-facing (wetter)

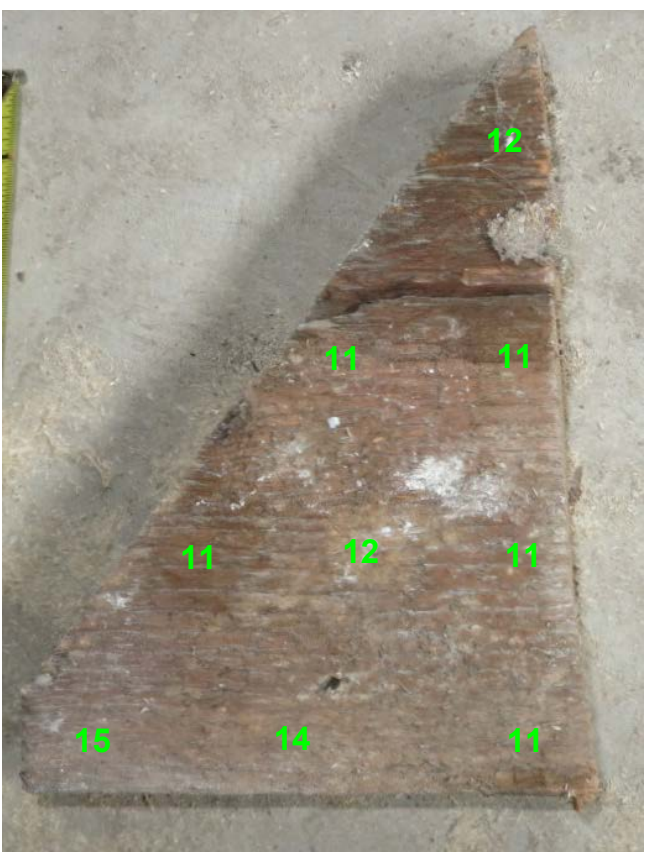

Outboard Face

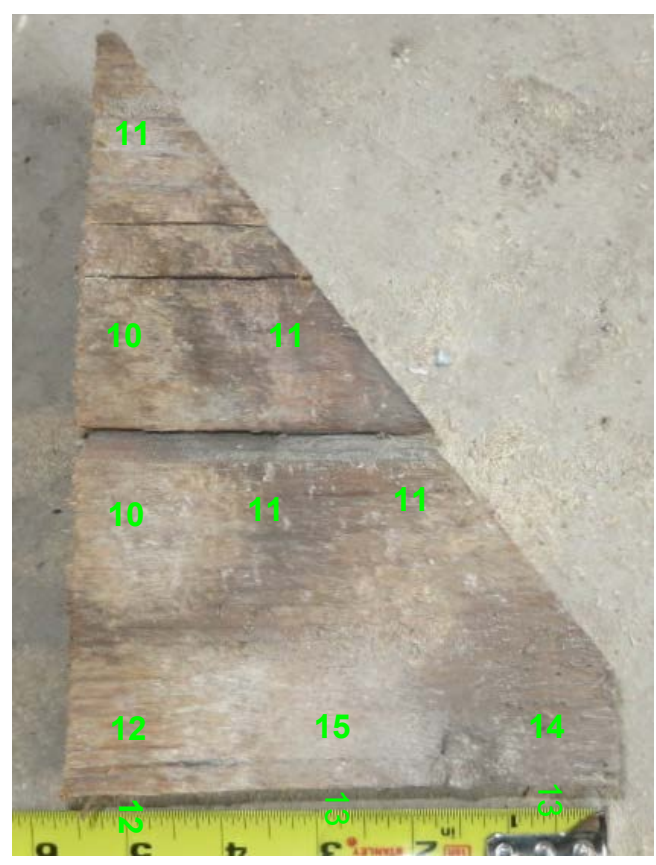

Inboard Face

Figure 63. Joist end stub MCs: southwest corner/west-facing (drier) 
The following conclusions were drawn from the samples and the MC measurements:

- The embedded joist ends - at least the species/samples taken at this building — can withstand sustained high MCs (40\%) without suffering structural damage or rot. This is not meant to imply that $40 \% \mathrm{MC}$ is a safe condition for this wood; rather, it indicates that the high MCs measured in this building do not necessarily indicate incipient failure.

- High MCs were observed in a joist end with no insulation, which proves important risk factors to joist ends other than insulation or no insulation. This joist end was also well separated $(\sim 4 \mathrm{ft})$ from the exterior grade. These joist ends were in an unheated part of the building; no space-heating-based drying would have occurred in this section.

- Orientation had a significant impact on joist end MCs: the west-facing joists had dry MCs that were well within the safe range; the east-facing joists had MCs that would be considered at risk of failure. This is consistent with the patterns seen during the monitoring period, when orientation had a strong effect: the west-facing joists were generally much drier than the east-facing joists.

- MCs showed a spatial distribution: the joist end parts (especially at the bottom) that were most deeply embedded in the wall had the highest MCs. This is also consistent with the monitoring data. 


\section{Conclusions}

\subsection{Conclusions on Field Monitoring Methodology}

The field monitoring methodology for joist end MCs (using extended wood MC pins) generally returns valid and relevant data that match the $\mathrm{RH}$ data of the joist pocket. This installation method has the advantage of not disturbing or demolishing the masonry pocket that surrounds the joist end (as done by Maurenbrecher et al. 1998). Demolition for sensor installation changes the conditions of the pocket and introduces construction moisture (new mortar) into the system.

Spatial distribution of MCs, with the lower MC wetter than the upper MC, was corroborated by the joist stub measurement. Elevated (wetter) joist end MCs were accompanied by high RH levels (often constant 100\%) in the joist pocket. Lower (drier) joist end MCs were accompanied by lower RH levels.

Several MC measurement anomalies emerged when measurements shifted suddenly (step changes) or went off scale high; these are not realistic results. These issues occurred at BSMTE1, BSMT-E2, and FIRST-N. One explanation was that moisture pins short-circuited against wet masonry; this could happen if the pins were accidentally overdriven. This scenario is consistent with the fact that in many Building America research sites dating back to 2003, this type of behavior was not seen in light wood frame wall monitoring that used the same equipment and algorithms.

Given the damage to sensors and wiring from monitoring an active construction site, electrical issues from wire damage could offer another explanation; multiple site trips were required to repair wiring and sensor damage.

\subsection{Summary of Field Monitoring Measurements}

The field monitoring work covers 11 joists during 28 months, which includes three winters and two summers of data. Digesting these varied measurements is difficult. To place the data in context, they are presented in Figure 64 through Figure 66 as whisker/box plots that show the overall range and distribution of measured MCs. The upper and lower joist end MCs are plotted, but not joist cheek MCs, because they were typically drier than the joist ends and therefore at lower risk for moisture-related failure.

The whisker/box plots show the median (center of gray box), lower, and upper quartile of data (extent of gray box), and maximum/minimum (lines extending from box). The graphs are plotted with the same groupings used previously of basement minimally heated areas (Figure 64), firstfloor unheated areas, and basement heated areas (Figure 65). Color bars are provided to indicate lower and upper joist end measurements. Some plots omit some of the data (as noted with $\dagger$ ) due to electrical or sensor anomalies.

Many of the minimally heated basement joist ends (Figure 64) remain at high MCs (25\%-35\%) for much of the monitoring period; the joist pocket RH measurements were a constant $100 \%$ for north- and east-facing joist ends. The south joist end, however, had much lower MCs (with corresponding RH data), and remained well within the safe range. The east joist end was between the north and south behaviors. 
The three north-facing joist ends (N1/foam insulation, N2/fiberglass insulation, N3/uninsulated) were set up to compare insulation strategies. However, the MCs overlapped significantly; drawing clear conclusions is difficult. Although the BSMT-N1 lower joist MC was wetter than others, the corresponding upper joist MC was the driest of the BSMT-N joists.

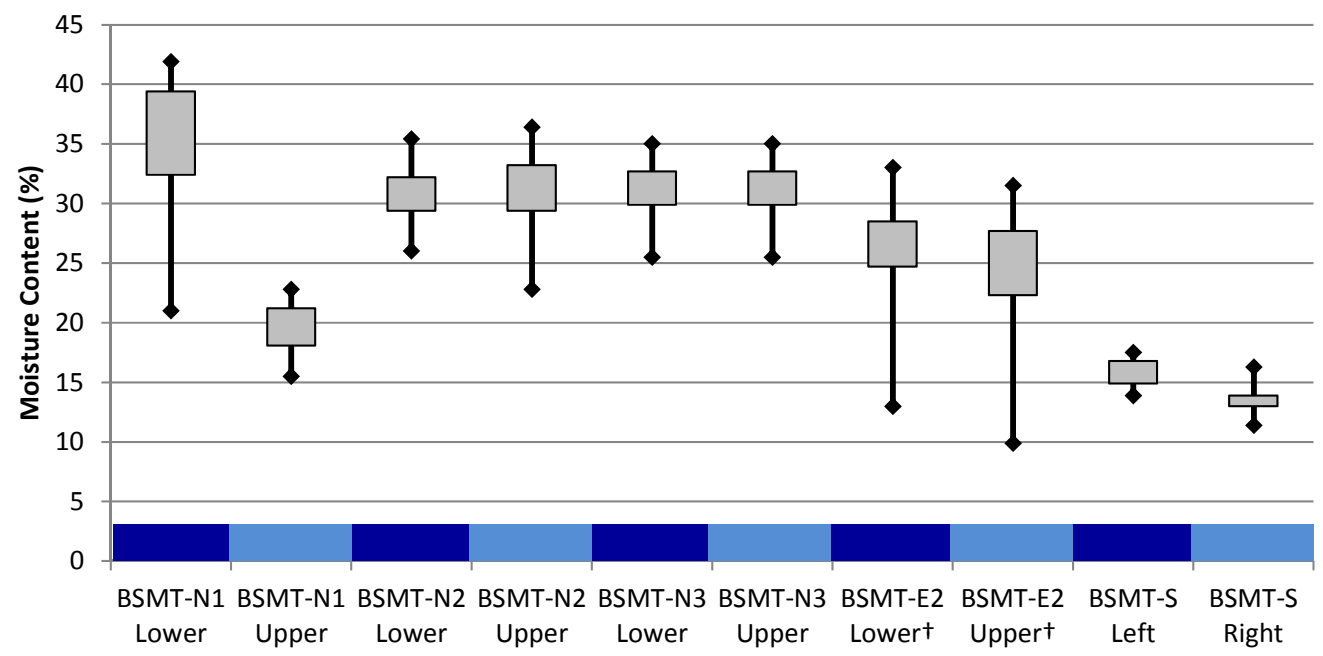

Figure 64. Box/whisker plot for joist end MCs; minimally heated basement joists

$\dagger$ : BSMT-E2: Data before October 12, 2013 are not plotted due to electrical anomalies.

Figure 65 shows MC results for the first-floor unheated-area joists. This area was typically warmer than the basement due to solar gain through windows and the stack effect. The joist ends were embedded in hollow clay tile walls with some filler brick in contact with the wood.

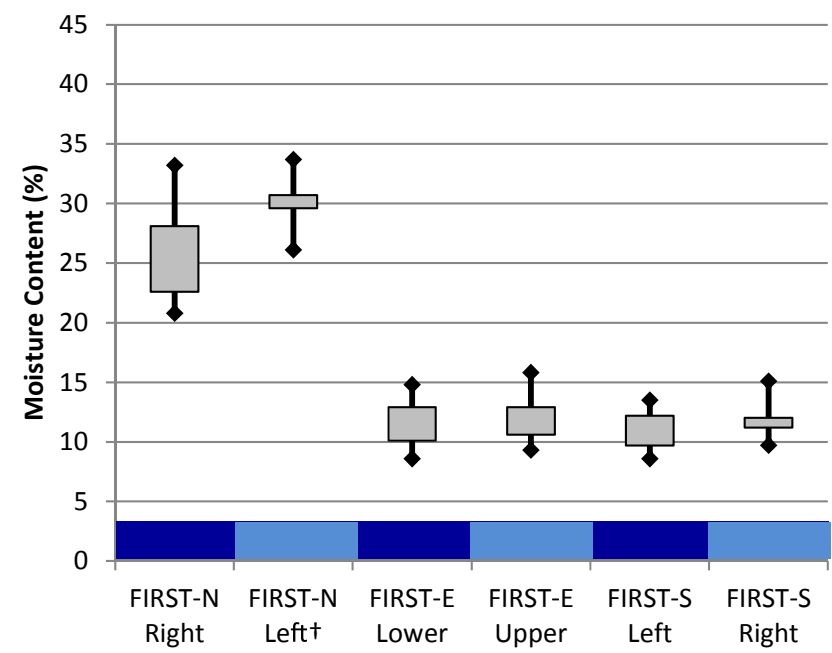

Figure 65. Box/whisker plot for joist end MCs; unheated first-floor joists

$\dagger$ : FIRST-N Left: Data before March 30, 2014 are not plotted due to electrical anomalies.

The north-facing joist (FIRST-N) had high MCs (typically 20\%-30\%), but not as high as the basement. In contrast, the east- and south-facing joists (FIRST-E, FIRST-S) were well within the 
safe range $(10 \%-15 \%)$. The east- and south-facing joists also showed minimal seasonal variation.

Figure 66 shows the basement heated-area joists; however, the wintertime set point was $50^{\circ}-75^{\circ} \mathrm{F}\left(10^{\circ}-24^{\circ} \mathrm{C}\right)$ with wide temperature fluctuations (the jobsite was open 3 days per week).

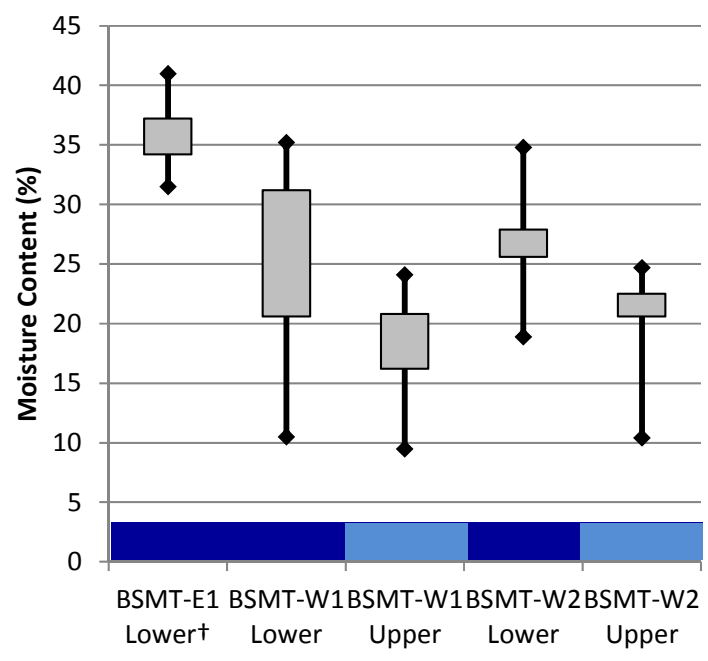

Figure 66. Box/whisker plot for joist end MCs; heated basement joists

$\dagger$ : BSMT-E1 Lower: Data before October 14, 2013 are not plotted due to electrical anomalies.

These joist ends showed a quick wintertime MC drop when interior heating was added. These joist ends showed wide seasonal swings; summer conditions were wetter and winter conditions were drier. However, the west-facing joists did not dry in winter 2014-2015, unlike previous winters. The east-facing joist end was wetter than the west-facing joists; BSMT-E2 was shaded by the building geometry. Figure 65 also clearly shows the difference between the upper and lower joist end measurements.

\subsection{Field Monitoring Conclusions}

\subsubsection{Moisture Content Overview}

Overall, the RHs and MCs measured in joist pockets were higher than the recommended range for long-term durability. Many of the joist pockets had sustained conditions of $100 \% \mathrm{RH}$, and many MCs were 25\%-35\% for extended periods. ASHRAE 160 analysis showed that high RH levels coincided with temperatures that were high enough to support mold growth for most of the monitoring period $(60 \%-70 \%$ of the hours) in most of the joists.

\subsection{2 “Mothballed" Conditions and Wood Durability}

Interpretation of the high MCs must be tempered by the operating conditions of the building. It was unheated for at least 2 years; during construction, heating has been intermittent and occurs only in parts of the building. Therefore, in many cases, the measured MCs reflect the "mothballed" condition of the building rather than its true operating condition. The joists would have come into equilibrium with cold and wet conditions in past years, which would have resulted in high MCs. However, a valid counterargument is that unoccupied, unheated conditions are not atypical for mass masonry buildings that are undergoing renovation. 
The data and stub measurements indicate that joists might have started at high MC levels before they were insulated and air sealed. No evidence of decay or damage was seen at the joist ends while the sensor pins were drilled, the joists ends were inspected, or the stub was examined. This lack of evidence suggests these wood members - especially dense, old-growth (1906 and 1930 construction) lumber - might be able to survive these MCs without damage. Apparently, this is even true for a species (Balsam fir) that is classified as "slightly resistant to nonresistant to decay" (the lowest of four categories).

\subsubsection{Orientation Effects}

Orientation has a major effect on RH and MC levels: all south-facing joists had MCs well within the safe range due to solar heating and drying. The east and west orientations had mixed results: some were in the safe range, but others exceeded the $20 \% \mathrm{MC}$ level. The north-side joists consistently had the highest MCs. Based on the measured temperatures, the consistent elevated temperatures in walls with solar exposure appear to be a factor in lower MCs.

\subsubsection{Seasonal Swings}

Almost all the joists showed a seasonal rise and fall; MCs and RHs were higher during the summer and lower during the winter. These changes are consistent with the hygrothermal simulations done by Ueno (2012), which showed moisture being driven inward during the summer due to the temperature gradient. In other words, during warm exterior conditions the temperature gradient would push moisture stored in the masonry inward where it can wet the outer portions of the embedded joist members.

One common durability assessment is to determine whether the seasonal year-over-year MC pattern is rising or falling. Unfortunately, some of the joist ends show rising MC patterns. However, interior heating at normal set points in the future may change the behavior.

\subsubsection{Response of Heated and Insulated Joists}

In the parts of the building that had significant wintertime heating, many joists had MC drops that coincided with the addition of heat, even after insulation and air sealing. This is corroborated by the fact that joists further from the heat source had reduced or slower drying. However, the response was muted during the final winter (2014-2015), possibly because interior gypsum board was installed.

\subsubsection{Upper and Lower Joist End Comparison}

Joist end MC measurements demonstrated a repeated pattern at the upper and lower parts of the member. The lower joist end was consistently wetter than the upper joist end, which can be attributed to contact with the masonry pocket, gravity drainage of bulk water to the bottom of the pocket, greater drying at the top of the beam or deeper embedment at the bottom of the beam, or a larger air pocket at the top of the beam. The cheek measurements were drier than the joist end measurements in almost all cases due to greater hygrothermal connection to interior space than the masonry pocket. These patterns were seen both in the monitoring and the stub measurements.

Another potential explanation for the higher MCs at the lower joist location is migration of salts from the masonry into the wood, which would increase the apparent MC due to electrical conductivity changes. This could be ascertained in this building in the future by analyzing the salt content in drilled wood shavings and performing gravimetric measurements of cut samples. 


\subsubsection{Sealing of Joist Pockets}

Ongoing construction through the monitoring period allowed for comparisons of the joist pockets before and after insulation and air sealing. The joists often showed increased MCs and RHs associated with insulation and air sealing; these increases are entirely logical, because they couple the wood to the damp masonry rather than to interior conditions (and possible drying). However, in an occupied building with higher interior RH levels during the winter, this connection to the interior could increase (rather than decrease) moisture levels. The air sealing also reduced the variability of the RH measurements, because the wood was coupled to the hygric mass of the masonry.

\subsubsection{Wind-Driven Rain}

Wind-driven rain on the exterior masonry can significantly affect joist MCs (Morelli et al. 2010). Joists were compared in an attempt to examine this effect (e.g., BSMT-W1 versus BSMT-W2); however, these selected joists showed no signs of differential wetting. Joist end MCs were also compared with calculated driving rain (Figure 45) and showed little correlation. Based on previous work (Ueno and Straube 2008), wood MCs often have a relatively slow response, especially when the wood adsorbs or gains moisture. In a crack-free façade, rain is more likely to have seasonal effects; the façade is unlikely to respond to individual wind-driven rain events.

\subsubsection{Hollow Clay Block Walls}

Weak evidence suggests that floor members that are embedded in hollow clay block (as opposed to brick) have drier joist ends; the first-floor joists had lower MCs than their corresponding basement joists. This difference is logical, given the network of airspaces and potential avenues for drainage and moisture redistribution in hollow block walls. This variance is also consistent with 1930s literature on clay block walls, which describes their advantages over solid masonry walls for reducing water penetration (White 1934).

Each block of hollow tile consists of a sort of clay box divided by interior webs or partitions so that a wall built of hollow tile is honeycombed with holes. These holes, or cells, are excellent in many ways. ... These cells also prevent the penetration of water through the walls.

It is claimed that interior plastering can be safely applied directly to the hollowtile blocks, thus saving the cost of furring and lathing. It is not considered good practice to plaster directly upon the inner surface of a solid brick or stone wall, as dampness often works its way through and is apt to stain the surface of the plaster and to destroy decorations or papers that may be applied to the plaster.

However, the measured differences may be due to other factors; the small sample size is a limitation for drawing conclusions. The ideal experiment would have compared the hollow clay block joists with above-grade joists embedded in brick, but they were not available.

\subsubsection{Insulated versus Uninsulated Conditions}

The north-facing basement joists (BSMT-N1/N2/N3) did not show a significant or consistent difference between insulated and uninsulated conditions. Also, all three joist pockets essentially remained at a constant $100 \% \mathrm{RH}$. A difference will likely be seen between the cases once the building is occupied, which will create a greater temperature difference across the wall. More 
representative interior RH levels will show whether the insulated but air- and vapor-open joist pocket (BSMT-N3) has risks of condensation. The joist stub measurements showed that high MCs can occur in uninsulated joist pockets. 


\section{Guidance for Retrofit Projects}

\subsection{Background}

Given the uncertainty revealed by the research, definitive guidance on the vulnerability of embedded wood members (i.e., simple go/no-go criteria) is difficult to formulate. Overall, many of the joist ends operated consistently at high MCs; the joist pockets had high RH (100\%). These factors suggest that the embedded members are at risk of moisture problems and potential degradation of their structural properties.

However, as mitigating evidence, Morelli and Svendsen (2012) conducted a literature review that covered multiple field studies. Those field studies found that driving rain alone did not cause moisture problems at beam ends. The researchers found that cracks in the façade could cause problems, but crack-free façades had acceptable performance.

As general guidance, reducing the water exposure of the masonry wall through careful rainshedding details, repointing, and other maintenance is critical to minimize risks at the beam pockets. Cracks in the façade near the beam and joist ends must be addressed before considering retrofit insulation. Visible evidence of water penetration at the embedded member (Figure 67) shows a clear need to address outdoor water shedding details and inspect the wood conditions.
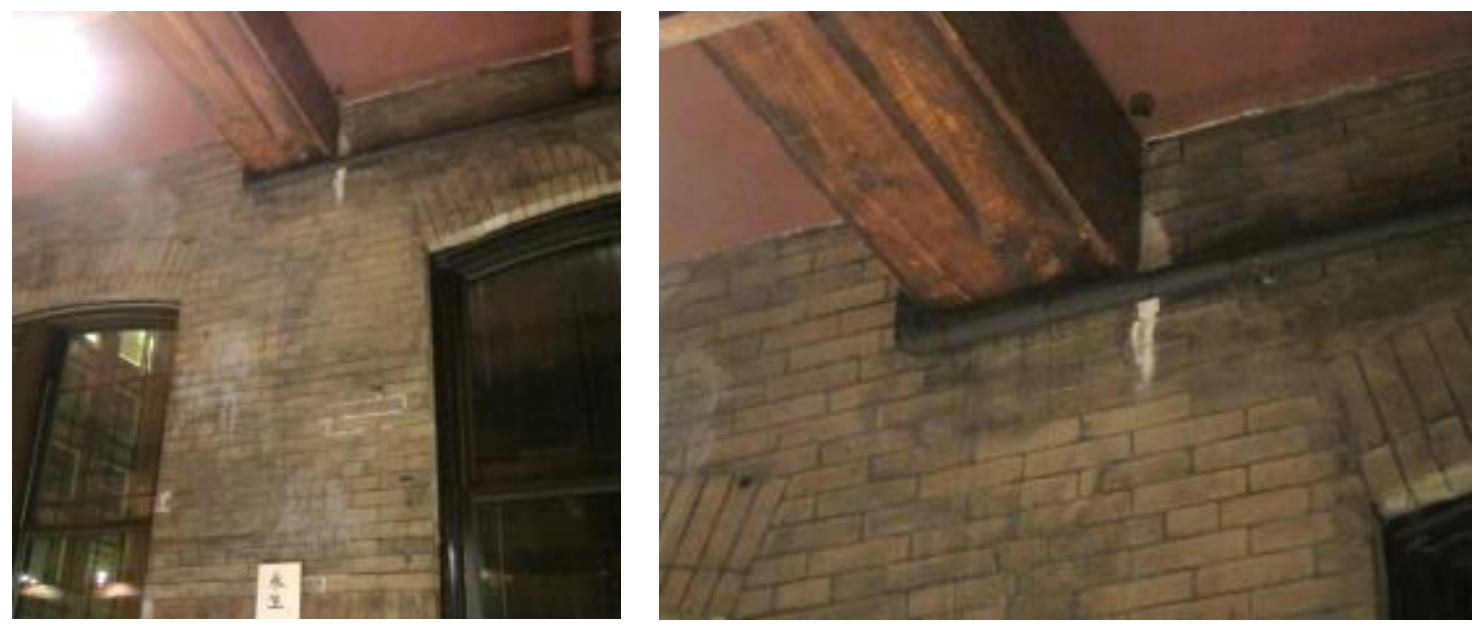

Figure 67. Evidence of water penetration at embedded beam end in masonry

Other mitigating factors are the durability of the old-growth wood that is typically used in these mass masonry buildings (discussed in Section 7.3.2) and the substantial structural redundancy of many of these older buildings.

\subsection{Risks to Joist Ends Near and Below Grade}

One high-risk condition for embedded beam or joist ends is proximity to grade, or worse, placement below grade. For reference, the test building in Massachusetts had good separation ( $\sim 4 \mathrm{ft}$.) from the exterior grade to the basement ceiling framing. Risks to below-grade framing were shown in Figure 12; eliminating the beam pocket condition would be a prudent step.

Embedded wood members near grade are vulnerable to moisture from splashback and capillarity. 
Splashback would be predominantly precipitation shed from the roof, which in turn wets the exterior wall surface near the grade.

Another moisture source is capillarity from ground contact. Lstiburek (2007) provided recommendations for adding a stainless steel reglet element into the masonry (to cut the capillary uptake path) in various configurations, depending on the dimensions of the exposed above-grade part of the wall (see Figure 68). This detail also includes the use of a sacrificial mortar parge coat to deal with the efflorescence and subfluorescence effects of capillary flow.
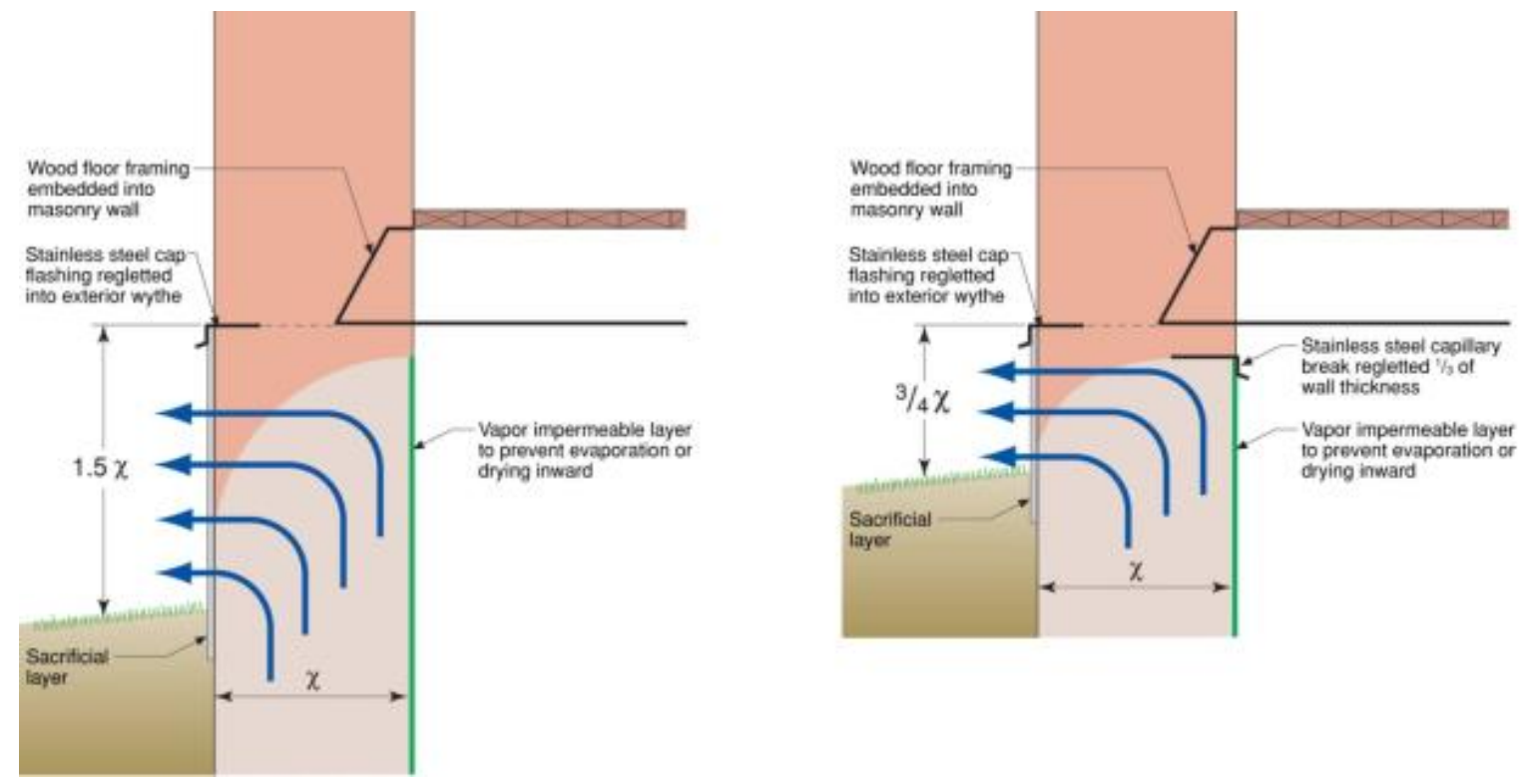

Figure 68. Guidance on protection of embedded floor framing near grade

Source: Lstiburek (2007)

Similar protection could be gained by eliminating capillary contact between the below-grade wall and the exterior grade; this would be done by excavating and waterproofing the exterior (e.g., Figure 69, which shows roofing membrane attached to the masonry below grade). This operation could also be accompanied by the addition of a drainage mat on the exterior (an air gap membrane) or possibly exterior insulation.
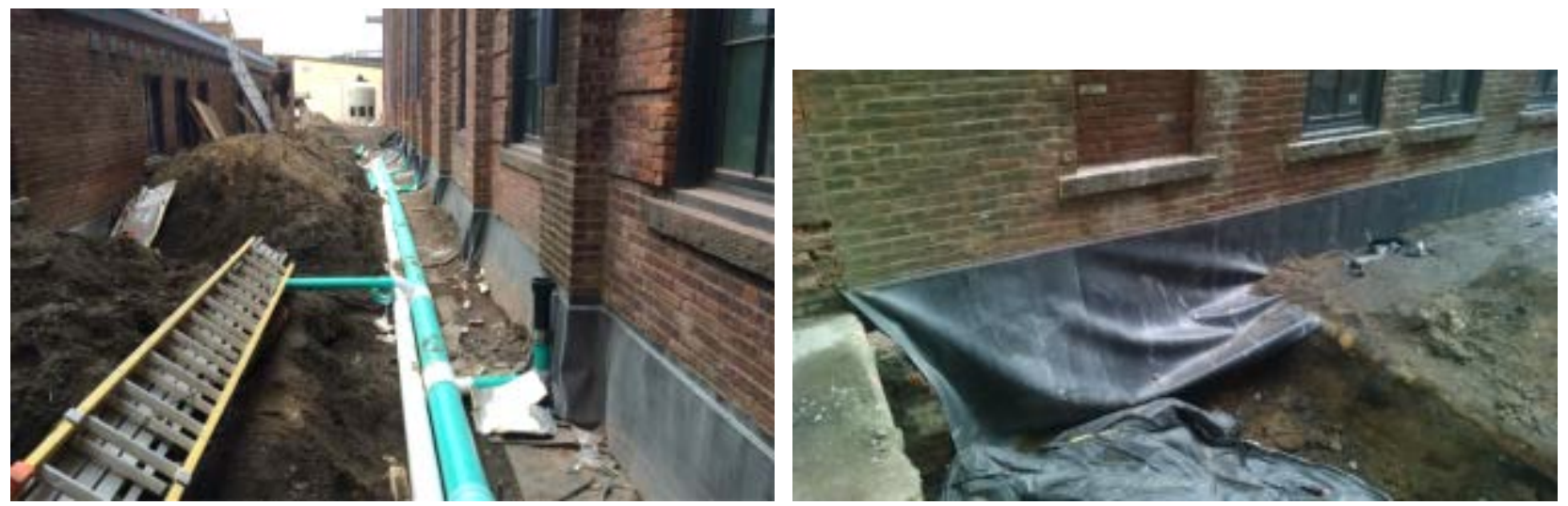

Figure 69. Exterior excavation of masonry building with water shedding detail below grade 


\subsection{Uninsulated Beam or Joist End Option}

One option researched by Morelli et al. (2010) was to eliminate interior insulation at the beam or joist ends so the beam ends operate at temperatures similar to preretrofit conditions. Of course, an energy penalty is associated with this detail, because each floor has a continuous thermal bridge. It could be considered a relatively defensible strategy, because the conditions of the joist ends have not been changed by the retrofit.

One caution, though, to this strategy is that although the assembly conditions are mostly unchanged, interior conditions may be different. An interior retrofit will often result in greater building airtightness; also, many retrofits are a change in use (e.g., industrial/mill to residential). These changes will result in higher wintertime RHs, because they retain interior moisture generation.

Ueno (2012) performed three-dimensional thermal simulations of joists in masonry (Figure 70); the image shows color-key temperatures for the uninsulated (left) and insulated (right) cases. The image shows the results of a static thermal simulation with an indoor temperature of $68^{\circ} \mathrm{F}\left(20^{\circ} \mathrm{C}\right)$ and an outdoor temperature of $7^{\circ} \mathrm{F}\left(-14^{\circ} \mathrm{C}\right)$. The masonry wall is removed from the image to show wood surface temperatures.
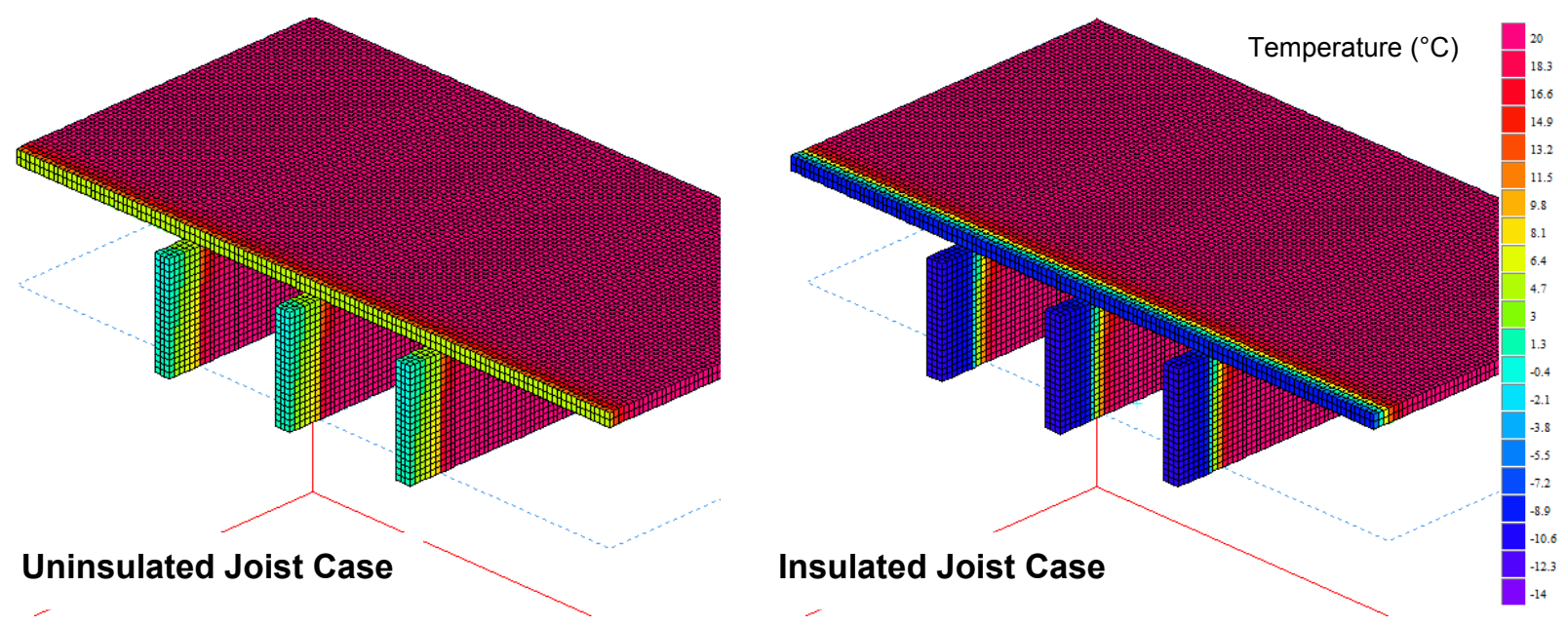

Figure 70. Thermal simulation of uninsulated and insulated joists in masonry

Source: Ueno (2012)

Of course, adding insulation reduces pocket and joist end temperatures. However, even in the uninsulated case the joist end pocket will be colder than interior set point: it shows temperatures of $31^{\circ}-37^{\circ} \mathrm{F}\left(-0.4^{\circ}\right.$ to $\left.3^{\circ} \mathrm{C}\right)$. These temperatures are cold enough to cause condensation at typical interior $\mathrm{RH}$ conditions; $31^{\circ}-37^{\circ} \mathrm{F}$ is equivalent to $12 \%-30 \% \mathrm{RH}$ at typical interior temperatures. Higher RH levels could cause condensation at cold temperatures.

Therefore, if the "no insulation at the beam or joist end" option is chosen, an interior liquidapplied air barrier must be carefully detailed around the penetrations to prevent air leakage into the joist or beam pocket (see Figure 71). 


\subsection{Exterior Insulation of the Beam or Joist Ends}

If exterior aesthetic changes are permissible, a possible retrofit would be to apply exterior insulation (e.g., foam insulation exterior insulation finishing system) in a band at the embedded wood members (Figure 71). This exterior insulation tends to warm the joist ends during the winter and reduce the risk of moisture-related damage. It is also likely to reduce the wetting of the masonry at the joist end. Note the sloped reglet drip edge at the top of the insulation band detail, which ensures the applied detail, does not introduce additional water into the wall at this location.

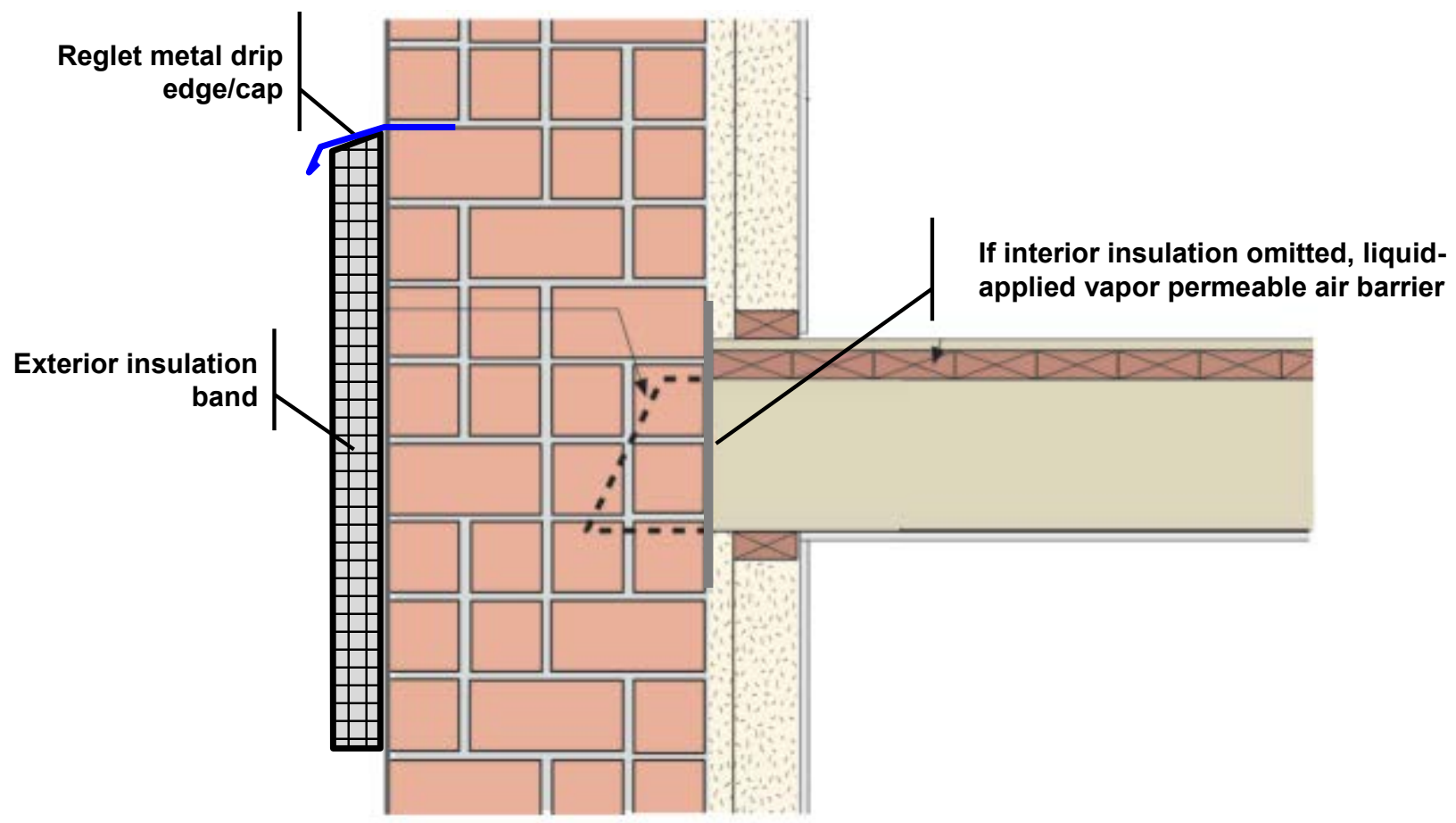

Figure 71. Conceptual sketch of exterior insulation at embedded floor members

Insulation at the embedded members may be omitted at the interior, as shown in the diagram, which will keep the joist end closer to interior temperatures (warmer during the winter). However, this should be done only if air barrier continuity is ensured by some other means such as a liquid-applied vapor-permeable air barrier.

The exterior and interior insulation should overlap to control thermal bridging at the discontinuity in insulation. Two-dimensional thermal modeling can provide guidance on the heat loss associated with various geometries. Previous thermal modeling has shown that an overlap of 1-2 ft provides reasonable thermal control at typical code insulation levels (Wytrykowska et al. 2012).

\subsection{Joist End Encapsulation}

One method under discussion was to protect the embedded end of the beam with a moistureresistant coating or material, which would isolate it from the masonry-sourced moisture. One concept was to inject a robust liquid sealant, such as two-component polyurea (the same chemistry as a spray-on truck bed liner). However, this approach is not recommended: retrofit injection into the cavity between the joist end and the masonry is uninspectable, and the cavity 
dimensions vary widely, so a consistent coating thickness cannot be ensured. More importantly, if the coating has imperfections, this technique would trap moisture within the wood if wetting ever occurs.

Indications of poor performance are consistent with historical examples. In the early 1900s, some beams ends were nominally protected by sealed sheet metal or cast-iron boxes that lined the masonry pocket (Friedman 2010). However, the author reported the 1909 collapse of a six-story factory due to rot of the beam ends. The rot was attributed to trapped water in the sealed metal box and resulting fungal growth.

\subsection{Joist End Preservation (Borate Rods)}

Decay risks can be reduced by protecting the joist ends with a preservative; one method used in outdoor structures is to install solid borate rods (Figure 72, left). Borate preservative can control insect infestation and fungal decay. This method is discussed by Lebow et al. (2012) as used on exposed wood bridge timbers. The preservative rods are commercially available and are composed of borate salts that are melted and cast into glass-like rods. The rods are installed into the core of the beam or joist via a hole drilled from the accessible side (Figure 72, right).
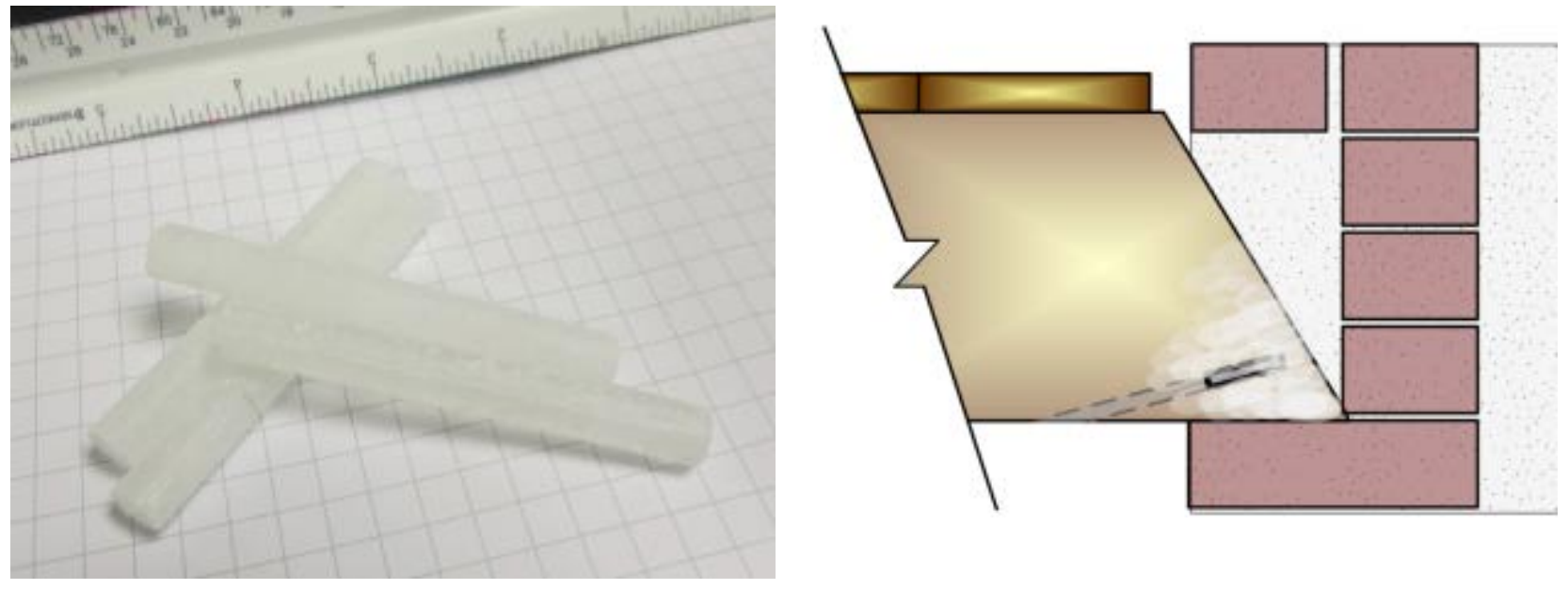

Figure 72. Borate rods (left); diffusion of borate into wood at joist end (right)

The borate salts diffuse or migrate from the rod in the presence of moisture; Lebow et al. (2012) state a minimum $30 \% \mathrm{MC}$ is needed for migration; the salts diffuse more rapidly at an $\mathrm{MC}$ that exceeds $40 \%$. The diffusion rate is also a function of wood species, and diffusion occurs more rapidly along the length of the wood grain. Therefore, the authors recommend installing the rods in areas where the wood will be wetted to allow for diffusion protection.

Typical guidance for spacing borate rods in southern pine is a maximum of 3 in. $(75 \mathrm{~mm})$ across the grain and 3-5 in. (75-125 $\mathrm{mm}$ ) along the grain. Manufacturers provide guidance on the size, number, and spacing of borate rods. Based on these figures, a single rod at the end of a 2-in. dimension joist end can protect the bottom part of the joist end.

The cost of this treatment is reasonable; borate rods retail at about $\$ 3$ each; most of the cost may be in installation labor rather than materials. 
A borate rod installation is recommended over a liquid borate treatment (an alternative treatment described by Lebow et al. 2012), because access will typically be available from below the joist or beam, which is a difficult geometry for pouring a liquid preservative into a vertical hole. Solid rod treatment also provides longer-term protection than liquid or paste treatments.

An additional benefit of this technique is that drilling the installation hole provides some indication of the structural condition of the embedded joist end and whether rot or decay is currently occurring.

One concern, though, is that if the joist end is extensively wetted (e.g., bulk rain leakage), the borate will be exhausted over time. Replacement of borate rods over the lifetime of the building seems unlikely. However, substantial amounts of water are required to completely dissolve borate rods; this seems unlikely in typical service conditions. Manufacturers describe rod life in years, but actual durability is likely a function of the degree of wetting.

\subsection{Elimination of Embedded Beam Condition}

In high-risk situations, cases with significant water damage or decay to the beam ends, or when a very conservative approach is warranted, the embedded wood member condition can be eliminated entirely. Figure 73 shows the starting geometry; joists are embedded in a solid brick wall with interior spray foam insulation.

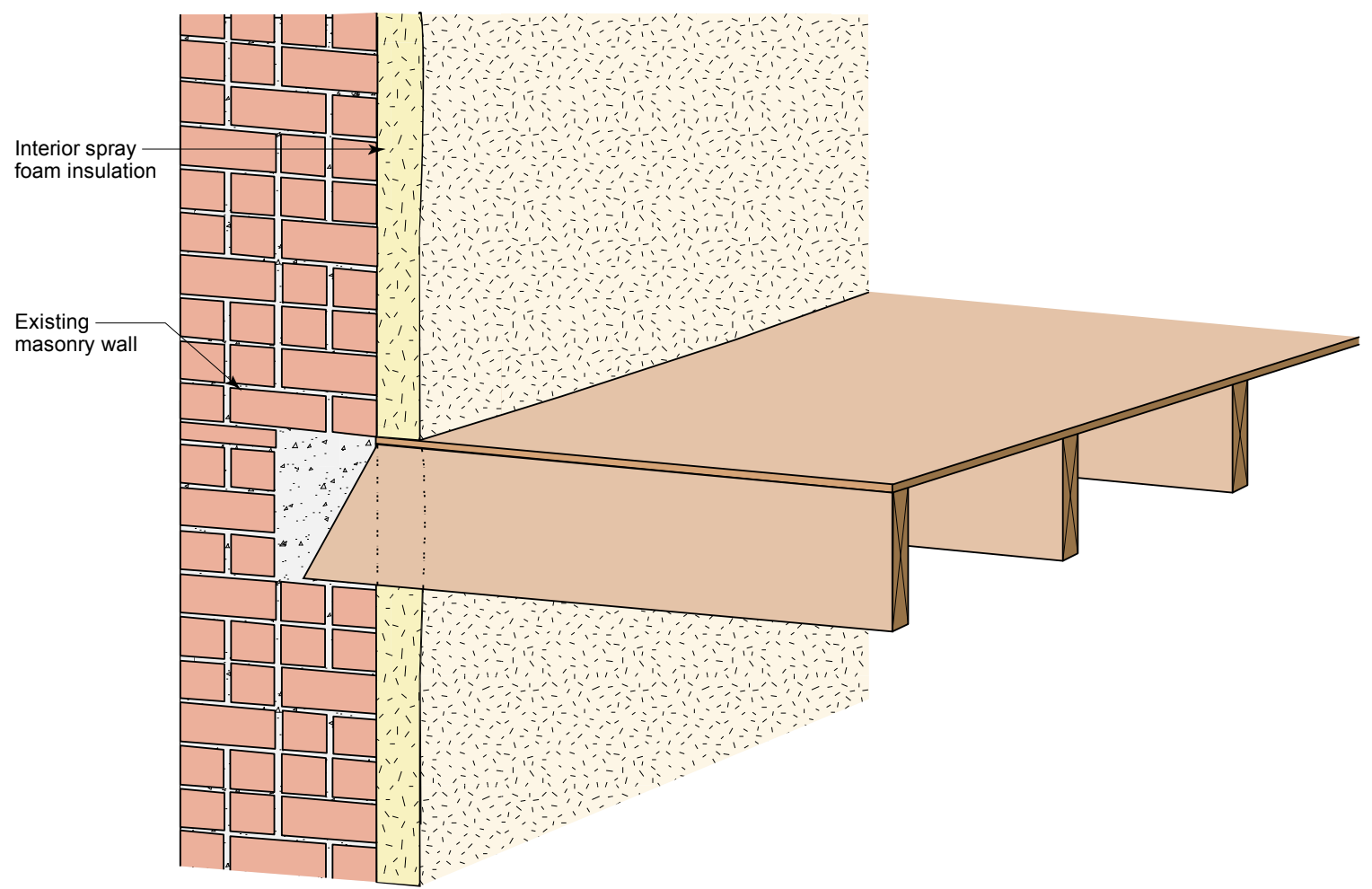

Figure 73. Conceptual sketch of embedded joist geometry with interior insulation

In general, the most conservative approach is to cut off the embedded tail of the joist and support the floor structure from another point. This cut eliminates capillary contact (wicking) from the wet embedded beam or joist end into the remainder of the wood. Ideally, a capillary break (self- 
adhered membrane, foam sill seal) would be installed at the cut between the embedded tail or stub and the joist. Leaving the embedded tail attached might be a reasonable (albeit less conservative) approach, assuming that wetting is not significant enough to spread along the length of the wood. However, cheek MC measurements indicated this moisture might spread somewhat.

The joists or beams must then be supported. International Residential Code (ICC 2009a) requirements for wood floor framing support are cited below, with minimum bearing distances (1.5 in. on wood or metal, 3 in. on masonry or concrete). The International Residential Code also requires lateral (antirotation) restraint at the joist ends in the form of blocking or a band joist:

R502.6 Bearing. The ends of each joist, beam or girder shall have not less than 1.5 inches $(38 \mathrm{~mm})$ of bearing on wood or metal and not less than 3 inches (76 mm) on masonry or concrete except where supported on a 1-inch-by-4-inch (25.4 $\mathrm{mm}$ by $102 \mathrm{~mm}$ ) ribbon strip and nailed to the adjacent stud or by the use of approved joist hangers.

R502.7 Lateral restraint at supports. Joists shall be supported laterally at the ends by full-depth solid blocking not less than 2 inches $(51 \mathrm{~mm})$ nominal in thickness; or by attachment to a full-depth header, band, or rim joist, or to an adjoining stud or shall be otherwise provided with lateral support to prevent rotation.

Figure 74 shows the option of using joist hangers that are attached to the masonry wall to support the members.

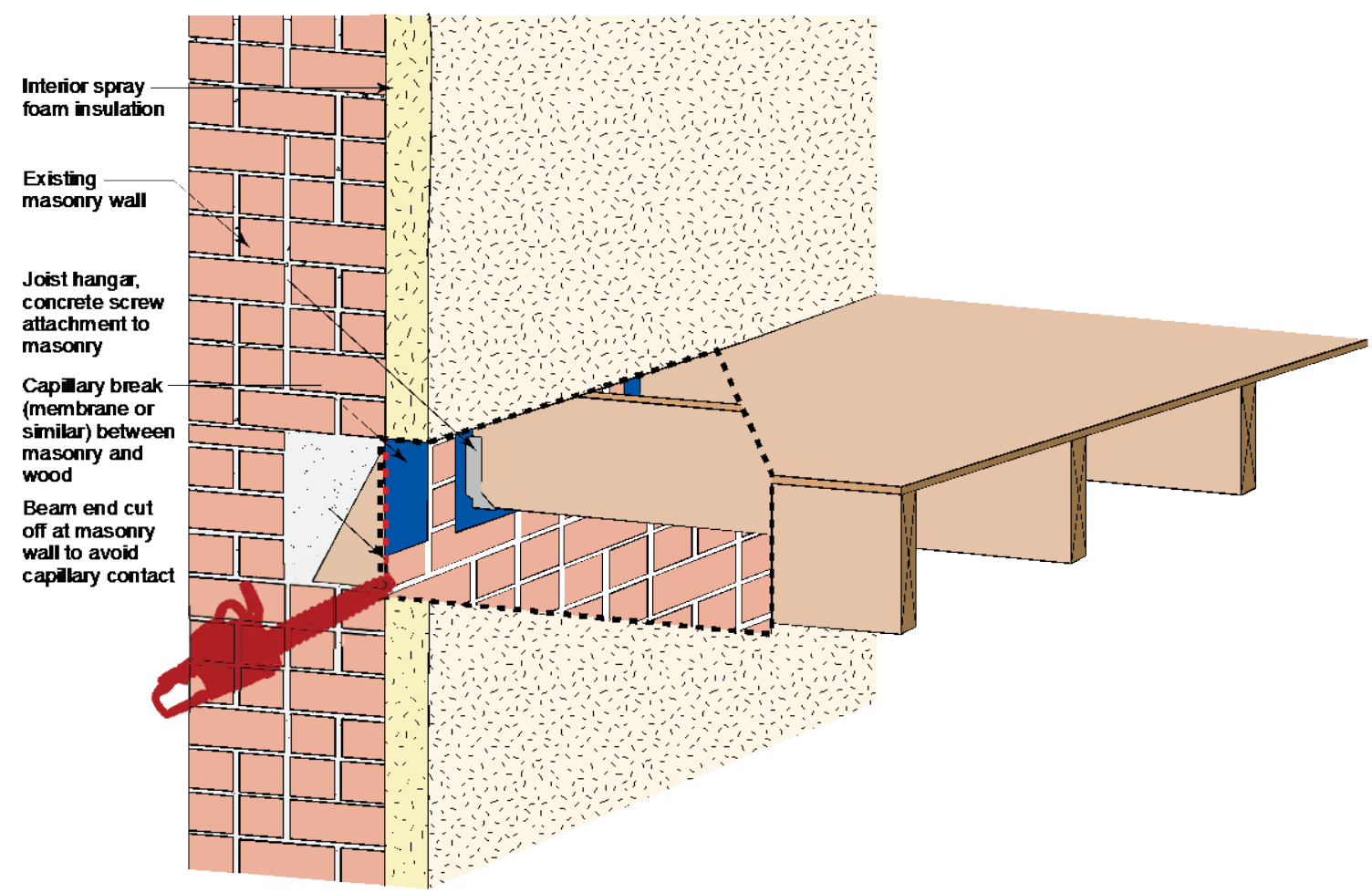

Figure 74. Conceptual sketch of joist hanger retrofit option 
The joist hangers might be installed using self-tapping concrete screws (see Figure 75, left) if these fasteners are structurally acceptable. Most historic buildings also have full 2-in. roughsawn dimension framing lumber; joist hangers that accept a 2 -in. dimension are commercially available (typically labeled "face mount hangers-rough lumber").
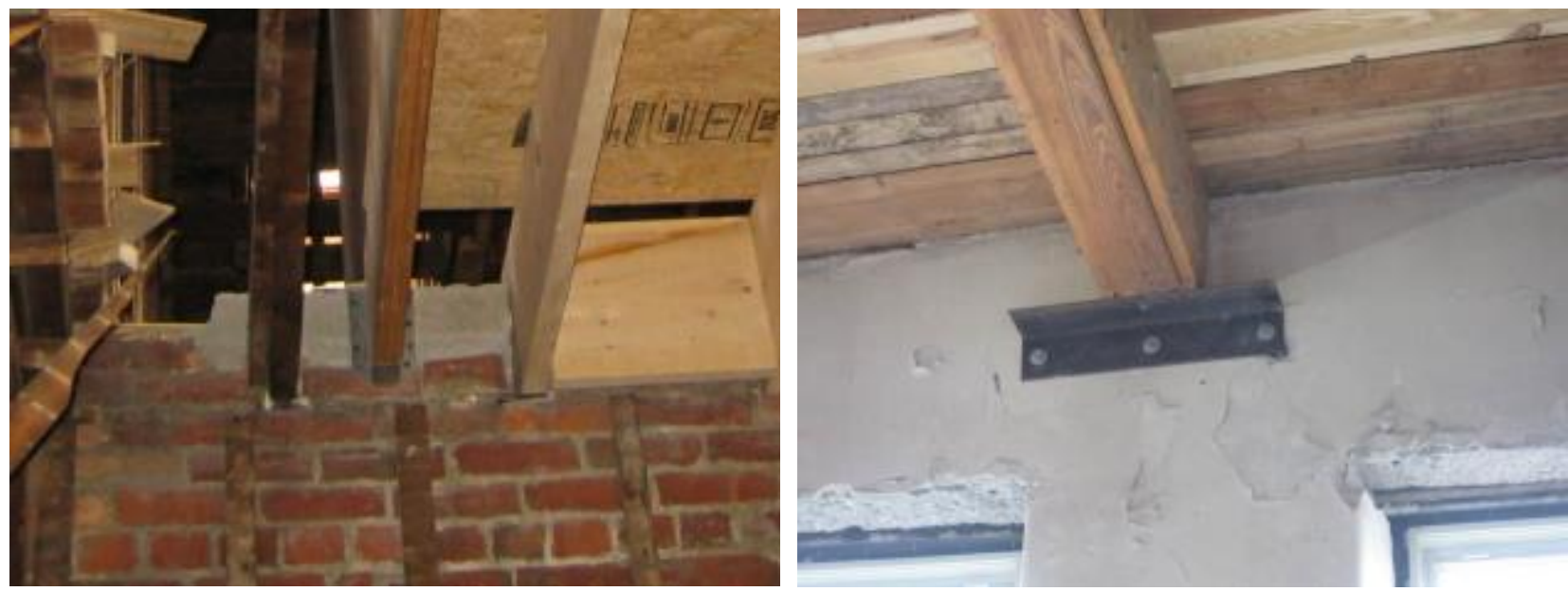

Figure 75. Transfer of load from masonry using joist hanger (left) or structural angle (right)

Another option is to use some type of a steel angle bolted to the masonry (Figure 75, right and Figure 76). The size and fastener spacing should be determined by a structural engineer. This system will require the installation of lateral restraint or antirotation blocking between the joists. A wood ledger could also be installed in a similar manner, but a capillary break (self-adhered membrane, foam sill seal) between the wood and the masonry is recommended.

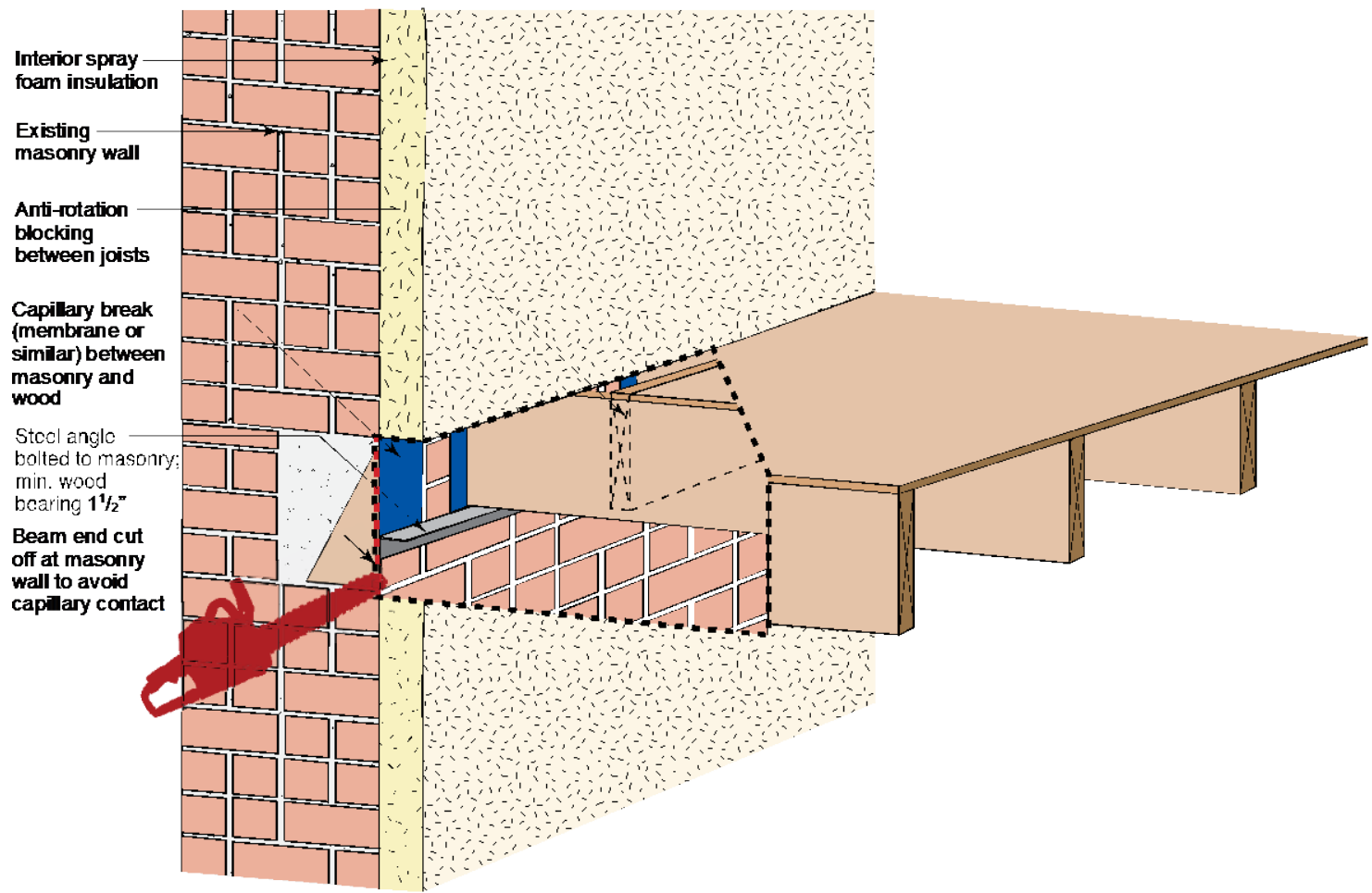

Figure 76. Conceptual sketch of steel angle retrofit option 
Finally, if the structure below has sufficient capacity, the joists could be supported with a structural wood frame wall inboard of the masonry (Figure 77). The bearing structure may need to be reinforced (e.g., retrofit of strip footings in basement condition). If only the first-floor framing is being retrofitted in this manner (i.e., vulnerable framing close to grade), the bearing wall needs to support the load of only one floor.

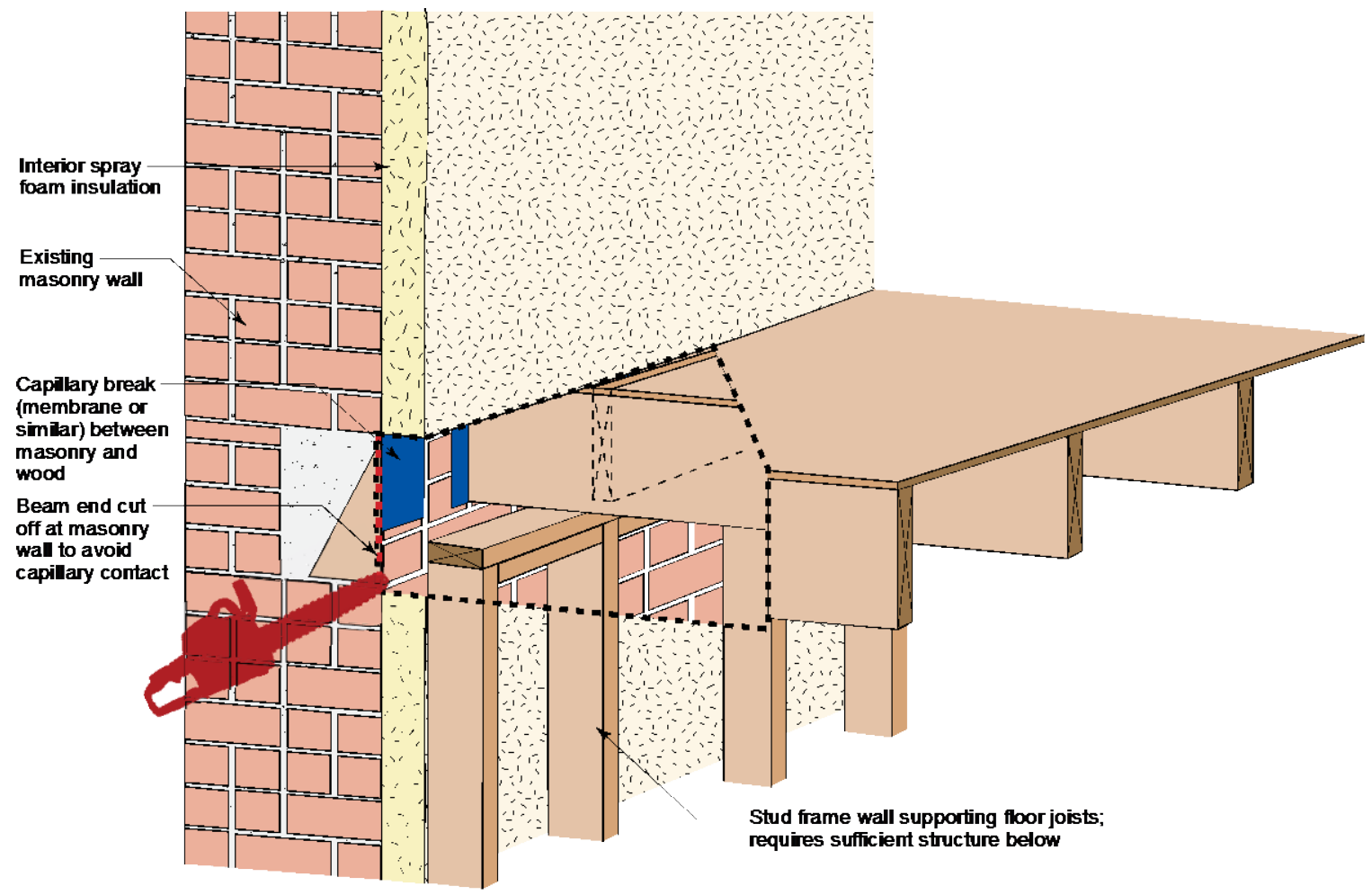

Figure 77. Conceptual sketch of interior bearing wall retrofit option 


\section{References}

Arena, L. 2014. “ASHRAE 160: Modeling and Measured Data.” Building America Expert Meeting 2014: Guidance on Modeling Enclosure Design in Above Grade

Walls. http://www.buildingscience.com/documents/bareports/ba-1403-guidance-modelingenclosure-design-above-grade-walls-expert-meeting/view.

Arena, L., D. Owens, and P. Mantha. 2013. "Measured Performance of an R-40 DoubleStudWall in Climate Zone 5A" Buildings XII Conference Proceedings. Atlanta, GA: American Society of Heating, Refrigerating and Air-Conditioning Engineers, Inc.

ASHRAE. 2009. ANSI/ASHRAE Standard 160-2009: Criteria for Moisture-Control Design Analysis in Buildings. Atlanta, GA: American Society of Heating, Refrigerating and AirConditioning Engineers, Inc.

ASHRAE. 2011. ANSI/ASHRAE Standard 160-2009: Criteria for Moisture-Control Design Analysis in Buildings: Addendum a. Atlanta, GA: American Society of Heating, Refrigerating and Air-Conditioning Engineers, Inc.

Carll, C.G., and T.L. Highley. 1999. "Decay of Wood and Wood-Based Products Above Ground in Buildings." Journal of Testing and Evaluation 27(2): 150-158.

[DOE] U.S. Department of Energy. 2011. Enclosures Standing Technical Committee Strategic Plan, v2011a, Revised: December 2011. http://energy.gov/sites/prod/files/2013/12/f5/ strategic_plan_enclosures_2_12.pdf Accessed August 2014.

Dumont, R., L. Snodgrass, J. Kokko, and C. Schumacher. 2005. "Field Measurement of Wood Moisture Contents in Wood Joists Embedded in Masonry Exterior Walls." Proceedings of the 10th Annual Conference on Building Science and Technology. Ottawa, ON.

FPL. 1987. The Encyclopedia of Wood. New York: Sterling Publishing Company, Inc.

FPL. 2010. Wood Handbook-Wood As an Engineering Material (Technical Report). Madison, WI: Forest Products Laboratory, FPL-GTR-190.

Friedman, D. 2010. Historical Building Construction: Design, Materials, \& Technology. New York: W.W. Norton Company.

Gonçalves, M.D. 2003. "Insulating Solid Masonry Walls.” Ninth Conference on Building Science and Technology, Ontario Building Envelope Council, Vancouver, BC, pp. 171-181.

ICC. 2009a. International Residential Code for One- and Two-family Dwellings. Country Club Hills, IL: International Code Council.

ICC. 2009b. International Energy Conservation Code. Country Club Hills, IL: International Code Council.

James, W.L. 1975; revised 1988. Electrical Moisture Meters for Wood (Technical Report). Madison, WI: Forest Products Laboratory, FPL-GTR-6. 
Lebow, S., G. Kirker, R. White, T. Amburgey, H.M. Barnes, M. Sanders, and J. Morrell. 2012. Guide for In-Place Treatment of Wood in Historic Covered and Modern Bridges (Technical Report). Madison, WI: Forest Products Laboratory, FPL-GTR-205.

Lstiburek, J. 2007. "Building Sciences: Capillary Suction-Small Sacrifices.” ASHRAE Journal 49: 58-61). Atlanta, GA: American Society of Heating, Refrigerating and Air-Conditioning Engineers, Inc.

Lstiburek, J. 2008. "Building Sciences: Energy Flow across Enclosures." ASHRAE Journal 50: 60-65. Atlanta, GA: American Society of Heating, Refrigerating and Air-Conditioning Engineers, Inc.

Maurenbrecher, A.H.P., C.J. Shirtliffe, M.Z. Rousseau, and M.N.A. Saïd. 1998. "Monitoring the Hygrothermal Performance of a Masonry Wall with and Without Thermal Insulation." Proceedings of the 8th Canadian Masonry Symposium (Jasper, Alberta), pp. 174-193 (NRCC42462).

Morelli, M., and S. Svendsen. 2012. "Investigation of Interior Post-Insulated Masonry Walls with Wooden Beam Ends.” Journal of Building Physics, June 2012 0(0) 1-29. Thousand Oaks, CA: SAGE Publications.

Morelli, M., G.A. Scheffler, T.R. Nielsen, and S. Svendsen. 2010. "Internal Insulation of Masonry Walls with Wooden Floor Beams in Northern Humid Climate." Performance of the Exterior Envelopes of Whole Buildings XI. Atlanta, GA: American Society of Heating, Refrigerating and Air-Conditioning Engineers, Inc.

Rudd, A. 2014. Evaluation of Crawlspace Retrofits in Multifamily Buildings. Somerville, MA: Building Science Corporation, accessed August, 2015: http://apps1.eere.energy.gov/buildings/ publications/pdfs/building_america/evaluation_crawlspace_retrofits.pdf

Scheffler, G.A. 2009. "Moisture Problems at Wooden Beam Ends after Building Renovation." LavEByg konference om strategi for lavenergirenovering, 22. April 2009, Hørsholm, Denmark.

Straube, J.F., and E.F.P. Burnett. 2005. Building Science for Building Enclosure Design. Building Science Press: Somerville, MA.

Straube, J.F., and C.J. Schumacher. 2002. Comparison of Monitored and Modeled Envelope Performance for a Solid Masonry Building. Ottawa, ON: Canada Mortgage and Housing, Report 63204.

Straube, J.F., and C.J. Schumacher. 2004. Hygrothermal Modeling of Building Envelopes Retrofits. Ottawa, ON: Canada Mortgage and Housing.

Straube, J.F., and C.J. Schumacher. 2007. "Interior Insulation Retrofits of Load-Bearing Masonry Walls in Cold Climates.” Journal of Green Buildings 2(2): 42-50.

Straube, J.F., D. Onysko, and C.J. Schumacher. 2002. "Methodology and Design of Field Experiments for Monitoring the Hygrothermal Performance of Wood Frame Enclosures." 
Journal of Thermal Envelope and Building Science 26(2), October. Thousand Oaks, CA: SAGE Publications.

Straube, J.F., K. Ueno, and C.J. Schumacher. 2012. Measure Guideline: Internal Insulation of Masonry Walls (Subcontractor Report)." Golden, CO: National Renewable Energy Laboratory, NREL/SR-5500-54163. www.nrel.gov/docs/fy12osti/54163.pdf.

Ueno, K. 2012. "Masonry Wall Interior Insulation Retrofit Embedded Beam Simulations." Proceedings of BEST 3 Conference, Atlanta, GA, April 2-4, 2012.

Ueno, K., and J. Lstiburek. 2015. "Field Monitoring of Cold Climate Double Stud Walls with Cellulose and Low-Density Foam Insulation." Proceedings of BEST 4 Conference, Kansas City, MO, April 13-15, 2015.

Ueno, K., and J. Straube. 2008. "Laboratory Calibration and Field Results of Wood Resistance Humidity Sensors." Proceedings of BEST 1 Conference, Minneapolis, June 10-12, 2008.

Ueno, K., R. Van Straaten, and C. Schumacher. 2013. Interior Insulation of Mass Masonry Walls: Joist Monitoring, Material Test Optimization, Salt Effects. Somerville, MA: Building Science Corporation, accessed July 31 , 2015: www.buildingscience.com/documents/bareports/ba-1307-interior-insulation-massmasonry-walls/view.

White, C. 1934. Hollow Tile: Advantages and Nature of Hollow Tile. Scranton, PA: International Textbook Company.

Wytrykowska, H., K. Ueno, and R. Van Straaten. 2012. Byggmeister Test Home-Cold Climate Multifamily Masonry Building Condition Assessment and Retrofit Analysis (Subcontractor Report). Golden, CO: National Renewable Energy Laboratory, NREL/SR-550053441. www.nrel.gov/docs/fy12osti/53441.pdf. 


\section{Appendix A: Testing and Monitoring Equipment}

The testing and monitoring equipment used at the embedded joist end moisture content monitoring work is as follows:

Table 2. Testing and Monitoring Equipment Specifications

\begin{tabular}{|c|c|}
\hline Measurement & Equipment and Specifications \\
\hline Temperature & NTC (negative temperature coefficient) thermistor, $\pm 0.2^{\circ} \mathrm{F}\left(0.1^{\circ} \mathrm{C}\right)$ \\
\hline Relative Humidity & $\begin{array}{c}\text { Thermoset polymer capacitive relative humidity sensor, } \\
\pm 3.5 \% \mathrm{RH}\end{array}$ \\
\hline Wood Moisture Content & $\begin{array}{l}\text { Electric resistance-based moisture content pin sensors } \\
\text { (see Appendix B) }\end{array}$ \\
\hline $\begin{array}{l}\text { Data Acquisition and } \\
\text { Collection }\end{array}$ & $\begin{array}{c}\text { Campbell Scientific CR1000 measurement and control system } \\
\text { with Campbell Scientific AM16/32B Multiplexers }\end{array}$ \\
\hline $\begin{array}{l}\text { Outdoor Temperature/ } \\
\text { Relative Humidity }\end{array}$ & $\begin{array}{c}\text { Campbell Scientific HMP } 60-\mathrm{L}-40^{\circ} \mathrm{F} \text { to } 140^{\circ} \mathrm{F}\left(-40^{\circ} \mathrm{C} \text { to }+60^{\circ} \mathrm{C}\right) \\
\text { range; } \pm 1.1^{\circ} \mathrm{F}\left(0.6^{\circ} \mathrm{C}\right) \text { accuracy; } \\
\text { RH accuracy at } 0^{\circ} \text { to }+40^{\circ} \mathrm{C} \text { : } \\
\pm 3 \% \mathrm{RH}(0 \%-90 \% \mathrm{RH}) ; \pm 5 \% \mathrm{RH}(90 \%-100 \% \mathrm{RH}) \\
\mathrm{RH} \text { Accuracy at }-40^{\circ} \text { to } 0^{\circ} \mathrm{C} \text { and }+40^{\circ} \text { to }+60^{\circ} \mathrm{C}: \\
\pm 5 \% \mathrm{RH}(0 \%-90 \% \mathrm{RH}) ; \pm 7 \% \mathrm{RH}(90 \%-100 \% \mathrm{RH})\end{array}$ \\
\hline Infrared Observation & $\begin{array}{c}\text { FLIR b40 Infrared Camera } \\
\left(-4^{\circ} \mathrm{F} \text { to } 248^{\circ} \mathrm{F}\left[-20^{\circ} \mathrm{C}\right] \text { to } 120^{\circ} \mathrm{C} \text { temperature range; }\right. \\
\pm 2^{\circ} \mathrm{C} \text { or } \pm 2 \% \text { of reading temperature accuracy) }\end{array}$ \\
\hline
\end{tabular}




\section{Appendix B: Wood Moisture Content Error Analysis}

\section{Electrical Resistance Circuit and Calculation of $\mathbf{R}_{\mathrm{w}}$}

The data acquisition system was a Campbell Scientific CR1000 measurement and control system with Campbell Scientific AM16/32B Multiplexers. Wood MC was measured via the electrical resistance of wood, using the circuit shown in Figure 78, and methods described by Straube et al. (2002). A nominal $12-\mathrm{V}$ excitation voltage is supplied by the data logger; the current runs through the wood and then the sense resistor $\left(\mathrm{R}_{\mathrm{S}}\right)$ in series. Voltage drop across the sense resistor is used to calculate the electrical resistance of the $\operatorname{wood}\left(\mathrm{R}_{\mathrm{w}}\right)$.

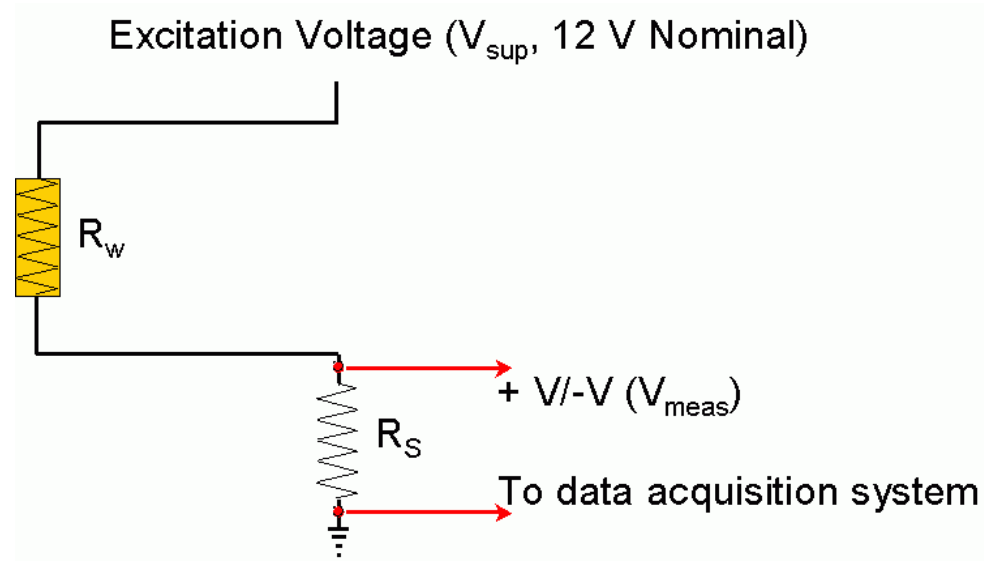

Figure 78. Schematic of resistance measurement circuit

The resistance of the wood is calculated using Equation 1 (based on the circuit in Figure 78).

Equation 1: Calculation of wood electrical resistance $\left(\mathbf{R}_{\mathrm{w}}\right)$

$$
R_{W}=\frac{R_{S}\left(V_{\text {sup }}-V_{\text {meas }}\right)}{V_{\text {meas }}}
$$

Where: $\quad \mathrm{R}_{\mathrm{W}}=$ resistance of wood

$\mathrm{R}_{\mathrm{S}}=$ sense resistor

$\mathrm{V}_{\text {sup }}=$ circuit supply voltage $(12 \mathrm{~V}$ nominal $)$

$\mathrm{V}_{\text {meas }}=$ measured voltage

\section{Error Analysis of Electrical Resistance Measurements}

The error of the wood electrical resistance measurement $\left(\mathrm{R}_{\mathrm{w}}\right)$ can be found as a function of the measurands and uncertainties $\left(\Delta \mathrm{R}_{\mathrm{S}}, \Delta \mathrm{V}_{\text {sup }}, \Delta \mathrm{V}_{\text {meas }}\right)$ per Equation 2 and Equation 3:

Equation 2: Calculation of electrical resistance error (step 1)

$$
\operatorname{Error}\left(R_{W}\right)=\sqrt{\left(\frac{\partial R_{W}}{\partial R_{S}} \Delta R_{S}\right)^{2}+\left(\frac{\partial R_{W}}{\partial V_{\text {Sup }}} \Delta V_{\text {Sup }}\right)^{2}+\left(\frac{\partial R_{w}}{\partial V_{\text {meas }}} \Delta V_{\text {meas }}\right)^{2}}
$$


Equation 3: Calculation of electrical resistance error (step 2)

$$
\operatorname{Error}\left(R_{W}\right)=\sqrt{\left(\frac{V_{\text {sup }}-V_{\text {meas }}}{V_{\text {meas }}} \Delta R_{S}\right)^{2}+\left(\frac{R_{S}}{V_{\text {meas }}} \Delta V_{\text {Sup }}\right)^{2}+\left(\frac{R_{S} V_{\text {sup }}}{\left(V_{\text {meas }}\right)^{2}} \Delta V_{\text {meas }}\right)^{2}}
$$

The inputs for these calculations follow:

- $\mathrm{V}_{\text {sup }}=$ circuit supply voltage: $12 \mathrm{~V}$ (nominal)

- $\mathrm{V}_{\text {meas }}=$ measured voltage: varies with wood $\mathrm{MC}$ (see Table 3)

- $\quad \mathrm{R}_{\mathrm{S}}=$ sense resistor: $10 \mathrm{k} \Omega(10,000 \Omega)$

- $\Delta \mathrm{V}_{\text {sup }}=$ circuit supply voltage error: measured by the data acquisition equipment with an accuracy of $0.01 \mathrm{~V}$.

- $\Delta \mathrm{V}_{\text {meas }}=$ measured voltage error: varies with wood $\mathrm{MC}$ (see Table 3$)$

- $\Delta \mathrm{R}_{\mathrm{S}}=$ sense resistor error: $\pm 1 \%$ precision resistors used (error $100 \Omega$ )

The voltage measurement accuracy of the Campbell equipment varies with the voltage measurement range. At a temperature range of $32^{\circ}-104^{\circ} \mathrm{F}\left(0^{\circ}-40^{\circ} \mathrm{C}\right)$ (the logging equipment was kept at room temperature conditions throughout this research), the error is $\pm 0.06 \%$ of reading + offset, where the offset is a function of the voltage range and measurement type (single-ended versus differential).

The error was calculated for moisture content ranges (and resistances) typical for this research in Table 3; the error is presented in terms of absolute value $(\Omega)$, and percentage of measurement.

Table 3. Calculation of Wood Resistance Error $\left(\Delta r_{w}\right)$ at Various Wood MC Levels

\begin{tabular}{c|c|c|c|c|c}
\hline $\begin{array}{c}\text { Wood } \\
\mathbf{M C}\end{array}$ & $\begin{array}{c}\text { Resistance } \\
\mathbf{R}_{\mathbf{w}}(\boldsymbol{\Omega})\end{array}$ & $\begin{array}{c}\text { Voltage } \\
\text { Measurement } \\
\mathbf{V}_{\text {meas }}(\mathbf{V})\end{array}$ & $\begin{array}{c}\text { Voltage } \\
\text { Measurement } \\
\text { Error } \boldsymbol{\Delta} \mathbf{V}_{\text {meas }}\end{array}$ & $\begin{array}{c}\text { Wood } \\
\text { Resistance } \\
\text { Error }\left(\mathbf{\Delta R}_{\mathbf{W}}\right) \\
(\boldsymbol{\Omega})\end{array}$ & $\begin{array}{c}\text { Error \% } \\
\text { Measurement }\end{array}$ \\
\hline $\mathbf{8 \%}$ & $5,240,169,344$ & 0.00002 & $3.01575 \mathrm{E}-06$ & $692,091,507$ & $13.2 \%$ \\
$\mathbf{1 2 \%}$ & $105,337,360$ & 0.0011 & $3.68945 \mathrm{E}-06$ & $1,110,734$ & $1.1 \%$ \\
$\mathbf{1 6 \%}$ & $10,032,756$ & 0.0119 & $1.01894 \mathrm{E}-05$ & 101,040 & $1.0 \%$ \\
$\mathbf{2 4 \%}$ & 601,088 & 0.196 & 0.000121023 & 6,044 & $1.0 \%$ \\
$\mathbf{3 2 \%}$ & 110,502 & 0.996 & 0.000602501 & 1,112 & $1.0 \%$ \\
\hline $\mathbf{4 0 \%}$ & 34,508 & 2.696 & 0.001624671 & 348 & $1.0 \%$ \\
\hline
\end{tabular}

The results in Table 3 indicate that error is typically about $1 \%$ for most MCs. However, at low MCs ( $8 \%)$, resistances become very high ( $\mathrm{G} \Omega$ range), and accordingly, voltages are very small $(20 \mu \mathrm{V})$. But as discussed in the section below, the resistance measurement has a much smaller effect on calculated wood MC measurements under dry conditions. In addition, low (or dry) MCs are of lower importance in building enclosure research: the key measurements occur during higher MCs, which are indicative of failures or problems. 


\section{Error Analysis of Moisture Content Measurements}

The end result of interest is the MC of the wood, as calculated from resistance measurements. The relationship used to obtain $\mathrm{MC}_{\text {uncorrected }}$ (not corrected for temperature or species) is taken from Straube et al. (2002), who used the equation developed by U.S. Department of Agriculture Forest Products Laboratory, as shown in Equation 4.

Equation 4: Calculation of wood MC from electrical resistance

$$
M C_{\text {uncorrected }}=10 \exp \left(2.99-2.113\left(\log _{10}\left(\log _{10}\left(R_{w}\right)\right)\right)\right)
$$

The uncertainty figures from Table 3 were used to perform a perturbation analysis of the MC measurements, calculating the resulting wood MC when the wood resistance error $\left(\Delta R_{w}\right)$ is added to the base measurement $\left(\mathrm{R}_{\mathrm{w}}\right)$. The results are shown in Table 4 .

Table 4. Calculation of Wood MC Error $\left(\Delta \mathbf{m c}_{\text {uncorrected }}\right)$ at Various Wood MC Levels

\begin{tabular}{c|c|c|c|c|c}
\hline $\begin{array}{c}\text { Wood } \\
\mathbf{M C}\end{array}$ & $\begin{array}{c}\text { Wood } \\
\text { Resistance } \\
\mathbf{R}_{\mathbf{W}}(\boldsymbol{\Omega})\end{array}$ & $\begin{array}{c}\text { Wood Res.+ } \\
\text { Error } \\
\mathbf{R}_{\mathbf{W}}+\boldsymbol{\Delta} \mathbf{R}_{\mathbf{W}}(\boldsymbol{\Omega})\end{array}$ & $\begin{array}{c}\text { Wood MC } \mathbf{~} \\
\text { Error }\end{array}$ & $\begin{array}{c}\boldsymbol{\Delta} \mathbf{M C} \\
\text { (Error) }\end{array}$ & $\begin{array}{c}\Delta \mathbf{M C} \\
\text { (Error) } \%\end{array}$ \\
\hline $\mathbf{8 \%}$ & $5,240,169,344$ & $5,932,260,851$ & $7.9 \%$ & -0.09 & $1.2 \%$ \\
$\mathbf{1 2 \%}$ & $105,337,360$ & $106,448,095$ & $12.0 \%$ & -0.01 & $0.1 \%$ \\
$\mathbf{1 6 \%}$ & $10,032,756$ & $10,133,796$ & $16.0 \%$ & -0.02 & $0.1 \%$ \\
$\mathbf{2 4 \%}$ & 601,088 & 607,132 & $24.0 \%$ & -0.04 & $0.2 \%$ \\
$\mathbf{3 2 \%}$ & 110,502 & 111,614 & $31.9 \%$ & -0.06 & $0.2 \%$ \\
$\mathbf{4 0 \%}$ & 34,508 & 34,857 & $39.9 \%$ & -0.08 & $0.2 \%$ \\
\hline
\end{tabular}

The wood MC error is $1.2 \%$ of the measurement at $8 \%$ wood MC (compared to the $13.2 \%$ electrical resistance measurement error); this is a function of the $\log _{10}\left(\log _{10}\right)$ calculation of wood MC (Equation 4). At higher MCs, the error becomes much smaller $(0.1 \%-0.2 \%$ of measurement).

\section{Synthesis and Other Sources of Error}

Clearly, the uncertainty of MC due to electrical resistance measurement error is insignificant in terms of the uncertainties typically accepted in field measurements (e.g., $\pm 3 \%$ for many RH sensors). Overall, the uncertainty is not founded in the measurements or computations: more of the uncertainty is caused by the variability of samples, because wood is a nonhomogenous, natural material.

As another example, Ueno and Lstiburek (2015) measured sheathing MCs in six double-stud walls; three sheathing MCs were measured in each wall (low, middle, and high). These walls were identical in one-dimensional section and measured the same material. However, peak differences of $\sim 5 \% \mathrm{MC}$ were seen in nominally identical (same wall/same orientation) measurements. Part of the difference was ascribed to the nature of oriented strand board sheathing: it is composed of wood wafers from multiple trees; measurement across various wafer flake boundaries could also influence MC measurements. 
Another potential source of error is electrical noise; at high MCs, the voltages are very low (20 $\mu \mathrm{V}$ range). The $60 \mathrm{~Hz}$ filtering feature was used in the data logger voltage measurements to reduce these effects. Similarly, wiring damage can have an influence on measurements, especially at high MCs. Wiring damage has occurred in the past at monitoring projects at active jobsites; some unexplained MC data anomalies occurred later.

The formula for $\mathrm{MC}_{\text {uncorrected }}$ reflects the wide range of resistance measurements found in the MCs of interest ( $8 \%-25 \% \mathrm{MC} ; \mathrm{k} \Omega$ to $\mathrm{G} \Omega$ range); this is also shown in Figure 79, taken from Forest Products Laboratory (FPL 1987), which plots the logarithm of resistance against MC:

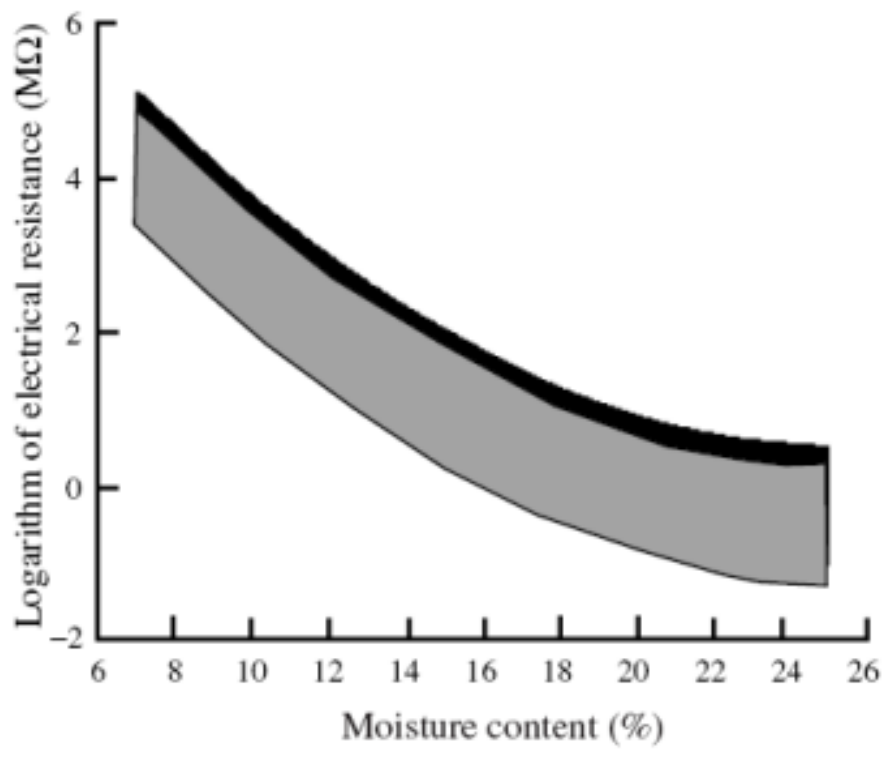

Figure 79. Log of $\mathbf{R}_{\mathrm{W}}$ versus $\%$ moisture content

Source: FPL (1987)

The gray region shows the degree of variability seen due to species corrections: this can be a significant source of error. This becomes significant, as mentioned earlier, when a grouping of species (such as SYP or SPF) is used: if a single species correlation is used for several species in a commercial group, this will result in less precision than if the species were considered separately (James 1988). The problem then becomes identifying the species of the sample. 
